\title{
BRITISH AND AMERICAN LOCOMOTIVE DESIGN AND PRACTICE. SOME COMPARATIVE COMMENTS THEREON FROM PRACTICAL EXPERIENCE.
}

By P. C. DEWhURST, Locomotive, Carriage, and Wagon Suphrintendirnt, Jamaica Govermment Railways, Member.

The intention of the Author in placing this Paper before the Institution is to draw attention to the comparative methods and practices in regard to structural and detail design of what may be termed the "British" and the "American" systems; and to indicate what in his opinion are the best features of the two partly opposing systems of locomotive engineering. His further object is to promote discussion on the subject, his view being that soine good will be derived from the ventilation of the two schools of design, by recording the methods of application in practice of each in respect to different sections of locomotive construction and maintenance.

It is no part of his purpose to deal with the fundamental principles of locomotive design, which are-or should be--the same in all countries, but to deal with their practical application. He would have wished to cover all sections of locomotive work, but such an exhaustive process is beyond the limits of a single Paper, and the hope is expressed that other Papers may be forthcoming dealing with other aspects of the matter, and from fresh points of view.

At the present time, when Colonial and Foreign trade is of great moment, it appears that everything likely to assist locomotive [The I.Mech.E.] 
builders to supply engines which will bring repeat orders from sheer merit of performance and economy of maintenance, should be brought forward. Having had the opportunity for some years of observing closely the performance of both British and American pattern locomotives under difficult conditions of curves, grades, and track, handled by native staffs, coupled with their maintenance under inadequate circumstances by only moderately skilled workmen, on the railway with which he is connected and on which there is an unusual combination of various types of British and American locomotives, the Author feels it almost a duty to record the result of his experience.

The Author does not claim that the views derived from his own experience are by any means the last word on the subject, and expects many criticisms will be made by those whose experiences have differed from his, and that by eliciting such, the subject may be fully thrashed out and the consensus of opinion thus obtained may be of sufficient weight to be authoritative, as he believes it is only by combination of the practice of the two countries that the best results can be ultimately attained. It is instructive to observe at the present time how a number of features of proved worth have been adopted by one country from another; undoubtedly this is as it should be, and those who are most successful in adopting the good and eliminating the poor features of each practice, will lead in locomotive construction.

It may be considered that the Paper consists mainly of a record of the Author's opinions, and this is correct to a degree--the whole subject is really a matter of opinions-and those given in the Paper and the reasons therefor, are based on experience of actual running and maintenance, in the majority of cases under similar working conditions. In such a wide subject it has not been possible to notice all parts of locomotives, nor to notice all the variations in respect of the different items dealt with.

General.-It is not intended to refer at length to the difference between the present British locomotives and the enormous engines now used in America, as this difference is almost entirely due to the relative topographical relationship of the railways of each country to the areas they serve, the British lines being more of an intensive system and not lending themselves to long, heavy hauls, as are common in America. Where the latter conditions are developing in the Colonies and elsewhere-as in India and the Argentine-British locomotive builders are producing proportionately larger locomotives to meet the necessities of such services. 
At the same time the Author's opinion is that in England much greater use could be made of powerful eight-coupled engines-with additional idle axles if necessary, on account of axle-weight limits, or even ten-coupled--together with high-capacity (and comparatively low tare) wagons, on coal and similar traffic in large, compact loads for reasonably long hauls. Great economies in the occupation of congested main lines, coal and oil consumption, repairs, and in enginemen's and others' time, could then be effected. To build goods locomotives of a capacity limited by six wheels and, with the assistance of a pilot, to haul long trains of minerals in wagons containing about 10 tons, with a tare of about $6 \frac{1}{4}$ tons each, as is done on some British lines, appears to be entirely out of date; presumably bridges of insufficient strength are the cause of such working. If this is the case, it would seem that the money wasted each year by uneconomical working would, if capitalized, cover the cost of renewing or strengthening a good number of weak bridges.

Methods of Designing.-The American system, where locomotive builders supply engines to general instructions, without the railway concerned furnishing fully detailed drawings before the engines are constructed, is not so satisfactory as where the whole of the design, including the details, is in the hands of the railway. It results in important items which could with advantage be made the same on different classes of engines on the same railway, frequently not being so made, and in smaller details such as lampbrackets, engine and tender couplings, hoses, etc., which for obvious reasons should be identical throughout a particular railway, often being supplied with variations on different orders, and which, in some cases, differ on the engines of repeat orders of one design.

Although the builders and the railway officers keep in touch as much as possible, and the builders are always anxious to fall in with the suggestions made to them, yet it is not so advantageous as when the whole of the design is actually in the hands of those who will have to operate and maintain the engines; they alone can make all necessary allowances for working-in standards already existing, for special service conditions, and for the facilities or limitations of the repair shops.

Subject to the amount of control indicated above, the builders supply to a great extent what is most suitable from their own point of view, in the way of axle-boxes, springs, coupling-rods, brake gear and similar parts, and this leads to considerable unnecessary variation; thus maintenance and service suffers for the sake of first cost. Designs made without full knowledge of all 
the conditions to be met, or not fully considered from the maintenance point of view, should never be placed on any railway. Engines designed with the view to their economical repair (and long wear in service) save the extra cost of such designing the first time that repairs of any extent are carried out.

Of course, it may be said that the American Railway "Master Mechanics Association," by its system of circulating proposed alterations to standard details, before these become "recommended practice," goes much further in the way of reducing unnecessary variations. However, this is only true to a degree; for instance, it is no consolation to a comparatively small railway, when it has axle-boxes, big and little ends, coupling-rods, brake gear, etc., of two different classes of engines, say, 4-6-2 and 4-8-0, which might have been made to interchange but varying in small degrees, to know that such parts supplied were the M.M.A. practice for each of the respective classes.

Features of American Locomotives popular in recently developed Countries.-Against this, however, must be set some important features of American design which make it popular in recently developed countries. Before mentioning these, however, it is necessary to refer to the fact that it is often said incorrectly in connexion with their advantages for new and difficult lines, that the bar-framed engine allows greater flexibility both vertically and laterally than the plate-framed engine. This, however. is not a function of bar-framing at all, which, in fact, is more rigid laterally, and (when the horn-stays are in position as when running) quite as rigid vertically as the plate-frame; the former advantage referred to, is due to the employment of flangeless. wheels and other devices, the latter being due to the compensating of the spring gear.

Their real advantages in this respect are:-11) Compensating gear in the spring rigging which gives an easy-riding engine even on poor track, and prevents a large proportion of the derailments which happen to uncompensated engines on such tracks; (2) the very substantial and rigid support given by the horn-blocks (or shoes and wedges as they are termed), which are an inherent feature of the bar-frame, and which have no frame-bolts to work loose; $(3)$ the design of axles and axle-boxes which have adequate bearing area, provides opportunity to allow ample side-play without unduly reducing the bearing area; (4) the use of flangeless wheels; and (5) a generous allowance of boiler power, enabling poor fuel to be used. All these features, with the exception of (2), which however 
is overcome in other ways, are as easily obtained in the British plate-framed locomotive, as will be shown later, under their respective headings. Outside cylinders are not regarded as particularly American practice in respect to new countries, as in British practice also, outside cylinders are always now used for such work.

Boiler Power.-The Author considers the American practice of providing a larger proportion of boiler capacity for a given cylinder capacity than in British practice, is the better policy, and even after allowing for the generally inferior quality (in respect of size, not necessarily composition) of coal used in America, there is still a large difference. It may be said that the British practice is to employ relatively large cylinders, in order to obtain economy by using a very early cut-off; by this means the cylinders are worked proportionally to the steam production of the boiler. In this way a large proportioned-and therefore heavy and costly-engine is not made full use of, and exerts only a part of its nominal power for sustained periods.

The general effect on the British locomotive, until recent years, has been that engines dropped behind in boiler capacity until only the full nominal cylinder capacity was equal to meeting the demands of traffic, with the consequence that boilers were overtaxed and the economy which might have been obtained from the relatively large cylinders, was probably lost by the reduced boiler efficiency. If a boiler is provided which has to produce almost its maximum amount of steam to supply the normal demands of the cylinders, and has to be "thrashed" to suit heavy loads, the result is certain to be wasteful in both fuel and maintenance.

Dome Position.-The dome is almost always located approximately at the centre of the boiler barrel in British practice, whilst in America it is most often on the last ring next to the fire-box. Inasmuch as the dome exists for the purpose of obtaining the driest steam possible with a given height of water, it is difficult to see a sufficiently strong reason for losing part of this advantage by placing it near the point of greatest ebullition.

Further, the position towards the rear is a great disadvantage when starting a heavy train up a steep incline chimney first, and the Author has experienced difficulties in practice in this respect. All enginemen naturally prefer to start a long severe pull with an ample supply of water, and the effect on long boilers of striking a long uphill section of 1 in 30 , after the water-level has been properly adjusted on 
the level, inevitably leads to priming, if the dome is far back, whereas with the dome further forward the effect is actually a lowering of the water-level there.

As an instance, a boiler of a length (including fire-box shell) of 25 feet, running on to a 1 in 30 gradient, will have its water-level raised about 5 inches at the fire-box end and lowered 5 inches at the smoke-box end; with the dome placed about 10 feet from the fire-box back, the rise there will be about 1 inch, but with the dome another 5 feet forward there will be a fall of 1 inch, in other words, a 2-inch higher water-level can be carried with the dome in advance, Fig. 1. Of course, in going up tender first, the result will be just the opposite, with the additional disadvantage that there is more danger of uncovering the fire-box crown. Against this must be set the very great advantage of the extra 2 inches of water allowed by the advanced position when the engine changes at the top of a gradient from 1 in 30 up, to 1 in 30 down, in 100 yards or so, and without stopping; this advantage quite offsets anything else. The Author has known a number of cases of scorched fire-box crowns caused by the lack of it, and for that reason entirely favours the position on the centre of the barrel. There is always, of course, the additional advantage in placing the dome well forward that the internal main steam-pipe is correspondingly shortened and there is thus a less volume of steam between the regulator and cylinders; consequently initial slipping of the engine is better under control.

Three-Cylinder and Four-Cylinder Locomotives.-The latest tendency in modern British practice is to use three or four cylinders when additional power is required, necessitating larger cylinder volume than can be provided either by two inside or two outside cylinders, owing to the restrictions of the British loading gauge. No such practice has been perpetuated in America; when an engine of such power is desired that it cannot be provided for by the employment of a single pair of outside cylinders, a Mallet or other special type is used.

Modern American practice proves emphatically that the more even turning movement obtained from three or four cylinders in one tractive group is not considered by them to be worth the extra complication. This is rather surprising, as a few years back fourcylinder balanced compounds were much in favour. Regarding compounding itself, even before the vogue of the four-cylinder compound of various types, the two-cylinder "Cross " compound, with its large cross-over receiver-pipe in the smoke-box, enjoyed some years of success, but eventually the P.L. cylinder could not 
Fra. 1.- Effect of Position of Dome and Waler Level on Gradients 1 in 30.

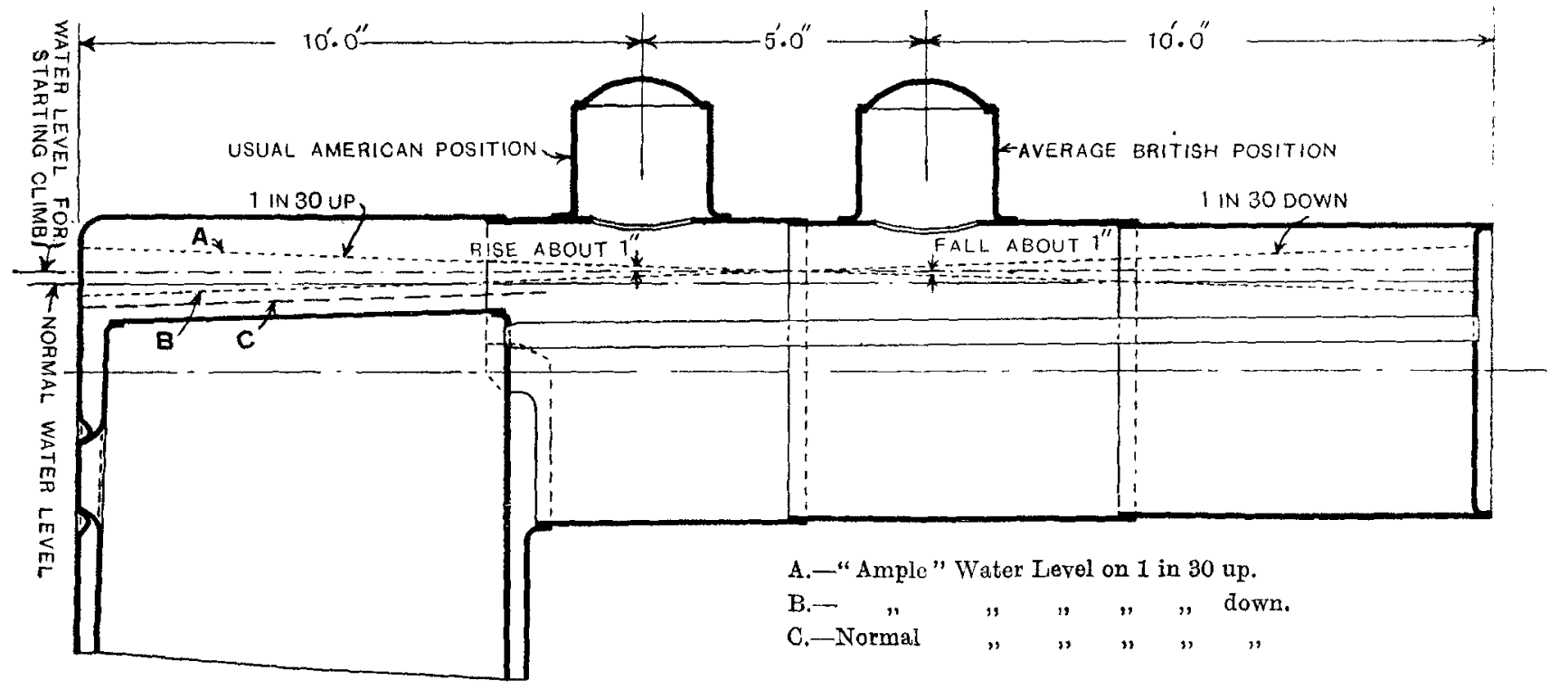


be made sufficiently large to provide for the increased power at the correct ratio.

The three-cylinder locomotive, either simple or compound, is practically untried in America, there having been only a few isolated instances of its use many years ago. The Author would like to see the three-cylinder type given a trial there under modern conditions, particularly as the centre-crank axle would leave plenty of room for the long axle-box bearings favoured. A few four-cylinder balanced simple engines have been tried in recent years, but the practice has not been extended.

Tank Engines,-It is surprising the comparatively little use made of tank-engines in America; the 0-6-0 standard shunting (or switching) engine in particular has always been fitted with an eightwheeled tender, and the latest classes of heavy 0-8-0 switching engines perpetuate this. There are, of course, many 0-6-0 tankengines used by industrial firms, but locomotives owned and used in railway service are referred to. Whilst these later locomotives are already sufficiently heavy for the four axles, and adding the water and fuel on the engine would produce excessive axle-weight, yet there seems no reason why pony trucks or a bogie could not be added, and so get everything on one frame. There is no question but that a self-contained unit is preferable for shunting, for obvious reasons; in addition, an appreciable saving would be found in the draw-gear, water, brake and other connexions between engine and tender, also a saving in weight with lesser number of wheels and axles, ete.

In regard to short trip and branch passenger services, it is possible that they are sufficiently provided for in America by ex-main line passenger engines relegated to lighter duties, but against this is the lesser life of American locomotives compared with British, which would lead one to expect a larger demand for passenger tank-engines in America.

One interesting fact in connexion with most American-built passenger tank-engines has been the custom of using "mixed" frames, the bar-frame as a rule terminating just behind the fire-box, from which place a plate-framing was bolted on and extended to the rear of the engine. The point of junction seems generally to have been the weak spot, and one is inclined to question whether this may have influenced the ordering of tank-engines on the principle of "giving a dog a bad name." The few later examples of these tank-engines, with a trailing bogie or truck have, however, been constructed with bar-framing through to the rear. The Author 
considers that for short trip and shunting engines, the British practice of employing specially-designed tank-engines is much more advanced.

Outside Cylinders.-The placing of the cylinders outside has always been the standard American practice, and after many changes in British practice, extending over a considerable number of years, during which the inside cylinder seemed to have become supreme, the tendency there is also in the same direction. The advantages of the outside position, namely, the absence of crank-axles, the facility with which ample driving axle-bearings may be provided, the machinery being outside and therefore easily inspected, oiled and repaired (especially if, as is standard in America and now becoming usual in England and the Colonies, etc., Walschaert valve gear is employed and the valves placed over the cylinders), are very real indeed, especially in countries where inspection-pits are scarce.

The " nosing" or " boxing " at the front end of outside cylinder engines is considered to be principally due to (1) insufficient lateral control at the bogie centre; (2) excessive sideplay of (particularly) bogie, also axle-boxes on axles and in horns; (3) (a) roll of driving-boxes on journals due to brasses having worn too large, (b) driving-boxes knocking. It is naturally observed to develop quicker and become more pronounced on $4-4-0$ and other short wheel-base engines ; on 4-6-2, 4-8-0 and 4-8-2 types even when badly run down, it is hardly perceptible. The "three-point" or double-suspension hanger type of swing link bogie gives the least opportunity, in the Author's experience, for "nosing" of outside cylinder engines, as is to be expected from its design.

Placing the cylinders outside is entirely preferred by the Author, except perhaps in certain cases of locomotives of medium power for fast work, where the slightly steadier running and the better protection from radiation losses make it worth while to accept the attendant disadvantages.

There is little to be said when comparing the modern British method in the installation of outside cylinders, of employing separate castings for the cylinders and steam-chests on each side, and a box casting between them under the smoke-box, with the American method of using two castings only, meeting in the middle and forming a saddle between the frames for the smoke-box. The methods are conveniently applicable to the plate- and barframes respectively. The American method possibly gives rather more weight at the leading end-where it is not wanted-but it 
is doubtful if this comparison holds good when the British arrangement includes a saddle casting for the smoke-box.

A very good feature of modern American practice is to design cylinders with renewable liners; this, in addition to providing for future wear, also allows the eylinder casting to be of tougher, but less hard, metal than would otherwise be the case.

Slide-bars of outside-cylinder engines seem to be more susceptible to wear, and occasional overheating, than do those of inside cylinders, probably because these cylinders being generally lower down than inside ones the bottom bars are nearer the ground; reference to slide-bars is made farther on.

Main Frames. Plale-Bar-Comparing the plate-frame of British practice and the bar-frame of American, the plate-frame has the advantage of a certain amount of lateral elasticity, which is of advantage on curves, although it is probable this lateral elasticity or "whip" is sometimes the cause of axle-boxes overheating. Cutting out very large spaces in the frames and employing coupling-rods of too (comparatively) rigid I section will render an engine liable to this trouble. The bar-frame also has its advantages, particularly in respect to the axle-box attachments, certain features arising out of the top of the frame being much lower than with plate frames, and the possibility of arranging the spring gear in its open spaces. The principal advantages and disadvantages of the bar-frame are as follow :-

Advantages :-

(1) Distance between top of horn space and top of frame being very small, allows springs to be overhung, except where the fire-box is situated ; this is convenient when wheels are small and underhung springs would be cramped for room and difficult to examine without a pit.

(2) Frame-spaces allow springs under fire-box to be placed in them, and provide space for compensating beams, etc.

(3) Provides a strong and effective system of horns by means of very simple shoes and wedges.

(4) Allows fire-box shell to be as wide as can be got between backs of tires in some cases, and in others where the coupled wheels under the fire-box are small enough, it allows for the fire-box to be over the wheels without much raising of the boiler centre.

Disadvantages:-

(1) Very weak in a vertical direction, and if care is not taken in shops the single top rail over the horns may get crippled-similarly 
any slackness developing in the hornstay (or pedestal brace as it is called) overstrains the same part.

(2) Has excessive lateral rigidity compared with plate-frames: does not "give" slightly on curves at speed.

(3) Restricts any between-frames fire-box shell to such an extent as to prohibit the use of such fire-boxes in modern-powered engines.

(4) The front end section beyond the cylinders is usually weak.

Further reference is made, in the appropriate sections, to the various detail features connected with the framing question, but it is convenient here to deal with the fire-box question in relation to the bar-frame. The narrow fire-box difficulty seems to be at the root of the American preference for types of locomotives with an idle trailing axle, which enables a wide fire-box to be placed over the rear wheels. There seems no doubt that, but for this it would be preferred to eliminate the idle wheel, thus reducing the number of axles, or alternatively to place an additional coupled wheel there. In other words, the narrow fire-box difficulty produced by the use of bar-framing was principally responsible for the original employment of the idle rear-wheels.

Of course, this does not apply to the special fire-boxes designed to burn low-grade fuel, nor to the huge locomotives now employed in America having fire-boxes beyond the possibility of being placed in the old position with any description of frame; but there are many engines of moderate size, particularly of the 4-4-2, 4-6-2, and 4-8-2 types, which need not have the idle trailing-wheel but for the bar-framing, and the loss caused by them is an important point adverse to the bar-frame. In the past the simplicity with which a plate-frame could be repaired compared with a bar-frame gave the former a certain advantage, but now that effective electric and other autogenous welding is cornmon, this is no longer the case.

Horns or Pedestals. - Reference has already been made to these details under "Frames." With American bar-frames the general width of axle-box vertical wearing surfaces is $5 \frac{1}{2}$ inches; this is narrower than the usual British practice, and is due to the shoe face being governed to some extent by the width of the bar-framing, whereas the separate horncheek of the plate-frame system is usually about $6 \frac{1}{2}$ inches wide. The advantage here is with the plate-frame system, but in practice this is more than offset, as wear is easily taken up with the bar-frame system, particularly on account of the front face or "shoe" being readily detachable without disturbing any driven frame-bolts. 
Regarding the wedge side of the horns, the difference consists in the wedge forming the wearing surface against the axle-box being held in position laterally, by a wide tongue let into a groove in the horncheek behind it, in the plate-frame system, as against it being held in position by lips on each side of the bar-frame, in the other. The British system again provides the greater bearing area, but the American provides better support for the wedge against side-thrusts of the axle-box; the wedge side of the horns are as lasting as the shoe side, whereas the Author has found the British pattern of wedge liable to develop considerable lateral displacement under severe track curvature conditions.

The bar-frame, by giving very substantial support, and in allowing "shoes and wedges" to be applied without any fixed bolts or rivets in the frame, scores an important point in its favour; there are no frame bolts to give trouble by working loose and the horns are very conveniently lined up between the back of shoe and the frame, thus forming a simple method of taking up further wear when a wedge has reached its limiting position of adjustment. This removable shoe system allows the lining-up and re-centering of a whole set of wheels and axle-boxes without taking the wheels from under an engine; wedges are always used.

The plate-frame type of horns as usually designed, can be arranged to meet the necessary conditions (except detachability of the front surface), by providing substantial horncheeks, with very strong and stiff hornstays composed of horizontal bolts and distance pieces. The old pattern of hornstay, composed of a plate or forging held up by $1 \frac{1}{8}$-inch studs at the base of each horncheek is quite insufficient; further, it is most essential that the frame bolts are well spaced and have full parallel holes in the frame-they may have shallow heads outside, but the length of fit should on no account be reduced by countersinking; horns will not stand up to their work on severe curves unless the above points are attended to. Riveting-on horncheeks proves quite a failure in such cases.

Axle-boxes and Journals.-Not much comment is necessary in respect to the constructional features of the axle-boxes employed by each country; cast steel for the body is now customary in each case, but the methods of inserting the brass differ. In British practice this is usually of a square-backed pattern bedded into the crown of the box so as to make a tight fit with the keep in position; the American method is to use a semi-circular crowned brass, and to obtain the fit in the box by inserting it in from the side, under pressure; a further difference is that in the former case the brass 
is prevented from moving laterally by locking-grooves in the crown, whilst in the latter, brass pegs are inserted from the body of the box into the brass when in position.

In American practice plain brasses without anti-friction metal insets are generally used, thus differing from British practice, but the experience of the Author is in favour of metal pockets, as not only do they tend to keep a box from running hot, but should this happen, the axle does not get so badly scored as when solid brass bearings are employed. Axle-box keeps-or cellars as termed in U.S.A.-are in American practice always removable in situ.

Contrasting the different methods of providing side-wearing surfaces, generally speaking the British practice is to depend on a small arc on the brass itself on the outside of the bearing, and an even narrower arc on the inside, butting against the shoulder on the axle, plus the radius in each case. The American practice is to have a very large wearing surface (of brass) attached to the side of the box on the outside only, no provision existing for taking up sidethrusts on the inside. There is no radius either outside or inside, and usually no bearing on the side of the brass at all.

The effective differences are, therefore, that the brasses of both boxes take the lateral pressure and transmit it through the boxes to both frames in British practice, whilst it is taken up direct by one axle-box and transmitted to one frame only in American practice. The taking up of the side-thrust by one frame only is possible owing to the lateral rigidity of the bar-frame, and the very effective cross-staying possible with outside cylinders.

The Author has experience of locomotives working over extremely sharp curves quite satisfactorily with the American type of axle and axle-box, whilst other similar type locomotives with the British pattern suffered much from quick wear on ends of brasses, and gave trouble from overheating, until the axle-boxes, were provided with side liners similar to the American arrangement, after which the trouble ceased. In particular the slackening of brasses in the axle-boxes also declined.

The balance of favour is considered to be with the American system, as being better both in principle and practice, but the Author considers the two methods complementary and not necessarily alternative.

Compensating or Equalizing Gear.-The employment of compensating arrangements in the spring rigging of all locomotives is the outstanding feature of American design, and, as already mentioned, has undoubtedly had great effect in obtaining the 
American locomotive's good reputation in countries having new and difficult tracks. In long and multi-wheeled locomotives it can be clearly observed that the levers assist the easy riding of the engines almost as much as the springs themselves, and the manner in which a defective high spot in the track passes along and articulates the whole compensating gear when passed over at speed, is conclusive.

As mentioned previously, compensating gear is not a necessary corollary of the American bar-frame, or vice versa, and similar results can be obtained with the British plate-frame locomotive, the compensating gear being almost as easily worked in with plateframes, except in cases where owing to small diameter of wheels the springs cannot be underhung, and a side-overhanging fire-box prevents the springs being applied above. In such cases the spaces in the bar-frame provide a position for both springs and compensating gear - the springs themselves sometimes forming an equalizing beam. A way of overcoming this difficulty with plate-frames, where there is insufficient space for the springs inside the frame, is to fit only the compensating beams at the awkward place, carrying the springs themselves at each end of it.

Typical instances of compensating arrangements are given in Figs. 2-6. Fig. 2 shows the usual arrangement for a 4-8-0 type locomotive, and clearly indicates the use of the spaces in the frame to allow the fire-box to set over the frame. Fig. 3 is of the same type, but noteworthy for the provision of three springs for the two rear axles, and Fig. 4 shows a similar type of British plate-framed engine as equalized by the Author. In Fig. 5 is given a compensating system for a 2-8-2, in which it is to be noted that the continuity is broken between the first and second coupled axles, and in Fig. 6 is seen a system for a 4-8-2, in which the combined spring-cradle compensator (not equalizer) between the rear coupled axle and the back truck, provided to act for the rear coupled axle, is specially interesting.

It may be noted that pony-trucks are always compensated with the axle next to them, but bogies are usually-but not alwaysisolated from the main compensation group.

Although the Author is aware that the system entails more wearing points-not necessarily pins, as " $\mathrm{V}$ " edges and rollers can be employed-yet the advantages are such that he is in favour of compensating levers for all locomotives, except those having few axles and designed for very high speeds. This exception is made on account of a tendency observed on such engines for the compensating gear to allow a low place in the track to affect the 
Compensating Gears.
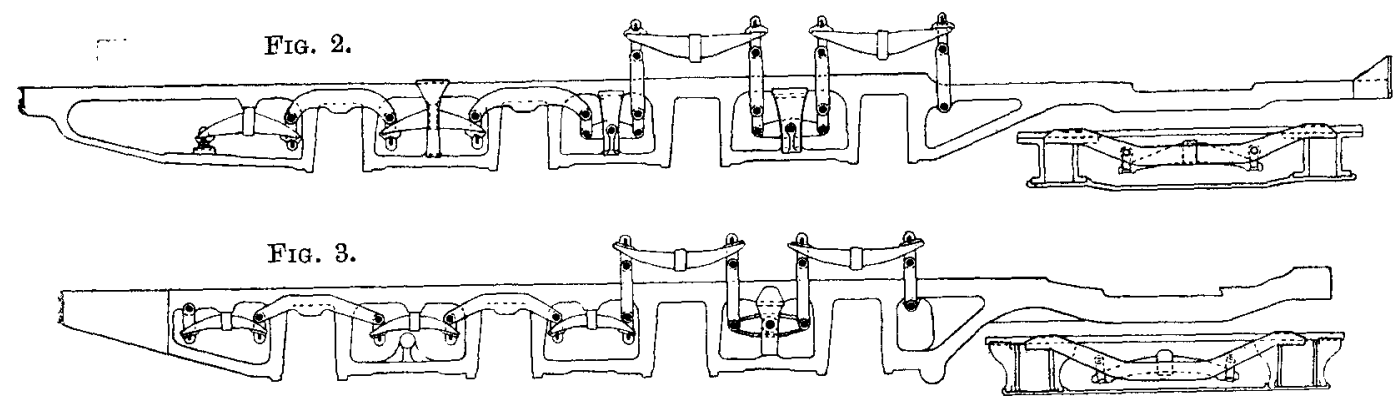

FIG. 4.
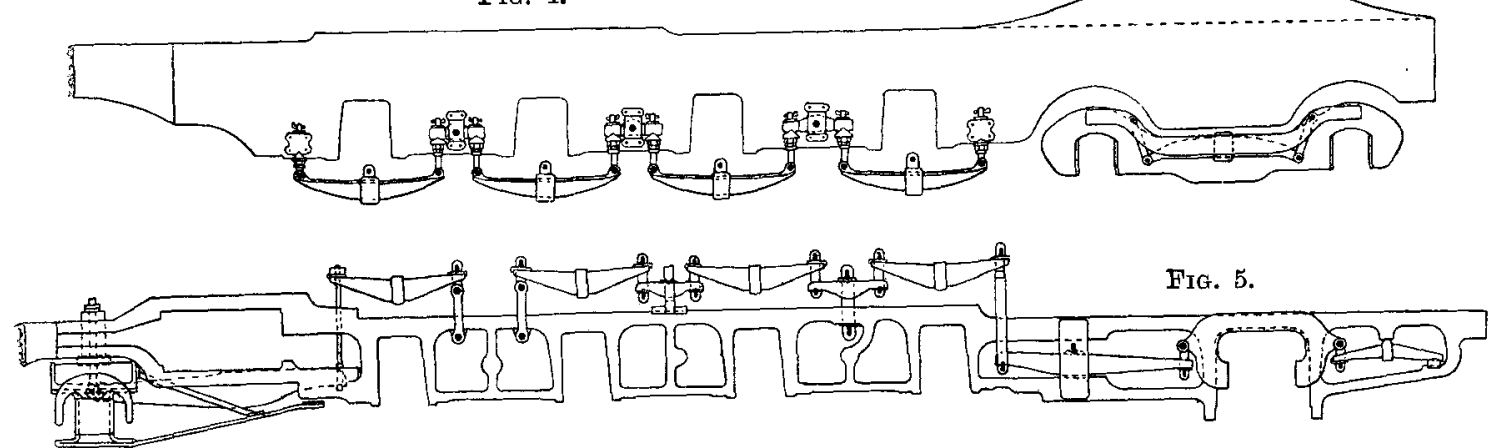

Fra. 6.

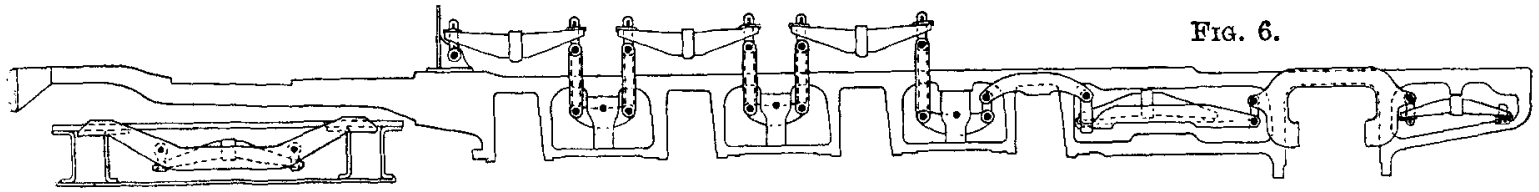

$\underset{g}{\mathscr{g}}$ 
roll of an engine, when it coincides with such roll, more than in an independently sprung engine.

Bogies, Bogie-Frames and Parts.-The various systems of controlling the lateral movement of the bogie centre are too well known to need description, all being used in British and Colonial practice. The sliding table or "Adams" type, however, is very seldom, if at all, used in American practice, the swing-link pattern having been always practically universal there. It is remarkable that quite often, even down to recent years in American practice, no differential spacing of the top and bottom pairs of pins nor double suspension hangers were used to provide strong centering powers, the simple force of gravity alone being depended on, top and bottom pins being equally spaced and no spring check provided. In respect to bogie control, the Author considers the British application of the various methods the best, although it must be remembered that the longer wheel-base of the average American locomotive reduces the tendency to "hunt" on straight track.

Regarding the bogie structure the British pattern is considered superior. The American pattern consists of a bar-framing running completely around the top part, with pedestal bars or castings bolted under it, connected together on each side at the bottom with tie-bars, and having the centre-casting bolted to the top bar (or rail), and has the following defects :-

(1) The longitudinal rigidity of the frame being mainly in the top rail, is too far above the axle centres.

(2) The cross-staying at each end being at the same high level is also faulty.

(3) The pedestal bars which usually are simply bars of the same sections as the top rail, present too narrow a wearing surface to the axle-boxes, and as shoes and wedges are not fitted as a rule (shoes are occasionally used) wear soon develops, and necessitates removing and reworking the bars, or alternatively, electrically welding-on making up material and re-machining.

(4) The top rail of the frame near the attachment of the centre casting is liable to fail, due to its being the weakest place and apt under certain circumstances to be overstressed.

The general design of the bogie assumes that the weight of the engine shall be transmitted from the centre casting to the axleboxes by springs, specially set with their inverted buckles nested directly under the outer part of the centre casting, these centre-bearing springs being an integral part of the design, 
and that the whole bogie frame is merely to keep the wheels in correct position and alignment. This is sound in theory, but in practice occasionally some weight actually is transmitted through the frame-as in passing over a bad crossing, which may cause the axle-boxes to strike the top of the horn spaces of each axle on one side in quick succession-and as it is evident the top rail of the frame cannot alone support the weight of the engine, it eventually suffers near the centre casting.

The British pattern bogie structure appears to avoid all these troubles and is quite capable, without its springs and cradles, of sustaining the weight of the engine :-

(1) The rigidity of the frame is in the correct place.

(2) The cross-stays are placed sufficiently low to prevent the lower parts of the horn spaces whipping.

(3) The horn cheeks provide a good bearing area for the axleboxes, and do not usually require attention for years.

(4) The centre casting is of substantial design and is attached to the side frames right down each side ; it usually extends towards each end in addition.

It should be noted that better provision for wear is usually provided than in American bogies, and more attention is paid to the lubrication of the pins and of the centre itself; the latter in American practice being considerably smaller in diameter than in British, and without the usual substantial centre socket to the casting.

Pony-Trucks and Radial Axle-Boxes.-Radial axle-boxes are rarely used in American practice, whereas pony-trucks are made very considerable use of; in fact nowadays there are probably more locomotives there fitted with pony-trucks than bogies. Three-point suspension links are being applied to pony-trucks in the latest practice as in bogies. The Author, unfortunately, has had no experience with radial axle-boxes, but from careful consideration of all the points, they appear to have no advantage over the ponytruck, provided the pony-truck is designed in a sufficiently substantial manner.

He finds that the two-wheeled truck does not by any means give results equal to the bogie on severely curved lines, for the reason that the limit of weight on one axle will not keep the flange down, if it is attempted in designing the control to cause the truck to do all the work of curving the engine; and in practice this results in the pair of flanges next after the pony-truck doing considerably more curving work than the truck itself. It is impossible to bave 
a flangeless wheel next to a pony-truck, thus preventing as short a rigid wheel-base being obtained with a pony-truck as with a bogie. It is significant in this connexion to note that express and passenger engines in America are never now designed with leading two-wheeled trucks, the 2-6-2 type having been rapidly displaced by the 4-6-2 ; and more recently, where an exceptionally powerful passenger engine is desired, 2-8-2 types are not used, but 4-8-2.

Mention should be made of a type of axle-box having special lateral movement, often used in America for idle trailing axles instead of an ordinary pony-truck. This is the Rushton truck and its modifications; the arrangement gives radial and lateral movement, which is controlled by hangers depending from trunnions on the axle-box top, front and back, and pivoted at their lower ends to specially deep-arched yokes incorporated in the spring rigging; the top trunnions, which pivot on a centre pin on the axle-box to allow radial movement, are usually single, depending on the simple force of gravity to control the lateral movement, but in recent practice double trunnions, giving the same effect as three point suspension links, are used. This truck, although performing satisfactorily within its limits, suffers from excessive wear on the pins and links, due to the dust thrown up by the whole of the engine wheels ahead and from its proximity to the ash-pan, etc. The Author prefers a standard pony-truck.

There is also the "Hodges" trailing truck, which is a special form of pony-truck differing from the usual pattern in that the radius rods are replaced by an encircling frame which also forms the main frame and horns in one piece; this framing passes outside the wheels and the bearings are therefore also outside; in some cases this frame does duty, in addition, as a compensating beam incorporated in the spring rigging. The Author has had no experience with this truck, but from the fact of its bearings being outside and that it has no pins, etc., to collect dust, he considers it a very good type of two-wheeled truck for the trailing end, but not for other purposes.

Boilers : Construction and Materials.--The fundamental principles of boiler construction are similar in both British and American practice. The American boiler is much larger than in British practice, but this is mostly a factor of the larger locomotives, and hence larger hauling capacity of the American locomotive made possible by their considerably more ample loading-gauge. Special types of fire-boxes are used in American practice, but this again, is a factor governed by the special fuel burnt by these boilers. The generally larger 
proportion of boiler capacity to engine power in American practice compared with British has been commented on previously.

Eliminating these three phases, the greatest difference is in the material used. In British practice acid steel plates are practically always used for barrels and fire-box shells, while in America basic steel is permitted and extensively used. The Author considers the acid process steel the more suitable, although it is fair to say that in practice the only deficiency he has observed in the basic steel has been the greater tendency to pit inside the barrel, and, to a less extent, to suffer from external corrosion under the barrel when dampness has accumulated.

The greatest difference between the practice of the two countries is, of course, in the use of steel for fire-boxes in America. This subject, together with the use of steel tubes and other subsidiary matters arising therefrom, the Author has dealt with at length in a Paper* before another Institution. From his experience, he finds that the copper box is superior from the point of view of ease of maintenance, facility of repair, and general dependability. The steel fire-box, however, can be quite successfully used under the most arduous service conditions and in British pattern boilers, even with the old system of patching when necessary; with the great strides made in electric welding, however, there now seems nothing to choose between the two materials in respect to repairs. The question is whether the extra cost of the copper fire-box is justified for the sake of its greater reliability under the circumstances and character of any particular railway and its services.

Another point in connexion with the American boiler, is the elimination for some years now of all forms of crown-bars and the use of direct radial stays instead. The Author is quite in accord with this, seeing no sufficient advantage in the crown-bars to offset their well-known disadvantages, such as scale accumulation and difficulty of access ; even in respect of the distribution of stresses in the outer shell-top, the direct stays are superior. Only a small proportion of American boilers have Belpaire fire-boxes, and the great popularity of the Belpaire fire-box in British practice in later years mostly applies to railways which previously used crown-bars, whereas, other railways which were using round-topped shells and direct stays have not, as a rule, adopted the Belpaire box extensively.

Prior to the general use of the wide (normal, not Wootten) firebox, with its accompanying small idle trailing wheel, the between-

* Inst, of Loco, Engineere, vol, ix, No 40, 1919. 
frames fire-boxes were generally associated with the wagon-top, and latterly with the extended-wagon-top type of boiler, in order to obtain increased fire-box capacity, and increased steam space above, without increasing the diameter and therefore the weight of the boiler at the leading end; such boilers have not been found necessary in British practice, the nearest approach being the raised fire-box type, in which the shell was raised a few inches only, above the general level of the barrel top. The exception to this rule is the present standard Great Western Railway boiler of "coned" type, which is really another form of the extended-wagon-top, and it is curious to note that its use came into vogue about the time that its prototype in America went out of favour.

The remaining principal difference is in the universal use in America of steel or charcoal iron for tubes, whilst British practice is still to use brass or copper. It is true that before the introduction of electric welding of steel tubes to the fire-box tube-plate, steel tubes were much more difficult to keep tight and rather apt to fail in service when used in steel fire-boxes; but the Author has not observed any difficulty in keeping steel tubes tight in copper boxes, and hardly sees sufficient justification for the use of brass or copper tubes unless it be in respect of their better conductivity. Some experiments in actual working would be of great benefit to settle this question definitely. In any event, owing to the greater heat to which tubes are subjected and the high coefficient of expansion of copper compared to the boilex barrel it is inevitable that the tubeplates will have to stand far greater distortion between cold and working temperatures when copper tubes are used than in the case of steel. Another point in favour of steel tubes is, that they do not suffer from the eroding at the fire-box end just inside the tubeplate; this is an important advantage with engines engaged on heavy work at long cut-offs.

A very great amount of autogenous welding is now practised in American boiler work, whole fire-boxes having their various parts welded up so that no laps or rivets exist anywhere. The Author considers it too early to pronounce an opinion on the entire success of this ; it is very alluring and from the good results obtained in patching fire-boxes by its use, appearances were all in its favour, but he observes from recent reports of locomotive boiler explosions in the U.S.A. by the Bureau of Locomotive Inspection, that where explosions are (or presumed to be) caused by low water, the welded seams in or near the crown give out in a manner entirely suggestive of weakness; in other words, shortage of water and overheating of crown-plates, which in fire-boxes of the old construction meant 
the bulging and sagging of the roof, cause disastrous explosions when there is a welded seam in the crown which becomes overheated and consequently fails. The remedy clearly is to confine welding to patches and other repairs up to half-sides, or at any rate to have no welding in the crown sheet or its adjacent attached plates, as this has been proved entirely unsafe.

Expansion Brackets.-Brackets corresponding to the simple and effective type generally used on British locomotives, Fig. 7 (page 396), are not customary in American practice ; even with boilers having fire-boxes between the frames rather crude clips capable of sliding along the top rail of the bar-frame are mostly used, Fig. 8; although a later type of bracket approximating to the British pattern is sometimes used on engines having fire-boxes of the same width as the outside of the framing and set over the top of the frame, Fig. 9.

The method generally adopted with the wide fire-boxes extending over the frames, as used in modern practice, is to support it by thin plates (about $\frac{1}{2}$ inch thick) fixed to the front and back sections of the foundation ring, being connected to the engine framing by a crossstay at the front end and by the back drag-casting at the rear. These plates are certainly a simple and inexpensive method of carrying the fire-box end, but the Author prefers a definite sliding bearing to take the weight of the boiler, although such plates as mentioned are a good method of holding the boiler down in position, in addition to plain sliding bearings.

Circulating Tubes and Brick Arches.-A prominent feature of present-day American practice is the use of circulating, or arch tubes (generally three in number) in the fire-boxes. These tubes, which are usually 3 inches in diameter, extend from the lower part of the front water-leg to the upper part of the back one, and serve the double purpose of promoting circulation and supporting the brick arch. They fulfil these duties effectually but need careful watching, and the inside of the tubes must be cleaned of scale, with a special tool, fairly frequently; undoubtedly the duty these tubes perform is an onerous one as the rate of ebullition in them must be very great, and this is evidenced by their often being unable to stand the extra duty entailed when oil-fuel is used; in such cases it is found necessary to remove them.

Some twenty-five years ago similar circulating tubes were used to a large extent on American engines, but were afterwards discarded, apparently on account of maintenance troubles ; certainly a number of accidents were caused by one end coming adrift under pressure, 
Fict. 7.- "Between-Frames" (British) Type Expansion Bracket.
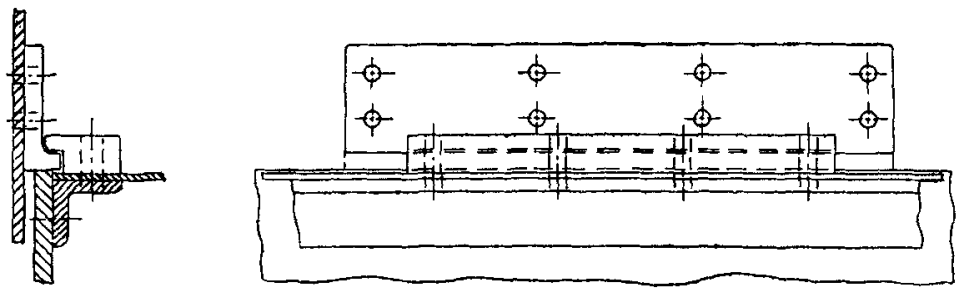

Fig. 8.--"Between-Frame" Type Expansion Brackets.

Ordinary Pattern.

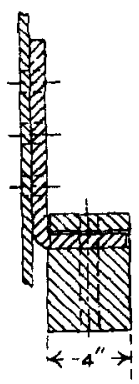

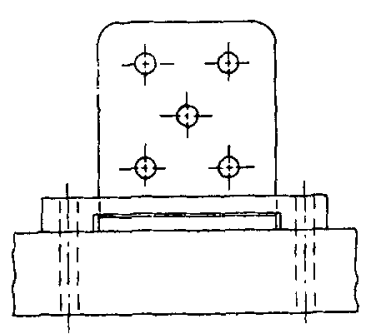

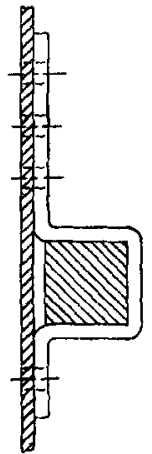

Clip Pattern.

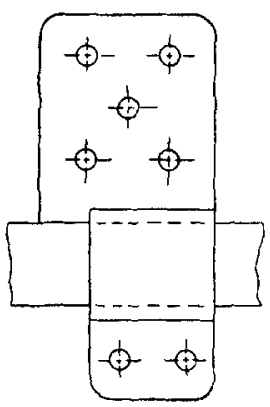

:FIG. 9.-" Over-Erame" Type Expansion Bracket.
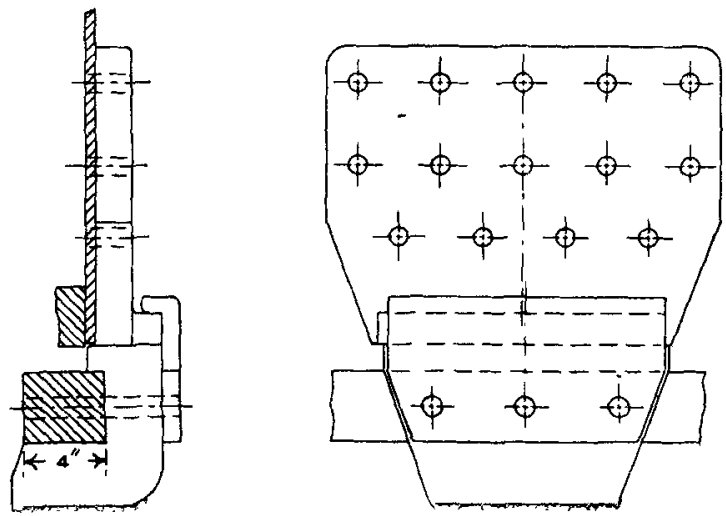
although the Author has always believed this to be mostly due to the tubes of that time being carried from the front water-leg to the crown-plate (near the back end), thus forming a loop between two surfaces approximately at right angles, whereas the present tubes always run practically straight between two opposing surfaces. There does not appear to be an absolute necessity for the tubes as arch supporters except for very wide fire-boxes, and on the remaining point as to whether the better circulation obtained is worth the increased maintenance, the Author has not yet had sufficient experience with them to offer an opinion.

In connexion with brick arches it is remarkable that for many years they were little used in American practice, and practically only came into favour again with the modern reintroduction of circulating tubes.

Fusible Plugs.-These are very often omitted in modern American practice; in fact the Author believes the majority of locomotives in Canada and the U.S.A. are without them. He has been informed that they have been done away with for the reasons that (1) they sometimes leak and cause delays when there has been no shortage of water; (2) when there has been a shortage of water they have been known to fail to act on account of $(a)$ scale and hard deposit having accumulated on the water-end so blocking the orifice, and $(b)$ some change having taken place in the fusible metal, causing it to withstand a higher temperature than was intended; (3) it is considered that with the large boilers now in use the comparatively small hole would not have sufficient effect.

Regarding (1), from close investigation the Author was led to believe that many cases of plugs leaking through the fusible section was due to the practice of using an inset consisting of practically a straight-tapped hole (with a large countersunk part at the top), and lining the inside of the plug before running-in the fusible metal. The tin in the lining, melting out at a lower temperature than the actual fusible metal, thus defeated its object and left a leak round the fusible core. Cases have been known where plugs have been heavily tinned and in a few days such tinning has disappeared and the inset has been loose enough to rattle, though still in position. With plugs cored out fairly large at the top, filled without any tinning, and the metal lightly tapped down from the top before cooling off, no trouble is experienced with false alarms. Regarding (2) $(a)$ and $(b)$ : this is a question of periodical removal for inspecton and renewal of the inset when needed. Regarding (3); this seems 
only a question of using a larger plug, or alternatively more than one plug in each area to be protected.

The Author is entirely in favour of retaining fusible plugs, after some years' experience with them applied (at front and back) to long fire-boxes operating over suddenly alternating grades of 1 in 30 ; although not having much effect on large fires, or on the pressure in the boiler, yet they are sufficient to call the attention of the engineman.

Fire-Holes.-The usual form of fire-hole flanging adopted in American practice is that in which the outer and inner plates are flanged towards each other and so have a riveted lap-joint midway between the shell and the inner box. This method, however, gives little opportunity for dealing with any leaks which may occur; if any rivets need to be removed it is impossible to replace them, and patch-bolts must be used instead; further, the laps are apt to be cut away in caulking leaks, and cracks sometimes develop through the laps to the rivet-holes. These are most difficult to deal with properly. Many of these difficulties disappear with the employment of electric welding, and in new boilers the plates are now generally welded together at the joint from the commencement, but nevertheless the experience of the Author with various kinds of fire-hole arrangements used in connexion with both copper and steel fire-boxes has been that there is nothing to equal the well-known "Webb" pattern.

Fire-Doors and Deflectors.-The various effective forms of firedoors in use in British practice for many years, appear to have had no parallel in general American practice, as until the introduction of the automatic fire-door the old swing type door held sway on most lines. The deflector, although introduced in America in the early "Sixties" was seldom used, and is so even now, the reason generally given being that it interferes too much with the proper distribution of the fuel on the grate. This is so in many cases and the length and droop of the customary British deflector would be out of the question with most large fire-boxes, but it is possible to shorten and modify the deflector to whatever extent is necessary and yet retain some of its advantages. The automatic fire-door, only remaining open while the fireman's foot is on the trigger, does not allow much cold air to enter, and makes more remote the probabilities of the deflector being much used in America.

Respecting mechanical stokers, they are absolutely necessary in many cases where the amount of fuel to be fed to the boiler 
precludes efficient hand-firing. They do not appear likely to be needed in British practice for ordinary fuel, nor even for the largest boilers likely to be designed to suit the British loading gauges.

Fire-Grates.-The entire difference in the practice of the two countries in respect to fire-grates is, of course, on account of the different class of fuel used; the rocking-grates and dumping sections (or drop-plates) used in America are essential for burning the class of bituminous coal used, which is often so small that it has to be heavily watered to prevent it being carried straight away off the fire by the blast. For the same reason the air spaces are less than in British practice, this fact explaining to a great extent why a greater steam-raising capacity can be got out of a given grate area in England than in America.

The dumping sections are required, as certain descriptions of coal used are liable to form clinkers and these can be worked to the front (or back) end and pushed through the drop-plate during the course of a few minutes'stop at a station. They are also of use when fires are drawn, as the fire is pushed through them into the ash-pan with facility. The Author would like to see drop-plates tried on some of the relatively long grates in British practice, to ascertain if their convenience is worth their upkeep in such cases. Trouble is likely to develop from warping, unless particular care is taken in designing the drop-plate casting, and the methods of locking the trunnions are important.

Ash-Pans.-Owing to the greater variety of wheel arrangements used in America the ash-pans are usually more complicated than the British, but conversely they are not so well constructed. A much thinner gauge material is generally used and less trouble is taken to secure reasonable air-tightness when dampers are closed; further, in most large modern locomotives the difficulty in providing sufficient air entrance area compels open spaces to be left all round the upper part of the ash-pan near the foundation ring, and these spaces remain open permanently; also in many cases ash-pan doors have been superseded by netting, placed at an angle to prevent fire falling on the line, and provision for removing the ashes made by a sliding or other type of door in the floor of the ash-pan. These arrangements are, of course, necessary, but the Author considers it should not be beyond the scope of designers to arrange for doors to close all air entrances, as the amount of fuel wasted due to the enginemen not being able to close all air-inlets when steam is not required is unjustifiable. 
Damper gear is not usually very well finished, and often forked end-connexions to the levers and rods are not provided where they might be; similarly, the accurate catches and close adjustments now common in British locomotives are not usually provided.

Flexible Fire-Box Stays.-In modern American practice a good many flexible stay-bolts are used, generally of the "Tate" or similar pattern, having the flexibility provided in the attachment to the outer shell. These stays are clearly very necessary in certain parts of the large fire-boxes used, as although there is not the difference in the expansion between the material of the inside and outside plates as when copper inside boxes are used as in British practice, yet the large area of plate exposed to the fire must produce very considerable relative displacement of the inside and outside plates and with a less ductile material.

Domes.-Domes are constructed in a similar manner in both countries, usually in one piece up to 2 feet in height, and in modern practice they are pressed out of a single plate; above that size, three-piece construction is generally adopted.

The "Helmet" pattern with the joint low down, enabling the regulator and gear to be easily got at, is not often adopted in America ; the domes used there, however, are much larger in diameter than in British practice and allow men to work at the regulator fairly easily without the low joint. The Author considers the large diameter domes an advantage for obtaining dry steam and giving facility for entrance, etc.; in cases where the size of the boiler prescribes only a small diameter dome, he considers the "Helmet" pattern preferable.

Lagging, Cleading, etc.-The American practice in lagging is similar to the British, but in respect to the cleading nothing like the same care is taken. No "Crinoline" bands are used, the cleading plates-always of much thinner gauge than used in British practice -being clamped directly on to the lagging, and neither the number or effectiveness of the securing clips and fastenings is comparable ; the result is that the cleading does not, as is usual with British locomotives, last the life of the boiler, and the appearance is always inferior. These remarks also apply generally to the dome casings and other mouldings on the boiler, the sand-box thereon, etc.

Regulators.-For many years the standard British regulatorvalve has been of the sliding through-port type with auxiliary 
pilot-valve, and regulator-handle moving in a sector across the face of the fire-box back head, although certain railways used a type of pull-out handle. In American practice the circular double-beat partly balanced regulator-valve has all along been favoured, being always operated by a pull-out lever of special design incorporating a notched quadrant and catch with fine teeth. Present-day British practice also tends in the direction of the double-beat pattern, although generally with the old type handle, or variations thereof, working across the fire-box.

It is unquestionable that with the circular type, it is easier to maintain a good seat, and, if properly designed, any failure of the gear should cause it to close automatically. It is doubtful if there was any real advantage gained by the preliminary opening of the pilot-valve in the sliding type, which could not have been obtained otherwise; all regulators are susceptible of gradual opening if proper leverage is provided.

Regarding the pull-out versus the cross-movement handle, the Author is in favour of the former pattern with lever and catch; the driver has better control over it, not having to turn himself sideways. It can be brought to the most convenient position to his hand and he is enabled to look ahead, having one hand on the regulator-handle, the other on the brake-handle and operate them both without taking his eyes off the line ahead of him.

Internal Main Steam-Pipes,-These are usually of copper with brass sleeves brazed on at the ends for jointing purposes, in British locomotives, the American practice being to use steel tubing with cast-iron or cast-steel end sleeves attached to the pipe by a number of small rivets. The steel pipes are liable eventually to suffer from corrosion, particularly near the sleeve at the front tube-plate end; the Author favours the use of copper for such pipes for this reason, also because of its better fastening to the end-pieces, although a good steel-pipe with bronze end-pieces properly attached should, and does, make a good job.

Superheaters.-The American-Schmidt pattern is now standard in America, this type being identical with the Schmidt, except that metalto-metal spherical-cone joints, Fig. $10(d)$ (page 409), are employed in connecting the units to the header instead of the ring-joints as generally used in British locomotives. The Author has a very high opinion of these joints, based on experience with them under the same particularly trying conditions as mentioned elsewhere. $\mathrm{He}$ is unable to see why the old ring-type joint with asbestos jointing 
is continued in British practice, and for the same reason he does not see any necessity for the method of fastening the unit tubes into the header by expanding them, as in some systems of fastening; this method appears rather an arduous one to accomplish a simple result.

There are practically no special arrangements of headers and units in use in America similar to the designs emanating from Swindon, Doncaster, and Eastleigh, etc., in England. There were a number of designs of smoke-box type superheaters in use in America similar in many respects to various designs in use in England prior to the general adoption of the smoke-tube type, but these have all disappeared in a similar manner to the British patterns, and no further reference to them is needed.

Regarding dampers to stop the draught through the superheater flues when steam is shut off, in the Author's experience with engines operating where up grades of $\mathbf{1}$ in 30 change at once to down grades of similar severity, dampers working automatically on the opening and closing of the regulator are essential owing to the heavy fire which it is necessary to maintain to the top of the grade being altogether too fierce to be allowed access to the unfilled units whilst drifting; the down grades are too deep to allow a small amount of steam to be circulated through. He has not tried a system of automatic air-inlets in the superheater circuit, but is averse to it on account of the very large amount of superheated air which he considers would be drawn through the cylinders on long downhill sections, and which would seem likely to cause lubrication troubles.

Smoke-Boxes.-The difference between the simple interior of the usual British smoke-box and the American with its deflectors and spark-arresters, is principally due to the grades of coal used, although the law in various parts of the U.S.A., being more stringent than British, no doubt has its effect also. With reasonable sized smoke-boxes, as in present-day British practice, which give a more steady vacuum than the old small patterns, coupled with the class of coal burned, there appears to be sufficient provision without elaborate fittings inside.

Where the major portion of the fuel burnt is small (or soft) coal, which even after wetting is liable to be lifted off the fire by the blast when engines are working heavily, more elaborate arrangements are needed, and in consequence one finds deflectors or diaphragmplates, dead-plates and spark-arrester netting. The diaphragm-plate is considered by the Author to be a good feature, as it ensures a proper proportion of draught through the lower tubes, and in 
conjunction with the netting causes the products of combustion to traverse the lower part of the smoke-box towards the front and through the netting, before escaping to the atmosphere; this circulation ensures that any incandescent particles larger than the netting shall be thoroughly "teased" until they are small enough to pass, by which time they have become dead and harmless. Undoubtedly in the case of locomotives built for Colonial useespecially tropical lines where fires of enormous extent are very easily started-smoke-boxes need to have fittings similar to, or a modification of, the American system and in particular to have ample length. The space between the diaphragm-plate and the tube-plate is made use of by means of a damper at the lower part (operated automatically by the admission, or otherwise, of steam from the regulator) to isolate the tubes containing the superheater units.

American practice in respect to smoke-box fronts and doors, also differs fundamentally from the British; the fronts are always made easily detachable, being bolted on, are generally of pressed or cast-steel, very often of cast-iron and the door, which is also of cast-iron, is always made very much smaller in proportion to the diameter of the smoke-box than in British practice, usually about half to three-fifths the diameter of the smoke-box.

The experience of the Author is entirely in favour of the American pattern, the smaller door, having its lower edge well away from the bottom of the smoke-box, does not suffer from warping and burning away due to drawing air, as frequently happens with British pattern smoke-boxes when engines are worked heavily. That this is not due simply to the larger volume of the American smoke-box is proved by the case of a set of engines under the Author's control, which gave endless trouble with the usual British pattern of door, carefully faced at the joint; this trouble was entirely cured by substituting simple cast-iron smoke-box fronts with cast-iron doors about two-thirds the diameter of the original doors, and without any special facing. Clips had been used round the original doors and were, of course, applied to the American pattern doors also, as is always done.

It is clear that the small door, together with the diaphragm-plate and other fittings inside the smoke-box, prevents the tubes all being properly cleaned out from the smoke-box end without a lot of dismantling; this difficulty is got over by cleaning the tubes from the fire-box end by means of long thin pipes conveying compressed-air (sometimes steam) and used as cleaners and blowers combined, the ashes being carried through to the smoke-box. 
Blast-Pipes.-This matter seems to have settled down in American design in a similar manner to the British, namely, a single circular orifice. For many years double nozzle-pipes composed of two circular orifices in line across the smoke-box were much favoured in American practice, but are now rarely used. High blast-pipes are entirely out of favour, and the top is never higher than-usually below-the centre of the tube area.

One recent American development consists of a circular orifice, but with four partial bridges projecting into it, and it is claimed to give better results than a plain circular orifice of an area equal to that of the special type, less its bridges; if this is so, and a considerable number of tests go to prove it, it is evidently due to the roughening of the outside of the exhaust cone and consequently its "pull." It would be interesting to see this type of blast-pipe tried on express work in England. The various forms of blastpipe adjustable orifices sometimes used in British practice find no favour in America. "Petticoat" pipes are, however, extensively used and project downwards usually rather more than in British locomotives.

Smoke-Box Steam-Pipes.-Cast-iron pipes are universal in American practice and last practically for ever, and no coppersmiths' work is involved; on the other hand, they are heavier (where weight is undesirable), and their extra thickness may obstruct the withdrawal of a few tubes. In some cases of older types of engines with the steam-ways in the saddle-casting, their position made the expansion of certain tubes a difficult matter; the joints are in all cases ground joints with the usual rings, as referred to later; these joints are very effective and there is no reason why they should not be used with copper steam-pipes. The solution of this question appears to be to use copper pipes combined with the joints mentioned.

Smoke-Box Fastening.-The old British method of bolting the smoke-box to lips on the cylinder casting front and back and riveting to the frame at each side, allows too much scope for air leaks and eventual "working" in the rivets, etc. The "Saddle" type certainly necessitates care in locating the position of the boltholes to enable boilers to be interchanged, but not more care than should be-but often is not-used in setting out the holes in the old square-set type.

The saddle type of smoke-box being circular calls for the use of the drum-head tube-plate, and in American practice this is always 
placed inside the front ring of the boiler barrel ; mention is made of this fact as it is not essential for drum-head tube-plates to be placed inside, and in some cases in British practice they are considerably larger than the diameter of the front ring of the boiler ; as this is an advantage in giving more opportunity for "breathing" of the plate between the outer row of tubes and the boiler barrel, the Author considers it preferable. He favours the saddle type of smoke-box base, both in connexion with plate- and bar-framing, as providing the most substantial fastening and being simpler to make and keep air-tight.

Cabs.-It is recognized in British practice nowadays that an adequate cab, more or less of the American style, is needed. A roomy cab is an advantage, and the Author considers particularly that it should be the full width of the foot-plate, thus allowing for doors on each side leading on to the running-plate without the necessity of going round the side of the cab. The exception to this is with the 4-4-0, and in some cases the 4-6-0 type, with large coupled wheels which preclude this arrangement. Where locomotives are built for use in hot climates it is essential that the cab be as high and roomy as the loading gauge will permit, and with ventilators in the roof.

Regarding seats for the enginemen, these are an advantage where the runs are long but at slow speeds with a good number of stops; they should, however, not be so comfortable as to induce the driver to remain sitting at every stop, where opportunity occurs for him to be better employed looking round his engine.

In one respect the British cab has, until recent years, been superior, that is, in being constructed of iron or steel. All modern American cabs are, of course, of similar material, but the standard practice until well into the present century was to employ wood; this, in the experience of the Author, and, as may. be expected, gave poor results.

Boiler Mountings in Cab.-The usual American method of attaching water-gauge and other small boiler mountings on the fire-box front (or back-head plate) is not very substantial, as it is customary to fix the ends of the gauge frames and other valves with a simple screw-shank connexion having a taper thread, and to screw the fitting bodily in until a tight fit is obtained at the correct aligament. This appearance of weakness is particularly noticeable in the case of gauge fittings having no direct attachment to the boiler at the top of the gauge-glass, connexion to the boiler being 
obtained by a copper pipe leading from the top of the gauge-glass to an entrance on top of the fire-box shell, such fittings giving the impression of being liable to fracture at the root of the thread if roughly handled. Another poor feature is the general use of screwcocks, taking some time to shut off, instead of a type of plug-cock shutting off by a quarter turn.

The method of making the upper connexion of the water-gauge through the top plate of the fire-box casing is an excellent arrangement-the entrance should be made some distance from the back end of the boiler-being less liable to indicate incorrect water-level, due to surging in long boilers, when starting and fluctuating in speed on steep gradients. It must be said in connexion with this question that American enginemen trust a good deal more to the three try-cocks placed conveniently to their hand, than to the gauge-glass; this may be from experience of its defects as applied there.

On the other hand, the system, universal in America, of mounting a steam-turret or "fountain," as it is called, on top of the fire-box within the cab, having one large dry-pipe leading thence from the dome, cannot be equalled by any other method. This steam-turret eliminates all other steam-taking joints on the boiler; it is a brass casting and the body is made sufficiently large to take further steam fittings if at any time needed, so that it is merely a matter of drilling and tapping an extra hole and fitting a steam-cock thereto. The latter is a minor job, as there is always one main centre stop-valve which shuts off steam from the entire turret, enabling any valve to be re-ground or attended to whilst the engine is in steam.

Injectors.-The Author's experience is altogether in favour of the American form of injector, namely, the self-acting restarting pattern of the "lifting" type. Its pull-out operating handle makes it much easier to "catch" the water than is the case with the British screw-cock, and further with the American injector the water-valve may be shut off to about 50 per cent after the injector has started to deliver, and thus more control over the rate of feed to the boiler may be obtained. Although it would seem that the under or "drowned" type of injector should give best results with moderately hot water, yet the self-acting restarting lifting type has been so perfected, as in practice to give the longest range of temperature of the water dealt with. The British "Combination" pattern, whilst being a very excellent injector, is quite unsuitable for Colonial use; its internal delivery pipe always gets quickly 
choked up, and the difficulty and time entailed in cleaning it out are great objections to its use.

Top delivery is now common both in British and American practice, although the British applications are usually much more refined than the American. Top feeds are an advantage, irrespective of any device for collecting deposit; in any event much of it will be converted into fine powder, which can be washed out. Whilst internal delivery pipes are most troublesome to keep clean, and side delivery arrangements become choked up just in the orifice into the boiler (due to its being the point where the delivery water meets the higher temperature water in the boiler), a top delivery obviates this and does not become foul even when very unsuitable water has to be used.

Safety-Valves.-The Ramsbottom type was until recently, almost exclusively used in British practice, but latterly various types of direct loaded valves have been adopted. In America the use of two independent valves of directly loaded "Pop" type has been the common practice from about 1866. Undoubtedly the Ramsbottom pattern is the most safe on account of its usual method of adjustment not allowing unauthorized persons to increase the pressure without an amount of work bound to draw attention, and on account of its construction allowing the enginemen to prove its action under steam without interfering with its setting. The directly loaded patterns, however, can be adjusted with facility and accuracy under steam by the repair staff ; they furthermore give, in the case of most makes of "Pop" type, a far less margin between the commencing blow-off pressure, the maximum, and the shutdown pressure. In the case of the Ramsbottom valve this is sometimes as much as $8 \mathrm{lb}$. per square inch, but with the "Pop" valves usually $5 \mathrm{lb}$., sometimes only $3 \mathrm{lb}$.; most of the "Pop" types are very efficient in this respect and in the discharge capacity.

The position of the safety-valves in British practice is now almost exclusively over the fire-box, whilst American practice generally places it on the dome. The Author considers the proper position is over the fire-box and apart from the dome; clearly it should be located nearest to the place of greatest ebullition, and it should not be near the regulator entrance for obvious reasons. On the other hand it should not be placed low down on the fire-box, as in that position a considerably larger amount of water will be lost from the boiler for a given release of pressure, than if situated on a subsidiary dome or other mounting of medium height. It should be noted, however, that in American practice the dome itself is 
usually fairly near the fire-box-this position of the dome being incorrect for reasons given in connexion therewith in a previous section of the Paper-and possibly the desire is to avoid further holes in the boiler shell.

Piping.-This is often rather scamped in American practice; on different engines built to the same specification the piping will sometimes be found to vary appreciably, and in the matter of brackets there is considerably less care than in British practice, and they are commonly fixed in different places. Clips are generally

FIG. $10($ a).

Copper-Ring Joint, Steam-Chest Cover.

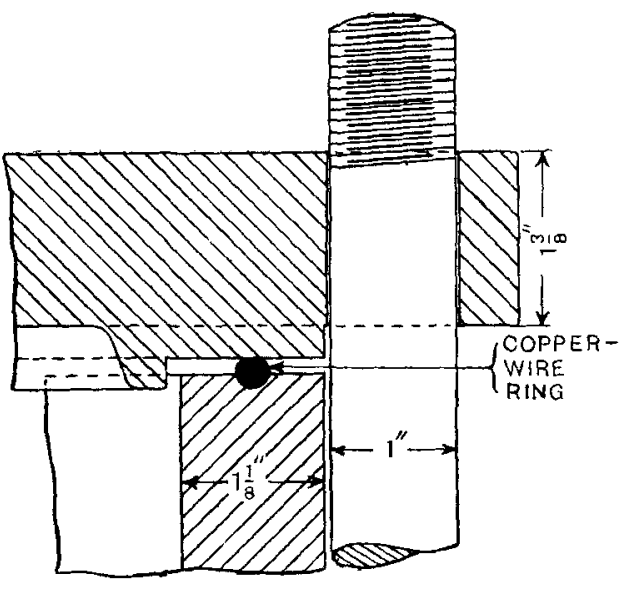

FIg. $10(b)$.

Direct-Contact Type Joint, Regulator Stuffing-box.

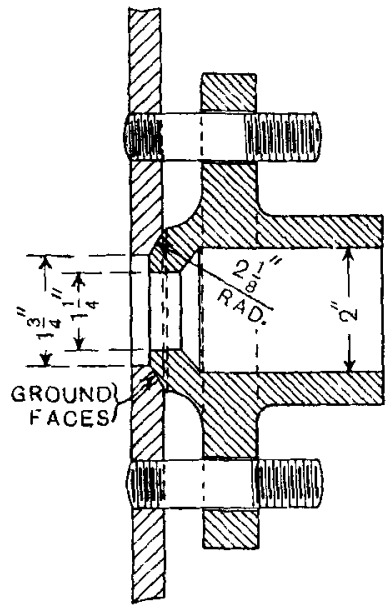

poor, being of a plain bent iron one-bolt pattern fixed by a bolt and nut without either check-nut or split-pin; there are quite a number of these clips around the engine, especially under the running plate, and they frequently come loose in service and drop off.

Joints.-Copper ring-joints in dome and other major boiler joints, also plain ground cone-joints for regulator-rod stuffing-boxes, as used in American practice, are very effective and far superior to asbestos or other similar jointing material as used with flat joints in British practice. They require no cleaning off and are much less expensive, as the copper rings can be re-used indefinitely by 
softening each time, and the cone-joints only need regrinding. Further, the American method of using plain metal-to-metal joints, ground together, either of the flat and spherical surface loose-ring type, or of the spherical-cone direct contact type, for all steam-pipe and superheater unit joints, is also far superior to the asbestos and special copper and asbestos joints commonly used in British practice. Such metal-to-metal joints require, if anything, less attention when under repair, seldom needing to be re-ground to any extent, and they have the great advantage that when fitted up and once tested and

FIG. 10 (c).

Loose-Ring Type Joint, Smoke-box Steam-Pipe.

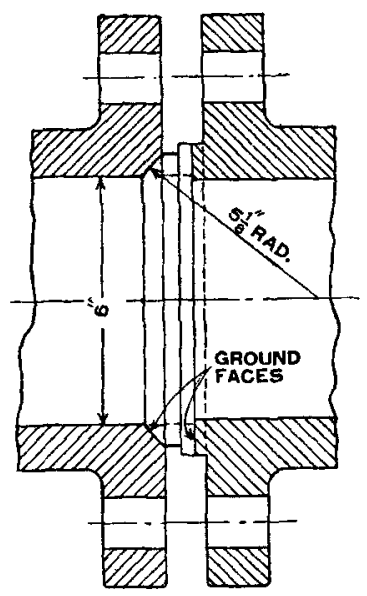

Fia. $10(d)$.

Cone-Sphere Joint, Superheater Units.

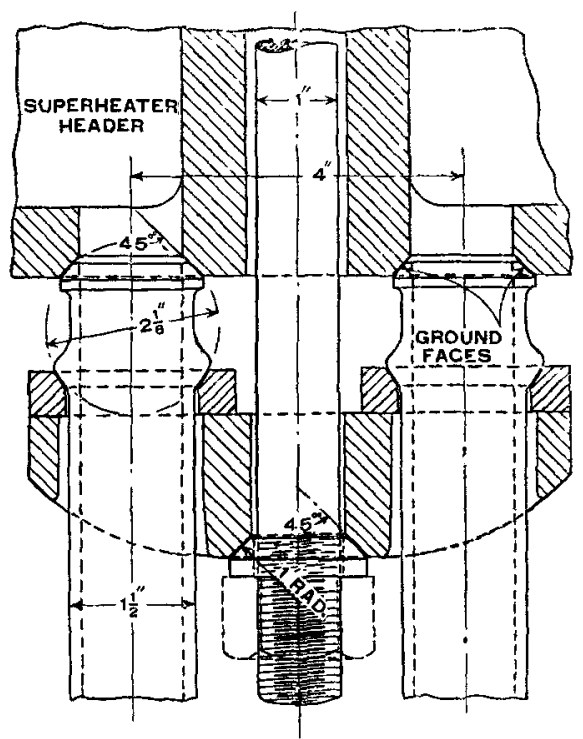

found satisfactory, they never develop leaks whilst in service or, in fact, need to be disturbed until the engine returns again to shops. Fig. $10(a)$ illustrates the copper-ring joint, $(b)$ the direct-contact cone joint, $(c)$ the loose-ring type, and (d) the direct-contact spherical and cone type as used with superheater units.

Reversing Gear.-Steam reversing-gear is practically always fitted to American locomotives of any appreciable size now, but for many years the old plain lever was retained on even the largest 
engines, until, finally, the duty became so heavy that power-operated arrangements were adopted. It is remarkable that the screw reversing-gear as employed in British practice for so many years was not commonly used, except on the Pennsylvania Railroad from about 1914. Observations show that drivers of engines with lever reversing-gear do not follow and take advantage of the variations of gradient, etc., as on engines equipped with screw-gears (and, of course, those with power reverse-gears).

The amount of fuel lost by the retention of the lever on practically all American locomotives during the forty years 1870-1910 must have been enormous, and even now comparatively heavy engines in American practice-as well as most goods-engines in British practice-are built with the old lever. There seems little gained by using close notches as in American practice, as it is not so easy for a driver to select the position desired when there are many small notches and a catch with a number of teeth, as with a lesser number of notches and a single catch. For shunting, a lever is perhaps preferable for quickness, but even pick-up goods-train engines doing much shunting on the journey would be better if equipped with a combined screw and lever-quite a simple matter to design. It is not necessary for reversing screws to be so slow-operating as they are commonly made, a good deal of the work to be done by them is often due to insufficient balancing of the motion.

Regarding the usual American method of balancing the reversing shaft by springs, as against the most common British method of using weights, there is no doubt that when weight is a consideration springs are preferable, but otherwise plain weights, applied as nearly opposite the link hangers as possible, seem the better.

The system of balance much used in America, namely, a semielliptic spring placed on its side athwart the engine, and coupled to a lever in the centre of the reversing shaft--sometimes weighing about half that necessary to balance by dead-weight-is not altogether satisfactory, being apt to give different resistances at different states of camber; it is also applied in a bad position. The other American pattern with coiled springs, under compression, in cases, acting in line (or nearly so) with the link carriers is the best spring arrangement; if the spring should break, the case, by holding the parts in position, prevents much alteration in the resistance, they are also readily adjusted by means of a nut and check-nut to give the exact balance required.

Bridle or reach rods from the reversing lever (or screw) to the reversing shaft are often, in American practice, made of tubing 
screwed at each end and fitted with the usual fork-ends; this is not merely a question of cheapness, as is sometimes supposed, but weight for weight a tubular rod is much stiffer and does not " whip " like the usual style, whilst the threaded ends with a check-nut provide ready means for minor adjustments in the length of the rod.

Valve-Gear, Motions.-The practically universal adoption of Walschaert valve-gear in America is not surprising in view of all cylinders being outside, for which that gear is so well adapted; it is, in fact, rather surprising considering the number of years that valves on top of the outside cylinders have been in vogue, that inside valve-gear necessitating rocking-levers, intermediate transmission bars, and sometimes indirect motion, was not superseded long before it was. The Author has known it stated that one of the reasons for the conversion was due to the abnormal weight of the eccentric straps of the large engines being developed at that time, causing trouble from overheating-to what extent this may have influenced the matter he is unable to say-he believes it was not customary in American practice to use anti-friction liners in eccentric straps, the cast-iron strap running bare on the eccentric, similar to the practice on certain British railways for goods engines, but often being of heavy and clumsy design-a few of the later link-motion engines of heavy type were provided with brass eccentric-straps, thus reverting to very early British practice.

Mention should be made of a practice which had a considerable vogue in America at one time, that of using solid eccentric-sheaves, in some cases cast on, and in others made solid, bored to fit the (parallel) axles and fitted before the wheels were applied. Sheaves cast-on or solid with the axle were also tried by Mr. S. W. Johnson on the Midland Railway for a few years in the "Eighties." The practice is understood to have been discontinued on account of imparting too much stiffness to the crank axle. In the case of the American pattern straight axles this trouble of course did not arise The Author, from experience, has nothing good to say about the solid sheaves, which eventually become slack and then nothing can be done to make a satisfactory job except to remove the solid sheave and fit one of the usual pattern.

A noteworthy point about the link-motion, as applied in American practice, was its frequently complicated arrangement, namely, transmission-bars sometimes with bends or loops in them, and almost always with side-sets, eccentric-rods with bends and very severe sets and often of short lengths. The motion pins also were generally of much less diameter than in British practice, and being 
"stepped," that is, not of one diameter throughout and secured by a nut on one side, were liable to loosen the nut and work out when they had developed any slackness in the rod. The old form of built-up link was not, in the Author's opinion, very reliable either. Even until recently with the Walschaert gear the links were often made unnecessarily heavy and complicated by means of large side-plates to carry the trunnions.

Distribution Valves.-In respect to the past practice in slidevalves, the American system of using large balanced valves-which the outside position on top of the cylinders made possible-was a great advantage over the British method of smaller shallow unbalanced valves; the freedom with which the steam got to and from its work, in spite of the longer distance to be travelled, had undoubtedly a great deal to do with the "freedom" which was noticed in comparison with British-built locomotives in newlydeveloped countries, which practically offset the advantage the British-built engine generally had in coal-consumption, due to the more careful design of ash-pan, fire-door and boiler.

The balancing of the valves, which became customary from about 1880 , was a complete success in eliminating wear, ports and valves being practically untouched time after time when engines were shopped; the valves were of cast-iron and often lasted as long as the cylinder-casting, and the frequent periodical examinations for wear necessary with the British pattern of unbalanced bronze-valves were not required.

The practice of the two countries in respect to piston-valves differs little, if at all, one very good feature of American practice being the use of combined steam-chest covers and valve-spindle guides; these are cast in one piece, the slides, being disposed symmetrically about the centre line, are simple to machine and automatically ensure correct alignment on erection. T'he Author considers these superior to any system of independently attached guides.

Pistons.-Piston-heads do not differ much in either country, the usual single-plate pattern now being practically universal. In American practice more attention is given to lightening the heads, rolled and cast steel being used for this purpose; this is a great improvement on the practice there a few years back of employing double-walled hollow piston-heads of cast-iron, some cast in one piece and others built up in a fashion very conducive to failures on the line due to small parts working loose. 
Piston tail-rods are not commonly used in American practice, and where these are used they are for pistons 27 inches diameter and upwards, as against the British practice of applying tail-rods to pistons over 19 inches or $19 \frac{1}{2}$ inches diameter, nor are supporting springs inserted in the piston head to confine the wear caused by its weight to the rings instead of the head itself.

One very good point in up-to-date American practice is the provision of sufficient length of piston-rod to allow the piston to be taken out of the cylinder far enough to enable examinations to be made and new rings fitted, without breaking the cross-head fit.

A poor feature of American practice is that of riveting over the thread at the end of piston-head nuts after tightening, and using no other security. Also tapered ends of piston-rods are frequently of considerably less diameter than the plain part of the rod, even at the cross-head end where the reduction of section caused by the cotter-hole has to be provided for. This seems a mistake, as if the ends are of sufficient section, the body of a normal length rod must be unnecessarily heavy even allowing for re-grinding. The British practice of enlarging the ends is undoubtedly the correct one; hollow rods, in which the hole in the plain portion is larger than those in the ends are, of course, not referred to.

Cross-Heads and Slide-bars.--Present-day comparisons show little difference in these parts. In British practice, with inside cylinders the old four-bar type is still generally favoured, being very well suited for $0-6-0$ and $0-8-0$ inside-cylinder engines where the distance between the cylinder centre-lines and the leading axle is limited. In respect to outside cylinders both countries appear settled to the two-bar or "alligator" pattern. There is one type, however, sometimes used in each country, especially with outside cylinders, namely, the "Laird" with two bars above the pistonrods; this is particularly referred to, as it is the one with its wearing surfaces furthest away from the dust of the line, and it has the advantage of presenting no horizontal surface for the dust and grit to settle on; it is a very good type for new and loose tracks.

Connecting-Rods.-Comparing the types of big ends generally used, it is noticeable that American practice usually favours the old "strap" type, similar to those commonly used on inside-cylinder engines; whilst this is no doubt cheaper in first cost, it is more troublesome to maintain than the open-end or closed-end rods generally used with outside cylinders on British engines. The large mass of metal in the strap type is concentrated in an unfavourable 
position, such weight being preferably beyond the big end centre, not between the two centres of the rod. In certain cases, however, where small diameter driving-wheels are combined with a long pistonstroke, open-ended big ends cannot be used owing to the chances of the filling-block bolt striking obstructions on the ballast, at leveI crossings, etc. No comment is made regarding little ends, the usual types being common to both countries.

Coupling-Rods, Crank-Pins and Bushes.-Coupling-rod pins on American locomotives are usually larger in diameter, but less in length, than British and the same thing applies to the knucklejoints and pins, also to the section of the rods themselves, which are seldom of the usual British $\mathbf{I}$ section on engines with more than six-coupled wheels. This practice enables very large cylinders to be placed, driving outside the coupling-rods, and still keeping within the required limits of width. Although the Author finds that the shortness of the pins leads to a rather short life for the knucklejoints particularly, yet such rods allow much greater lateral flexibility than the British practice and on severely curved lines the American practice gives less coupling-rod breakages and overheating of bushes. As mentioned in reference to frames, it is a disadvantage to have a coupling-rod section giving too much lateral stiffness compared to the engine frames-this being more likely to occur in connexion with plate-frames. It is possible, with a much cut-out plate-frame, together with coupling-rods of excessive stiffness, to have a locomotive " running on its "rods."

The methods of securing coupling-rod bushes in America are by means of a set-screw underneath-Fig. $11(a)$ or by a combined set-screw and oil-cup fastening-Fig. $11(b)$; Fig $11(a)$ is also sometimes used on British locomotives as well as Fig. $11(c)$ and $(d)$. The Author's experience is that with heavy duty only type $(d)$ is satisfactory. If a bush is inclined to move, it generally causes the under set-screw to slack off and fall out; the same thing applies to the combination oil-cup fastening and set-screw at top, except that the results are worse, and the tendency to slack out the set-screw is aggravated by the motion of the rods helping to throw the oilcup off them. In fact, he knows of no method of fastening so unsatisfactory and troublesome as this; the side-pin fastening is certainly better than either of the above, but is not such a definite fixing as is desirable.

Failure of the first three types allows the bush to turn the oilhole out of register, stopping the oil supply in addition to the trouble of the loose bush, and possibly causing a delay, whilst the latter 
arrangement of a key and keyway not only prevents the initial movement towards slackness, but in any event does not allow the bush to turn, and so prevents any delay.

Wheels and Tyres.-There is not now much variation in the Four Methods of Securing Coupling-Rod Bushes.

FiG. $11(a)$.

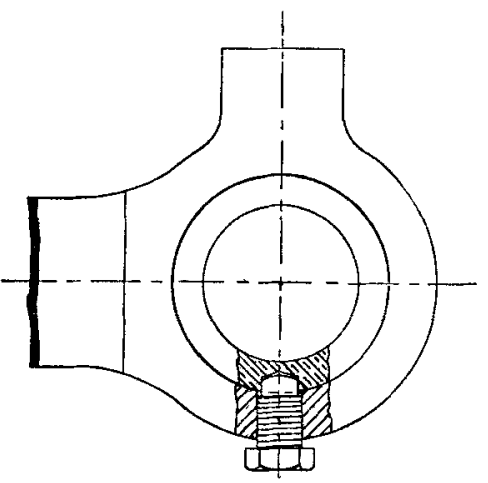

FIG. $11(c)$.

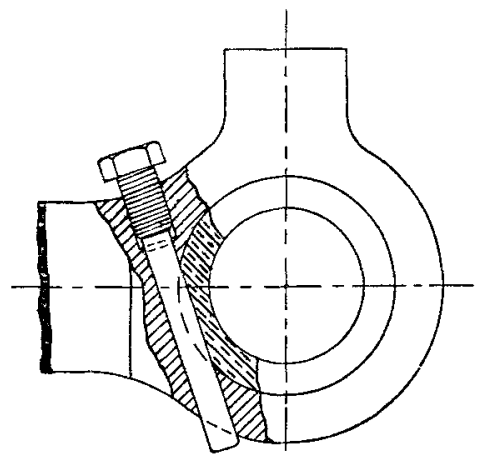

Fia. $11(b)$.

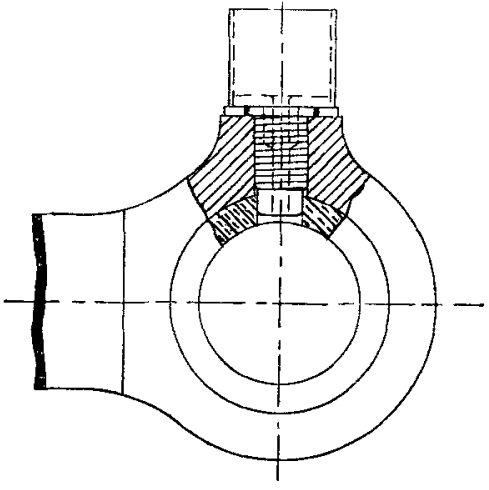

Fig. $11(d)$.

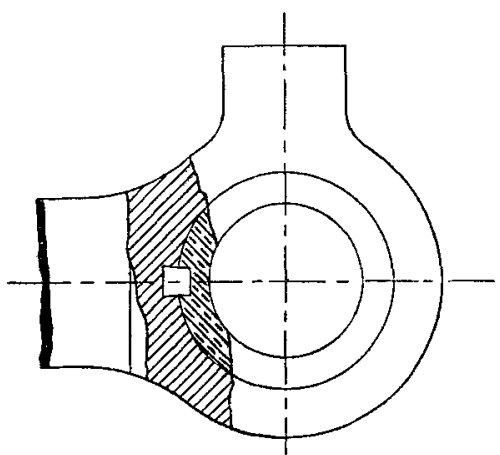

practice of the two countries in respect to locomotive-wheel centres ; cast-steel is always employed, with a few exceptions in goods and shunting engines in each country where cast-iron is used. Up to long after the time when cast-steel came into favour in British practice, cast-iron continued in use in American practice, having been employed for very many years; comparatively few wrought- 
iron wheels were made during the long period through which such wheels were so successful in England.

The general standard American practice has been for tyres to be secured by shrinkage only and with a lip about $\frac{1}{4}$ inch by $\frac{3}{8}$ inch provided on the outside of the tyre; the shrinkage allowance being approximately $\frac{1}{5} \overline{0}$ of the diameter-about 50 per cent greater than in British practice-and the Author has many engines so running on lines with curves up to 3.6 chains radius and long gradients of 1 in 30 , on descending which, the continuous brake-block pressure often heats the tyres till the paint begins to blister.

On recent American locomotives, however (mostly passenger engines) tyres of 5 feet 6 inches in diameter and over are now being provided with security rings of the Mansell and other types, or with lock-lips on the tyre itself. The Author's experience is that the majority of broken tyres are fractured through the holes of the setscrew fastening, and as these holes inevitably weaken the tyre, he prefers a system of outside lock-lip and inside check-ring when such security is necessary.

Lubrication.-American railways use a heavier bodied oil than British, generally speaking, and mostly depend on saturated elastic packing, as it is termed-composed of cotton and wool waste with a small proportion of horse-hair, then saturated and drained-in the keeps or cellars of the axle-boxes; auxiliary oil-boxes, etc., are never used either for the journal-bearings themselves or for the horn-slides, some strands of the elastic packing worsted, leading from the small well of oil in the axle-box top to two holes running into the journal oil groove, and a few other strands leading to the rubbing faces of the box, being the usual method.

Slide-bars, motion, rods, etc., are lubricated similarly to British practice, but controlled by adjustable needle-valves instead of trimmings, although considerable use is now made of grease for connecting and coupling rods, being placed in the ordinary oilcups (but with the stems removed) and caused to work its way into the bearings, partly by initial pressure applied by means of a long plug-cap substituted for the ordinary cap, and partly by the heat generated by the bearings themselves. A great many Americanbuilt engines are now running, in which the axle-boxes are also grease-lubricated-from below-special spring operated "lifters" fitted in the keeps causing the grease to be applied under the axlejournal ; this is stated to give great economy in lubrication costs.

Another point of interest in the lubrication of American locomotives is the entire absence of independent suction-lubricators, comparable to the "Furness" type, to come into action 
automatically when the engine is drifting. This is explained by the practice current there, of running down-hill with the throttle slightly open, as mentioned elsewhere, thus keeping sufficient steam circulating to afford lubrication, together with the ordinary sightfeed lubricator. In some cases a special steam-cock is provided in the cab for the express purpose of supplying this small amount of steam when drifting with an entirely closed regulator. An excellent refinement on all modern American sight-feed lubricators is a master cut-out cock which controls all feeds (except that to the Westinghouse air pump when used) without interfering with the "setting." This avoids time and accuracy being sacrificed, and risk of inattention to signals etc., with the driver occupied at each restarting of the engine.

The Author's experience in the use of elastic packing versus the spring-supported lubricating pads of the British system is, that whilst the former needs more attention and hot boxes are rather more frequent than with the latter, yet the elastic packing is more economical. It must be remembered that although the first cost of either system is about the same, both the waste and the oil are reclaimed from the elastic packing, the waste used again in axle-boxes and the oil for a lesser service. The Author, lubricating on the American plan with oil, obtains the following average consumption for heavy $108 \frac{1}{2}$-ton, twelve-wheeled engines with eight-wheeled tenders ( $=20$ axle-boxes) working over the same severe ourves and grades previously referred to, of : engine oil, 30 miles per pint, and valve-oil 68 miles per pint, which he believes will compare favourably with many British locomotives of much simpler design and on less difficult work.

Sand-Boxes and Sanding-Gear.-The primary difference between the British and American sanding systems is in the position of the sand-boxes, which are placed on or under the running plate, or on top of the boiler barrel respectively. The other difference consists in the respective use of steam and compressed-air sanding apparatus, hand-gear being used in both countries.

The position of the sand-box on top of the boiler has always been explained to the Author as being for the purpose of keeping the sand dry by utilizing the heat of the boiler. Although the sand is certainly kept hot, yet he cannot altogether support this, as experience shows that the position is, under certain conditions, actually conducive to "sweating" and packing of the sand, unless special ventilation of the sand-box is provided. When handoperated valves are provided they are located in the base of the 
sand-box, and in the majority of cases in modern practice the airoperated valves are also placed there; in some instances the outlet is doubly controlled by hand and air, and the pipes therefrom, only containing sand when the valves are opened, give little trouble although a certain amount of sweating takes place. With airoperated valves placed about the line of the running plate, as was frequently the case and still is occasionally, the shut position leaves the pipes from the sand-box to the valve permanently full of sand, and this is liable to cause stoppage through the sand packing and sweating in the pipe. No difficulty is, as a rule, experienced between the air-valves and the discharge, even though there may he considerable lengths of horizontal piping of small diameter.

There is further the disadvantage that sand is often spilled (generally over the motion and axle-boxes) when filling the sandbox on top of the boiler at out-stations and at night, etc.; if an obstruction chokes any of the outlets it is much easier for the fireman to go along the footplate and remove the obstruction by hand from inside the box, when placed as in British practice, than it is to go on top of the boiler. The large quantity of sand carried in the one box on the boiler, and the fact that it becomes fairly hot, makes it practically impossible for a man's arm to get down to the valve entrances.

For the foregoing reasons the Author favours sand-boxes being placed as in British practice, with the sand-valves attached immediately under them; regarding steam versus compressed-air apparatus he can only say the steam system has the advantage of cleaning the rails, whilst with the air system much greater length and liberty in running level with small piping is obtained.

Brake-Gear.-It is not proposed to go into the question of air-brakes versus vacuum-brakes-this being a subject of sufficient magnitude to form a Paper by itself. Certain points in connexion with brake-rigging-foundation brake-gear as it is termed in America-may, however, be noticed. The methods of attaching brake-hangers to frames did not generally receive such care in American practice as in British, but nowadays more attention is given to the matter, and it has become general to provide special bosses and lugs integral with the bar-framing for the purpose.

Another point of difference is that all, or almost all, modern American locomotives have the brake-blocks applied at the back of the wheels instead of the position usual on British engines; there is, of course, a reason for this, as it is found that the brake action with the blocks in front added the pull on the blocks to the normal 
weight on the engine springs-made worse, the lower the blocks were applied-and affected them unfavourably. Subsequent developments indicate that the most convenient position for the brake-cylinders is between the frames under the front ring of the boiler. By placing them there at about the height of the top rail of the frame and applying pressure towards the rear on long levers fixed to a shaft, attached to the lower rail of the frame, which has the necessary short levers extending downwards to couple with the brake pull-rods, a most straightforward arrangement is obtained. A further reason against placing the brake-cylinders (when operated by compressed air, as in American practice) at the rear of the engine is that the heat from the fire-box and ash-pan quickly perishes the piston-leathers.

A good deal of trouble and expense is gone to, in order to make the brake-gear equalized to allow for variations in the rods and wear of blocks, etc. This appears rather unnecessary, as if ordinary gear is properly adjusted when in the shops any subsequent variation, owing to some brake-blocks being softer than others, is kept under control by the non-compensated gear and all the blocks caused to wear at approximately the same rate.

There is, of course, no question but that a form of "clasp" brake is always most desirable, to prevent any tendency to displace axles, and the Author considers the British pattern as applied to the coupled wheels of many North Eastern Railway 4-4-0 type and to the Midland Railway compounds, in which a small floating cylinder and piston is used--due, he believes, to the late Mr. W. M. Smith-the most satisfactory yet devised; it is, unfortunately, not easily adapted to locomotives with four or five coupled axles owing to considerations of space.

Couplings and Draw-Gear.-It is unquestionable that central automatic couplers as used in America are superior to the old British system of hooks, links, and draw-bars, together with sidebuffers. Side-buffers increase the resistance of trains rounding sharp curves-unless the couplings are slack, which is a defect in itselfand are theoretically incorrect. Further, the hooks and links are not sufficiently strong to cope with the large loads which are hauled in America, and in some of the Colonies.

The automatic coupler has the disadvantage for passenger work, that no matter how well it is maintained, there is always a certain amount of play in the interlocking together of the coupler knuckles, and it is possible in the case of a long train stopped rather quickly and couplers crowded-in, for a driver to produce an appreciable 
jerk when starting the train; in this respect it is inferior to the British method when screw-couplings are used, as on passenger stock.

Engine: Tender Couplings.-The usual methods of coupling engines and tenders together as practised in America are much less effective than the British methods; in many cases no spring device is fitted, the slack being taken up by a system of wedge and shoe. As provision for curving has to be made, it follows that there must be an allowance of slack when on the straight, and this leads to considerable jerking and strain on the draw-bar anchorages. Recently, devices have appeared in which a spring is incorporated, although, as a rule, no provision is made for coupling under compression, and other designs providing for the angularity between engine and tender when on curves without allowing slack on the straight, have been brought forward.

Tenders.-The fundamental difference between British and American tenders is that the British pattern is constructed on the same principle as the locomotive with main frames, axle-boxes working in horns, etc. The American tender is of a similar type of construction to a wagon, the frame consisting of four steel channels and it has bogie-trucks of the pattern used for wagons, having, as a rule, arch-bar side-frames. These frames have axle-boxes rigidly affixed thereto as on wagons, but the bogies otherwise differ in having better springing between the frames and truck bolsters. Several recent designs of bogies for very heavy tenders show a tendency to adopt independent or equalized springing for the axle-boxes, together with considerable modifications to the archbar frame ; in some cases a similar "bar and pedestal "frame to that employed for engine bogies is adopted. The channel-frame American tenders usually last about fifteen years, by which time the main channels and other parts require renewal, whereas the British tender, as is well known, lasts forty years or so and is often used on a second locomotive after its original partner has been scrapped.

Many varieties of tender-tanks are employed in the United States, and have different advantages for special conditions, but the most common for many years has been the " $U$ " shape pattern, although it is now being generally superseded by the water-bottom sloping floor pattern. The " $U$ " type compels the fireman to stoop to shovel from the bottom of the coal, and further, the coal space is not fundamentally self-trimming, although such effect is nowadays obtained by fitting direction plates, 
The Author considers the locomotive type of framing, the placing of the axle-boxes in horns, and the water-bottom tank having the lowest part of the sloping coal space at a convenient height for the fireman, as in general British practice, much to be preferred to the American practice in these respects. It is remarkable that hardly any use is made of the water-trough pick-up system as in England, as the water capacity, and therefore weight of most of the tenders, is very great.

Chilled Cast-Iron Wheels.-Although not now used on locomotives, but on wagons only, yet they are so characteristic of American railway practice that mention is made of them. They are, as would be expected, less reliable than any other form of wheel, but their simplicity and the combination of wheel and tyre, together with their cheapness, justify their use in many countries. They suffer particularly from flats on the tread caused by shelled spots or by skids, occasionally from cracks in the flanges, and less often from cracks in the bosses ; these defects, however, are easily seen and the defective wheel replaced. Condemned wheels areat any rate abroad - used in the locomotive foundry and are found to give excellent results. The Author has cast cylinders, also locomotive spoked wheels, from such scrapped wheels, with the addition of only 15 per cent of pig, with success. It should be understood that he is not advocating the use of these wheels, considering that the various rolled and cast steel wheels are much better; but not having any direct comparisons to base an opinion on, he is naturally not prepared to say that a practice universal in America and particularly with the large capacity wagons with such wheels in use there, is incorrect

Coal Consumption.- Unfortunately the Author is not able to give a comprehensive table of comparisons owing to the extreme variations in the services worked; he has, however, had a Table prepared which refers to five locomotives on identical services, namely, heavy fruit trains weighing 160 tons to 170 tons on the hill sections meeting about 37 per cent of 1 in 30 up-hill gradient on the run.

The first section indicates a small difference in favour of the British locomotives (despite that their boilers were too small at that time), and this is supported by the second section; the aggregate increase in consumption being due to increased loads. It is to be noted that although by the second period the British engines had been rebuilt with 50 per cent larger boilers, the increased consumption was less than that of the others; this result is similar to that found in 


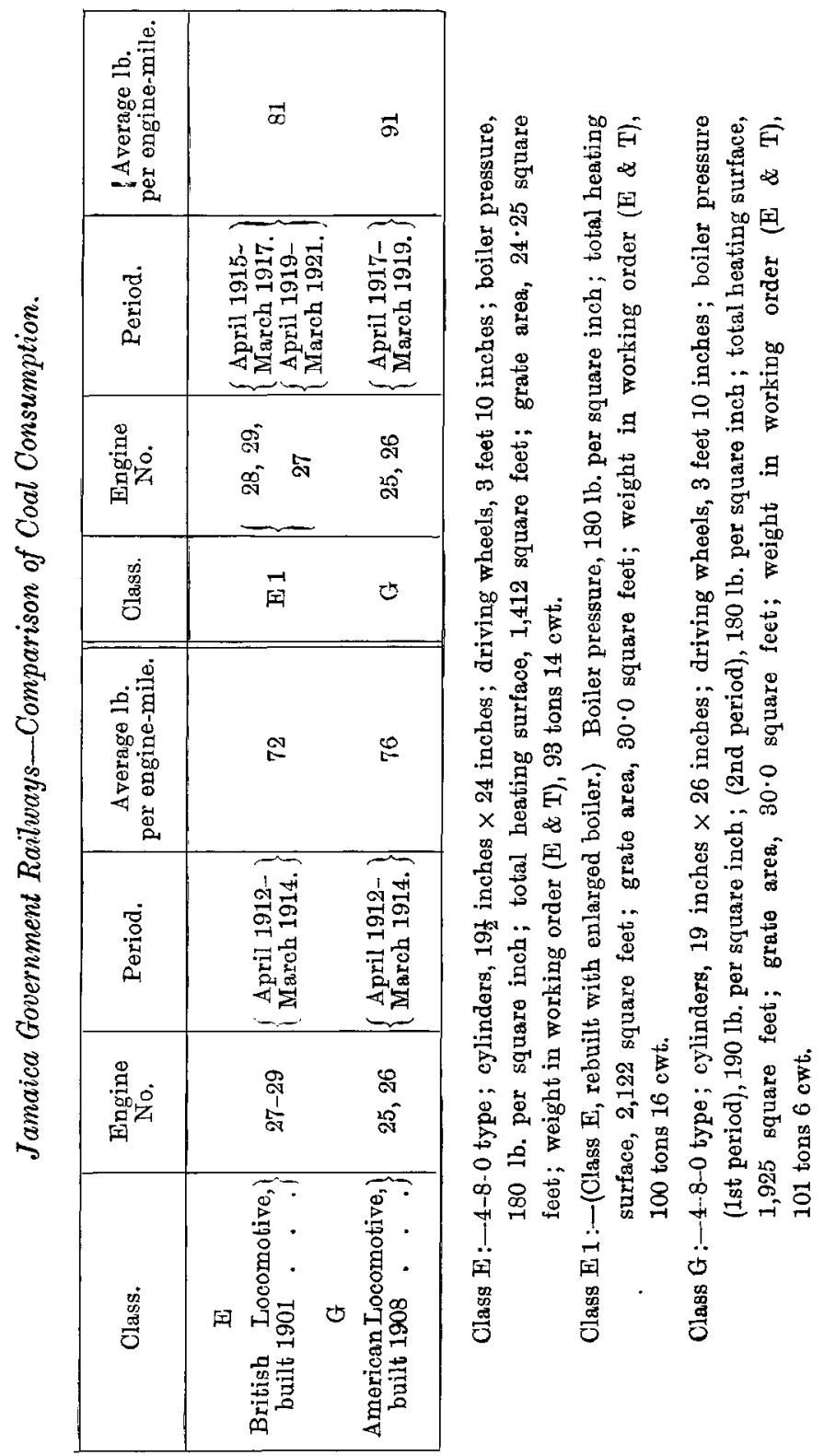


the case of the Great Northern Railway 4-4-2 type, in which the larger boilers were found the most economical. This is subtantiated by the running results during the past year or so of two sets of locomotives under the Author's observation, in which the set with larger boilers shows less coal consumption per mile than those with smaller boilers although the locomotives are otherwise similar and on similar services.

In conclusion, the Author believes it will appear clearly from the Paper, and no doubt this will be supported by most locomotive engineers who have had control of British and American locomotives, that the locomotive has developed on the same basic principles both in England and the U.S.A., the principal differences being due to the respective conditions and service requirements.

In regard to details, however, it is considered that there is scope for improvement, on the British side by adopting American practices suitable for service in partly developed countries, and on the American side by the adoption of more substantial and wearresisting details as developed in British practice.

On the most important point of divergence-the bar versus the plate frame-the Author considers the bar-frame per se undoubtedly most suitable for North American conditions of development; and that the plate-frame is most suitable for conditions in Great Britain, and likely to remain so whilst the present loading-gauge remains. For Colonial and Foreign conditions he rather favours the bar-frame--except for side-tank engines in which the plateframe raised well above the axle-boxes provides advantages for supporting the tanks not possessed by the bar-frame-not for its merits as a frame, but on account of certain facilities it provides for other details ; the point is a very fine one, providing, as already mentioned, the horns of plate-framed engines are of specially substantial design for such service.

The Paper is illustrated by 11 Figs. 


\section{Discussion in London on Friday, 17th March 1922.}

The Presrdent said the Meeting was very fortunate in having present a great authority on locomotives, Lieut.-Colonel Kitson Clark, who had just been promoted to the Chairmanship of Messrs. Kitson and Company, of Leeds, and in the absence of the Author, who was in Jamaica, Colonel Kitson Clark would present the Paper.

Lieut.-Colonel E. Kitson Clark (Member of Council), in the course of introducing the Paper, said that he thought that all who dealt with locomotives were so keenly interested that they generally had bias one way or the other, but he presented this Paper as being the unbiased opinions of an extremely practical and honest-minded man. He thought the great question of natural flexibility or rigidity of the plate-frames or bar-frames had never been thoroughly investigated. The plate-frame as made in England and as at present stayed, was a box girder of a very rigid type. He considered that the bar-frames in the American design might be taken to represent two separate units which were not so boxed together, and that each bar-frame was stiff enough in itself to give a certain primary lateral rigidity. The bar-frame and the plate-frame certainly were rigid or the reverse, accordingly as they were traced by diagonals, or merely tied by cross-stays. He ventured to put this view forward as a little contribution on this debated subject.

In his reference to tank-engines, the Author touched on an important question of policy, and a reply on this point would be of great interest. With regard to shoes and wedges, one very strong point made by the Author was that the shoe in the horn was fastened against the side of the horn opening in the bar-frame and did not depend on bolts and nuts and rivets in the same way as in the ordinary horn block in an English frame. He thought that was a matter well worth comment in the discussion. Those who built their engines with a forging which was fastened on to the side of two tongues which hung down below the horn blocks, knew the great difficulty of getting it fitted quite tightly in the first instance, and of preserving it from being made easy in the treatment in the sheds; the result was that reliance was placed on the shear of the bolts. He noticed the Author's praise of the distance-piece which held the bottom of the horn together in a definite and practical manner. With regard to the compensation of the springs, he did not think it was possible to go into that question that evening, 
because it was complicated and had very much to do with the different kinds of work required from the different engines, the number of axles and the relative arrangement of the boiler, fire-box, bogie, and driving axles.

Engineers were always told about the great difference between basic steel and acid steel, but he had never done any flanging with basic steel boiler plates because consulting engineers had never really allowed basic steel since he was interested in making locomotives; but if there was any experience on the subject of the treatment of basic steel in flanging and the heats at which the plates suffered from scaling, and at which they could be set finally when they were flanged, it would be a very valuable piece of evidence to add to the Paper. With reference to the fire-box, it appeared to him that even locomotive engineers were influenced by fashion. When the Belpaire box was introduced, there was not room above the fire-box for the steam to get away from the water, and where there were crown-stays on the top of the fire-box these often became coated with deposit and a positive danger to the life of the fire-box and the boiler. If through stays were adopted, they went diagonally through the shell-plate, and the remedy was to get a flat top to the casing so that a stay would go normally through both plates. By that means a large space was obtained for steam and everything was satisfactory, only he thought designers were continuing the motion without occasional reference to the original reasons. It appeared to him that it was time to reconsider the proper methods of having a round top fire-box, because he felt certain they were far cheaper to make, which was a very important thing, and it was to be observed that the Americans retained them.

With regard to the fusible plugs, his experience was that enough tinning was not done. On the subject of regulators, he thought the opening of the regulator was easier in America than in England. He had the honour of being in the first trip of an "Atlantic City" engine going to Atlantic City, and the ease with which the man sat comfortably and pulled the regulator open with his left hand was something he had never forgotten. With reference to safety-valves, the Author had not said what clearance there was between the wings of the valve and the valve-seat.

The Presidens formally moved that a vote of thanks be given to the Author of the Paper and in that vote included Lieut.-Colonel Kitson Clark for presenting it so ably.

The motion was carried with acclamation. 
The President said it was apparent from the number of able speakers and authorities present that the discussion would probably have to be adjourned to Friday, 24th inst. He asked the members to remember that this year the Institution celebrated its Seventyfifth Anniversary, which coincided with that of the Liege Association of Engineers, to which function the Members had been invited to attend. It was also the seventy-fifth anniversary of the Presidency of George Stephenson, their first President. He thought the discussion should not be shortened in any way, as it was a subject of vast importance to mechanical engineers all over the world, especially British Mechanical Engineers.

Sir Henry Fowler, K.B.E. (Vice-President), said it was a matter of some difficulty to discuss a Paper of this kind, but he felt that the presentation of it was of very great advantage, more particularly to the junior members of the Institution interested in locomotive work. The Paper gave in a concise form what he thought Lieut.-Colonel Kitson Clark would agree with him would take a lifetime under ordinary conditions to get together. He was placed in somewhat of a difficulty because he had not quite appreciated whether the Author had proposed to bring forward the difficulties which he had experienced with locomotives built in accordance with English and American practice, or whether he proposed to discuss the differences in locomotive practice in these two countries.

He raised two points which were always in the minds of locomotive engineers when dealing with design in this country-the loading gange and the weight on the bridges. Those things did not press to anything like the same extent in America that they did here. As far as the bridges were concerned, the Author said it was quite an easy matter to deal with the question of bridges if the money saved in using larger and heavier locomotives was capitalized. He himself had travelled lengths of 200 or 300 miles on various lines in America, going over perhaps a dozen bridges across streams but practically never a bridge over a public road. Engineers in this country were constantly meeting the difficulty of bridges over roads.

With reference to the use of ten-wheel engines, the Midland Railway, of which he was the Chief Mechanical Engineer, was the only one that had a ten-wheel coupled engine running on a main line, and in a distance of two and a half miles that railway ran over road bridges-not large bridges-and the locomotive had to be designed to suit those particular bridges. It was a point to consider that in this country the number of bridges were intense and immense.

With regard to wagons, the question of increasing their size was 
always in the minds of railway engineers in this country. The remedy largely lay with the owners of wharves and coal screens, etc. Taking the capital value of making the necessary alterations, it would be found to be an immense sum. The first President of the Institution, George Stephenson, was such an artistic man that he put a little

FIG. 12.-Steel Splasher for Locomotives.
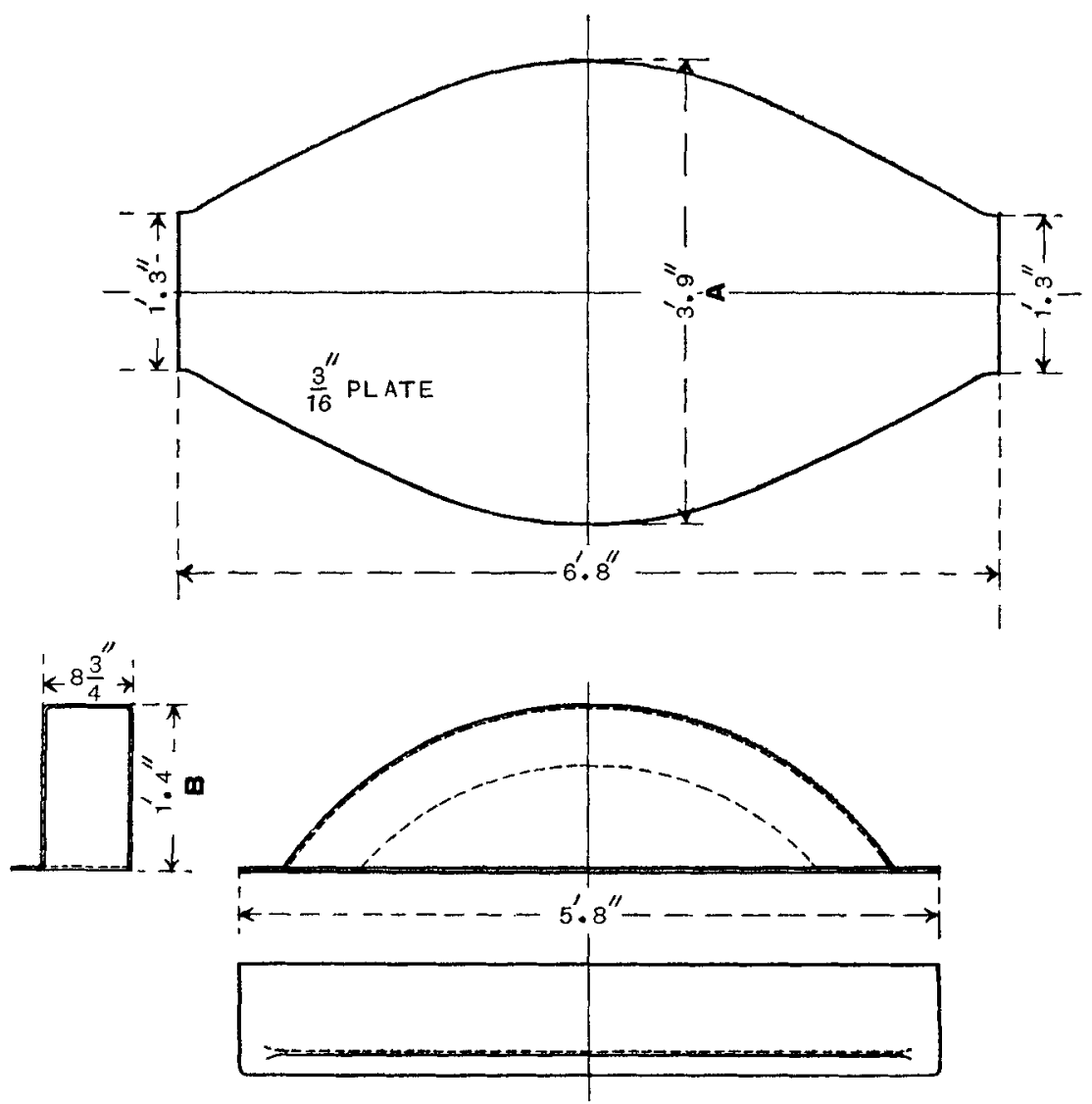

crown or ragged piece of tin work on the top of the "Rocket," probably, but for this the head-room would now be even less.

It was only possible to touch very lightly on the details of the Paper, and practically speaking an evening might be devoted to almost every one of the points mentioned, and several evenings on 
those not mentioned. The question of outside cylinders was an important one, and the Author showed that they were practically universal in American locomotives. In the majority of Colonial countries there were no platforms. One of the things with which the railway engineer had to contend in outside cylinders was coming within the gauge. Every engineer would like to have a larger boiler, and he advocated very strongly that the best way to burn coal was to burn it fairly slowly, not intensely, not with a blast that carried a very large proportion of the fuel through the tubes into the smokebox-if it went no further-and there again came up the question of weight. He held that there was no more efficient way of using steam in a locomotive than in using it in a compound and with superheat.

The question of basic versus acid steel he felt was not a question of basic or acid, but a question of how the basic steel was made. If an engineer could be perfectly satisfied with the way in which it was made, there was no difficulty at all in using basic steel for any purpose, and the way in which it was made included of course the material. He would like to satisfy Colonel Kitson Clark with regard to the question of how basic steel could be flanged. On the railway with which he was connected, they had recently taken a plate shaped somewhat as shown in Fig. 12, the distance at $A$ being 45 inches. It was not a thick plate but it was flanged into a splasher with quite a sharp corner, and the distance at $B$ was 16 inches. He thought that should be conclusive proof that there was no difficulty in flanging basic steel. The thickness undoubtedly made a difference. They were able to flange the cross-stays and other parts made of basic steel up to $\frac{3}{4}$ inch in thickness, with ease.

With regard to the use of copper and steel in fire-boxes and tubes, he had just had an opportunity of seeing about half a dozen steel boxes which were put in during the War, and he stated without hesitation that he did not wish to use steel fire-boxes on his railway. It might be that it was the condition in which the coal was burned or the coal itself, but the whole of the lower portion of the boxes would have to be scrapped much earlier than they would have been, had they been copper. With regard to the erosion which took place in copper tubes, he could say from an experience of between 2,000 and 3,000 locomotives that there was no difficulty at all, but when his Company and certain other companies used brass tubes there was considerable erosion just inside the tube-plate with certain coals. His Company had used during the War a large number of steel tubes, but replaced them as soon as ever an opportunity occurred, the reason being that the copper tubes gave infinitely less trouble. 
He had gone through month by month the casualties due to leaky tubes, and in spite of the fact that there were three times as many copper tubes in service as there were steel tubes, he thought the casualties were ten to one on the other way round.

With reference to fusible plugs, the Americans had evidently considered the matter of sufficient importance to get the National Bureau of Standards to make an investigation into the subject. He knew it was not universally held amongst his colleagues in this country that a fusible plug was exactly the right thing. Such a plug must be properly made and looked after, and he thought even if a fusible plug had anything happen to it, at all events the attention of the firemen was called to the fact that there was something happening. Since the Midland Railway had adopted the principle of filling the plugs, and re-heating them in a muffle to just above the melting point of lead, the difficulties had disappeared.

The Author also dealt with the somewhat complicated question of the superheater elements and the headers. On the Midland they used with advantage a copper ring of diamond section fitted into grooves both in the header and in the collar on the superheater element. He thought there was a great advantage in a loose flange over a fixed flange which rigidly connected the superheater elements as used in many cases. The shrinkage of tyres mentioned by the Author was employed by certain railway companies. The allowance given by the Author was $7 \frac{3}{50}$, whereas his company employed II 100 . That was very largely dependent on the finish obtained on the tyre and the centre. On a rough centre a greater shrinkage was required than with a smooth one. When his predecessor came back from America some years ago, he was very delighted with the system of lubrication in which a mixture of waste and horsehair was used. It was given an extended trial, but there was difficulty from the fact that the horse-hair tended to get into the oil channels and curl up into small balls.

With regard to oil consumption, in this country, with mechanical lubricators under the axle-boxes, it had been possible to reduce the consumption 66 per cent on what the Author mentioned. He was in the position of having to look after not only Belpaire boilers, and boilers with roof bars, but also round-top boilers with direct stays, and he was just dealing with the question of replacing direct-stayed boilers with boilers of the Belpaire type.

Mr. R. P. C. Sanderson (Baldwin Locomotive Company) wished to preface the few remarks he had to make by stating that there was internal evidence throughout the Paper that what Colonel 
Kitson Clark said was correct. The Author was speaking from practical personal knowledge throughout, but his personal experience of some of the American designs was not up-to-date-not through any fault of the Author - he was not criticizing him or the Paper in the least in that respect-but due to the fact that the railway he served on was of such a kind that he could not advantageously use large locomotives, and there had been very few small locomotives such as he could use built in America for many years. In speaking of the American methods of designing, the Author had criticized the old-fashioned methods of designing locomotives and selling them to people, whether they suited them or did not. It used to be done, and was still done in this country as well as in America in connexion with industrial locomotives, saw mill engines, and work of that character, but America did not now build locomotives for stock or to stock patterns for fully organized railways. As was the case in this country the mechanical engineers of the American railways designed their own engines and gave the manufacturers their drawings and standards to work to. Most of the great railways in America, however, had their own drawing offices with such complete equipment that they did not need to ask the manufacturers for any assistance, but in either case the design was their own in detail, and it was the duty of the American mechanic official to see that their own railway standards and those of the Master Mechanics' standards, which it was imperative should be used, were embodied in the design.

With regard to the use of flangeless wheels as tending in American locomotives to greater flexibility on crooked or bad tracks, the American locomotive designers did not now use flangeless wheels for general railway service, except for shunting engines of the 0-6-0 type in yards, and for the 2-10-2 type of heavy locomotives, where the centre axle was equipped with bald or flangeless tyres. Otherwise six-coupled and eight-coupled engines of all types in general railway service were always equipped with flanged tyres. The front and back tyres were usually set in a little so as to add to the freedom in curving, instead of thinning the centre flanges.

The Author also referred to the fact that the three and four cylinder engines in America had largely gone into innocuous desuetude. It was found to be more economical to maintain a twocylinder engine, taking the annual net cost to the railway, than it was to keep up the multiple cylinders. America did not use tankengines nearly as much as they were used in England. There were two sound economic reasons for that. First, the loads handled, 
even in the shunting service, were very much heavier than the loads handled here. When trains weighing from 3,000 to 7,000 tons came into a train yard and had to be broken up and each part handled with a shunting engine, it was necessary to exert a great deal of power; and to do a full day's work, it was not possible to build a tank-engine to carry enough water to go through a whole shift without having to run for water three or four times, and when doing that the shunting crew were idle and the train yard was interfered with, as if a train was scheduled in, the shunting engine could not get in. As far as possible, engines were designed so as to run through a shift without having to go for water, and that could not be done by designing a tank-engine for heavy work. Similarly in the suburban service there was a need for more water than could be carried in a tank-engine. It was water capacity that forced the railways to do without the tank-engine, which otherwise they would welcome in many services. As shunting engines generally ran head on to their work, the tender was not any great inconvenience so far as the driver's convenience was concerned.

There was a point in connexion with theinside and outside cylinder controversy to which he wished to refer. He had never yet seen mentioned anywhere the fact that one could not make a long engine nose; a pendulum would only swing at a rate of vibration in proportion to its length. If the engine was long, one could not make it nose because the length of the pendulum was too great to swing in synchronism with the speed of revolution of the engine, so that nosing became, with long heavy engines, an entirely negligible question.

With regard to the main frames, the Author discussed the relative merits of the plate- and bar-frame and spoke of the plateframes accommodating themselves to the curvature of the railway. Any mechanical engineer accustomed to heavy services would admit that if the plate-frames did accommodate themselves to the curvature of the railway, they would not run very many trips before the frames would crack. The rigidity of the bar-frame was not only in the section of the frame itself, but in the fact that in modern practice the two bar-frames were braced together quite as rigidly and formed as stiff a unit including the bolting to the heavy saddle and the heavy cast-steel foot-plates, the cast-steel braces in the front of the fire-box and the cast-steel and bar-braces at each axle-box above and below, as could be found in any combination of plate-frame and gusset bracing as used in this country. It was figured in America-and he thought it was right-that in the matter of design flexibility had to be provided separately and distinctly 
from any yielding or flexure of the frames, otherwise fractures and breakdowns were almost unavoidable.

The Author had referred to the development of the trailer-truck type of engine in America which had grown into very great favour, and he thought the Author had not expressed any very valid reason why it had come about. In actual fact it had been purely a question of boiler. The limitations even in the case of America, where there were far greater running clearances than in England, had compelled engineers to build boilers of greater capacity to get the full use out of the chassis under the boiler, and to get, as Sir Henry Fowler had pointed out, the very important feature of economic combustion. It was found that even if there were the clearances, it was not possible to build a boiler of satisfactory dimensions to give the full steam supply economically which was needed for the adhesive weight, unless a part of the load was carried on a trailing or carrying axle. Therefore, to get the necessary size of boiler, the latter had been extended back and the overhang supported on a trailing truck. The 4-6-0 had been turned to $4-6-2$, the $2-6-0$ to $2-6-2$, the $2-8-0$ to $2-8-2$, and the $2-10-0$ to $2-10-2$. In that way it was possible to get a better boiler and greater steam capacity with more economical combustion, and more consistent steaming under hard service.

With regard to the wearing surface between the face of the wheel-hubs and the boxes, he thought the Author was wrong. His own observation was that the general practice in America was to use a renewable liner on the hub of the wheel, not on the box. They often put them on the box after the box was badly worn to save it, but it was very common practice to make a box lopsided, $\frac{1}{2}$ inch or $\frac{7}{8}$ inch more on one side than the other, and then, after long usuage, turn the box round, but the general practice was to use renewable hub-liners, generally standardized by each railway, and spares were carried and put on in halves so as to bring the distance between faces of hubs back to standard dimension by renewing the liners. In certain cases, more especially where the axle concerned was provided purposely with lateral motion, the two driving boxes were cast in one piece integral with a bridge, so that they moved with the axle.

The Author referred (page 390) to what he stated was the prevailing practice of American bogies having plain swing hangers, without proper control of the lateral motion. The speaker suggested that in modern locomotives this was not the case, but most generally, for a good many years, the lateral movement had been controlled principally by the use of three-point hangers. The Author further 
spoke of American pattern of bogie-frame consisting of a bar running completely around the top part, ete. Not many frames of this kind would be found in use on engines of recent design in main line service.

On page 392 the Author discussed trailing trucks, but he failed to mention one of the best designs which had so far been produced, and which was known as the Pennsylvanian Railroad Pattern. It was a development of the "Hodges" truck, but had very many advantages, the truck frame being of cast steel, and serving both as equalizer and radius attachment.

With regard to copper and steel fire-boxes (page 393), he thought that if the Author would take their first cost, including the difference in the cost of the necessary staybolts, plot them down on a scale covering the life of the engine and draw a diagram covering the accrued interest, repairs and maintenance, for the two fire-boxes, he would see that the copper fire-box did not pay. The Pennsylvanian Railroad and the Great Northern Railway were the only two railways who had continued to use the Belpaire type of fire-box for any great length of time, and it was understood that these railways were now abandoning its use.

The Author referred (page 394) to the old style of American engine having a raised wagon top, and went on to say that it was curious to note that the use of the wagon top on the Great Western Railway in England came into vogue when its prototype in America went out of favour. As a matter of fact, the "coned " boiler had not gone out of favour in America, and probably never would. The Author referred to steel fire-boxes which had been welded instead of riveted, claiming that the seams had given out in a dangerous manner when there was a shortage of water and overheating. In modern practice when welding steel fire-boxes throughout, the only seams which were welded were the junctions between the wrapper plate embodying side and crown plates in one plate, and the flanged tube plate and the flanged back head. These were transverse seams, and even if due to overheating, the welding material forming the seam were to melt and become disconnected, dangerous results would be no more likely to happen than with a riveted fire-box, so long as the crown staying held.

The Author referred (page 395) to the modern American practice of supporting brick arches on circulating tubes. He also stated that these tubes were used some twenty-five years ago and abandoned, and again came into fashion. He had, however, hardly appreciated the real cause of this lapse in their use. As originally used, the tubes were connected from the lower part of the tube plate into the back part of the crown-plate. They could not be expanded in, but were 
secured in place by means of taper screwed bushings, and these were very unsatisfactory, proved themselves to be decidedly unsafe, and were therefore abandoned. Later on, with the change in the design of boilers, the tubes were run from the bottom part of the tube plate to the back plate above the fire-door. Opposite the end of each tube, at both ends, a screw wash-out plug was provided, large enough in diameter so that the tube expander and beading tool could be used.

The spark-arresting devices in common use in America were not a question of choice, but the laws of the United States for the protection of the property owners adjacent to the railways, and the laws of the individual States, were so worded that the railway companies in case of fire had to prove that the engine which was responsible for starting the fire was equipped with the most up-todate approved device for the arresting of sparks, or they had to pay all damages and costs.

Reference was made (page 411) to the obsolete practice of using solid eccentric sheaves. Very few locomotives, even industrial engines, to-day were built for eccentrics of any kind, and the solid sheaves had gone out of use, certainly on nain line railways, many years ago. Piston tail-rods came into fashion in America at least twice or three times, and after having been tried very thoroughly, had been abandoned as a useless addition to the reciprocating weights, and a worthless addition to the running shed cost of maintenance. With regard to the piston-rod, there was a form of cross-head and piston-rod considerably used in the States which was not seen here. This had no key on the cross-head end, but the cross-head was so designed that the rod was held in the cross-head by means of a nut which drew the taper fit home tightly, and was secured with a safety cotter beyond the nut. Solid bushings in the coupling-rods in America were usually pressed into place hydraulically, and were therefore not so prone to work loose as would be the case otherwise.

Captain H. P. M. Beames (Divisional Mechanical Engineer, L. and N.W.R.) said there were many points in the Paper with which he was in complete agreement, and some where his own experience led him not to see quite eye to eye with the Author, and there were other points on which he would like some more information.

With regard to horns and pedestals, it would be noticed that the Author said that the removable shoe system allowed the lining-up and recentring of a whole set of wheels and axle-boxes, without taking the wheels from under an engine. That might be of great advantage in its way, but he ventured to think that it could 
not be an unmixed blessing, because in the hands of inexperienced men it was quite conceivable that the centres of the wheels might be pulled to such an extent as to cause very considerable trouble, both with boxes and the bushes of the side-rods and with loose and broken crank-pins; he believed it was not at all unusual. On the railway with which he had the honour to be connected, they had always adhered to the old-fashioned horn block. The late Mr. Webb carried out a number of tests in which he proved that the centres of the horns of an engine, after it had been in traffic for some time, were extended-in fact, he found that on a six-coupled engine the extension of the frame was as much as $\frac{1}{16}$ inch.

With a view to standardizing both shed practice and workshop practice and to prevent the necessity of boring axle-boxes out of centre, and decreasing the life of the horns, Mr. Webb put on a suitable length to the centres of the side-rods, making the latter slightly longer than the original length on the drawing, with very excellent results. Many engines of that type were rumning to-day. With regard to axle-boxes, very satisfactory results had been obtained on the L. and N.W. Railway with axles without collars on the journals, and he could not himself conceive that a collar on a journal could be of any other use than to set up heat; whereas the big bearing surface on the boss of the wheel and the face of the box was a very excellent check on any side-play there might be.

So far as circulating tubes were concerned he asked the Author if he had had any experience of the Nicholson thermic siphon system, which he understood was now used on a considerable number of engines in the United States. He himself had tried one last year on a large passenger main line locomotive, but could not say that he had met with the success for which he hoped. Possibly the method of manufacture and application was against it.

With regard to blast-pipes, in 1916 his railway tried a blast-pipe which he believed was precisely similar to that which the Author described. There were four wings protruding into the bore of the pipe. It was found to be satisfactory for a time, but liable to carbon up, and unless very carefully cleaned, it had the reverse effect of what was desired.

On the question of safety-valves, it would have been very interesting at the present moment if the Author had been able to give some American statistics as to the clearances allowed between the wings of the valves and the seating, and the angle of the seating, because those two factors had been very much discussed lately. He had recently carried out some tests to find what really was a suitable clearance. With a Webb-Ramsbottom type of safety- 
valve, with three wings, thoroughly warmed through, and with the outside temperature that of the shop in which the test was carried out; he found that a valve with $4 / 1000$ inch clearance was liable to stick slightly. He was speaking of a diametrical clearance on a 3 -inch valve. $3 / 1000$ inch was just binding; $5 / 1000$ inch was quite free. He went on and tried the test with the same valve surrounded by a bath of cold water, and found that at $6 / 1000$ inch the valve was sticking. The $6 / 1000$ inch clearance was when both the bush and the valve itself were cold. With 8/1000 inch clearance it was quite free. The same test was then carried out with water which had been cooled down by the addition of ice, and it was found that at $9 \frac{1}{2} / 1000$ inch it was absolutely free. He then tried a test to see what would be the result of a blast of very cold air. An appliance was rigged up which gave a sort of half gale, at 32 miles an hour, measured by a Short and Mason anemometer; it was blown through an ice box, so that the temperature was down to $8 \frac{1}{2}^{\circ}$ of frost, and it was found that with $8 / 1000$ inch clearance the valve was quite free, so that the effect was less than with ice-cold water, which was really what might be expected. But a curious thing was noticed. In the bush which had been bored out to a standard it was found that, after all the tests had been carried out, the bush was smaller by 2/1000 inch, and that, he believed, was due to the very drastic treatment that the valve had received. It would be interesting if the Author could give some American statistics where very great differences in temperature had to be dealt with.

With reference to lubrication, on the L. and N.W. Railway they had tried grease and the Frankland type under grease Iubrication for axle-boxes and the Menno grease lubricators for big ends and side-rods, but he had to admit that for the heavy fast traffic that had to be dealt with on the railway, he did not think there was anything that could beat good oil suitably applied and consistently fed. The feeding depended to some extent on the design of the oil-box. He had found that a worsted trimming would only siphon oil in proportion to the height of lift, that was to say, if the box was full the worsted trimming would siphon the first $\frac{1}{4}$ inch at more drops per minute than in the second $\frac{1}{4}$ inch and so on. Therefore he thought it necessary, in designing main line engines which had to do long runs without stops, to design a box so that at the finish of a run the oil would be the maximum required. Horse-hair and waste had been tried with not very great success, one of the reasons probably being that when the engine harl to be 
lifted out of the shops after packing the boxes, the weight of the axle came on the pad and pressed it down, and then perhaps the engine was running without that type of lubrication at all.

Mr. E. R. Dolby asked whether it was to be understood that the diameter of the valve spoken about was 3 inches and that the diameter of the bore of the column was 3 inches plus $8 / 1000$ inch and so on. He was not quite clear whether the valve was reduced or the hole enlarged.

Captain Beames said the bush was 3 inches in the case spoken of, and the valve was $8 / 1000$ or $6 / 1000$ inch less.

Mr. J. A. Hoокнам (North Stafford Railway) said he agreed with Mr. Sanderson that the Author's experience did not seem quite up to date-with the English any more than with the American practice. First of all there was the round top axle-box; this was used by the L. and N.W. Railway, and it was not peculiar to America. There was also the side surface of white metal which was used in this country instead of the American brass liner. Inside collars were in many cases omitted in this country, and quite rightly, too. Steel tubes were very largely used; in fact, he thought that there were more steel boiler tubes in England and Scotland now than there were brass or copper.

With regard to boiler capacity, the statement made by the Author was what he should have expected. He did not know very much about American locomotives, but from the fact that they could use steel fire-boxes, which could not be used successfully in this country, it would appear the boilers in America were not so much pressed as they were in this country, which meant that the boiler capacity was very much greater. The Author mentioned the Belpaire fire-box, and said that the round-topped shell was much more popular in America. He noticed also that none of the speakers mentioned, in referring to this point, what appeared to him to be the intention of the flat-topped shell, and that was to allow a certain amount of freedom to the rise of the fire-box. He remembered seeing, in boilers which had the round-topped casing and the squaretopped fire-box with direct staying, that the corners of the box, where the stays were very short, were crushed downwards, and the copper fire-box top (which was put in flat with fairly large radius corners) came in with a camber after working for some time, showing that the long stays gave by buckling, while, of course, the short stays were much more rigid. This appeared to him to be a point, 
in favour of the Belpaire box, and it was, of course, to give freedom to the box that the old roof bars were used.

He was rather inclined to agree with the Americans that fusible plugs were not of very much use. They were useful to get a driver in trouble occasionally, but it was never possible to tell whether it was the plug or the fireman that was in fault. The Author appeared to have rather a curious view of the use of the pilot-valve in the ordinary sliding regulator; it was not so much a question of getting gradual opening as of being able to open the regulator at all without great effort. The pilot-valve moved easily, being very small, and admitted steam to the back of the valve, enabling it to move with a reasonable amount of effort. Expanded tubes in a superheater he agreed were very tiresome things; they took about a day longer to pull out when under repair than the other type.

With regard to dispensing with superheater dampers, his railway had done so for a long time and had never found any difficulty. The Author did not say what the American practice was.

The Author spoke of the admission of air to the header, and said that he would look for lubricating difficulties. It would probably cause more carbonization. A diaphragm spark-arrester was being put in now on his railway, and it was said that it was going to create a better draught in the bottom tubes, but his experience was that most spark-arresters did nothing either to stop sparks or to improve draught.

With regard to the safety-valve, Mr. Pickersgill some time ago made some experiments and proved that it took something like $30 \mathrm{lb}$. above initial blowing-off pressure to get a proper opening with the Ramsbottom valve when the boiler was heavily fired. His railway were now using the Ross safety-valve which was somewhat of the American type. He thought the Author's figure of $3 \mathrm{lb}$. between the opening and closing pressures was very much greater than obtained with the Ross--it was more like $1 \frac{1}{2} \mathrm{lb}$. between maximum and minimum pressures.

The lever reversing gear was said to be predominant on goods engines in this country, and that was one of the things that made him think the Author was a little old-fashioned. The Jong piston-rod, allowing the piston head to be drawn out without uncoupling the cross-head, seemed an excellent idea. Perhaps the only reason why it was not more general was the difficulty of finding room to get it in. With reference to the Author's remarks about stiff rods and weak frames, it seemed to him that a weak frame was a very bad thing, but if an attempt was made to make rods with little lateral stiffness to compensate for that, he did not see the object. If the 
frame was not as stiff as it should be, there would be no advantage gained by making the rod buckle.

With regard to the bar-frame versus plate-frame - a point which did not appear to have been touched upon was the difficulty of making the former as against the simplicity and straightforwardness of the latter. It was quite possible to ensure practical perfection in a rolled plate, but he did not see how this was obtained in the barframe, which must either be a mass of welds or a steel casting, as he did not imagine the practice adopted by an English firm was usual in America, of forging a slab and cutting out the openings by drilling and slotting.

As to the weakening of the tyre by screw fastening, theoretically he supposed it did weaken the tyre, but it was not uncommon to see a broken tyre where the fracture had missed the stud-hole ; the only question was whether tyres required fastening on at all, whether the American practice of simply making a lip so that the tyre would not come off inside was not good enough. It was not so many years ago since keys were used on axles of all wheels, but now they were only used on the coupled wheels really to locate the centres. A driving axle would drive a wheel quite well enough without a key, and if that was the case, he did not see any occasion to fix the tyre. When a tyre was worn too thin it would get loose, but it would not come off ; it could not come off inside because of the lip, and it could not come off outside because of the flange.

With regard to the central combined buffer and coupling, he did not know why it was not used in this country, as it was an excellent thing. Perhaps the reason was that it meant altering thousands of vehicles all over the country.

Lieut.-Colonel E. Kitson Clark said he would write to the Author, who had been for a long time a personal friend of his and a close correspondent on all locomotive matters, and tell him that his Paper had been highly appreciated and that the audience had been extremely interested. It had been of great value to hear Mr. Sanderson. He would like to have heard him reply to Sir Henry Fowler on the subject of Belpaire fire-boxes as he did not think the last word had yet been said.

Another point of great interest Mr. Sanderson touched upon was the streteh of the bolts in the pedestal braces or the horn-stays. He almost thought the time was coming when it would have to be considered what steel bolts should be made of, because it was wellknown that in fastening the cylinders to the frames the erector was inclined to tighten them up very tight and ran the risk of drawing 
them slightly, so that they might soon become loose in the hole. That was a question which might be considered in a Locomotive Standards Committee. Sir Henry Fowler had mentioned successful flanging with basic steel plate of $\frac{5}{16}$ inch thick. It was a very different proposition flanging a thin plate from flanging a thick one. The problem was to get the heat through to the centre of $a \frac{7}{16}$-inch or $\frac{5}{8}$-inch or thicker plate without oxidizing its surface, and he foresaw danger and difficulty unless one knew thoroughly about the behaviour of basic steel plates under those circumstances.

The reason given by Mr. Sanderson why tank shunting engines were not used in America was of great interest. There was a point which might be added; in shunting it was necessary to use all the adhesive weight the whole of the time, and one of the disabilities of tank-engines was that with the loss of coal and water the adhesive weight became reduced.

With regard to safety-valves, it was an interesting fact that, taking a three-wing valve and a four-wing valve, and turning them with exactly the same tolerance, the three-wing valve would move more than the four-wing valve. At the same time when the heating-u]' took place, the three-wing would jam just as easily as the four-wing valve. A man putting the valve into its place, if he had a three-wing valve, put it in and said : "That is easy enough." Then he would perhaps take a four-wing valve and put it in and say: "That is not easy enough." The man putting the valve in had not got a micrometer gauge to try the valves. He thought that it was a point to be considered whether three-wing valves or four-wing valves would be used.

\section{Discussion in London, on Friday 24th March 1922.}

Mr. Alan E. L. Chorlton, C.B.E. (Member of Council), said the Paper was particularly interesting to an engineer who was not a locomotive engineer, as the practice that could be drawn from it applied to other branches of engineering. It was also interesting to see how the locomotive engineer applied practice learned in other branches of engineering, and it was really in that way that he had welcomed the Paper.

There was no doubt that the greatest difference between an American locomotive and a British locomotive was in the size of the boiler. It was a fundamental difference to an outsider, and remained to-day one of the things that did not seem to be satisfactorily explained. The British locomotive engineer alwavs 
complained of the restrictions of the loading gauge and the axleload as being fundamental factors which prevented him from following the American practice, it being agreed that the larger boiler was the more economical one. To the outsider, the British locomotive engineer did not apparently put on as large a boiler as he could do. That might be seen on the Great Western Railway, where they had one locomotive with a grate area of 25 or 30 per cent more than the standard engine. He began to wonder whether the large boiler as made by the Americans, and as described in the Paper as being the more economical, was so.

A point that interested him oven more was the application of special steels to locomotive work. In the discussion Sir Henry Fowler had spoken of the limiting factor of axle-loading, and he would like to ask whether the axle-loading was dead loading; that was to say, was the load per axle a dead load on the limits set up by the permanent way engineer for the locomotive designer. Did Sir Henry mean that the spring loading must not exceed 18 or 20 tons, and did he take into account the loading set up by the action of the unbalanced forces on the axle itself?

There were some very interesting experiments carried out by the Pennsylvania Railroad in which they used high value alloy steels to reduce the weights of the moving parts and so minimized the out of balance forces, by which the eventual load on the rail would be correspondingly reduced. In effect, he understood, they were able to put up the dead load on the axles very much above the 20 tons that had been customary; and, as that seemed to be a fundamental point, it would be very interesting to learn whether it had been considered in this country, and to what extent and how far it might be possible to go with a view to increasing the axle-loadings and the size of the boilers. It would be valuable to have the experience of locomotive engineers using high value steels, which, no doubt, they had done for various parts of the locomotive, as it would enable a comparison to be made between locomotive and general engineering practice.

Mr. J. D. Twinberrow said he could not proceed to enliven the discussion by differing wholly, or even in part, from the conclusions so clearly expressed in the Paper, but there were, however, many points which could be usefully enlarged upon. Recent investigations by French engineers showed a very close parallel between the oscillations of a locomotive on the track and the movement of a ship in a seaway. The plane of elastic support was defined by the point of attachment of the bearing springs to the frame. The normal 
through the centre of gravity became inclined by the application of a lateral force, bringing a greater weight to bear upon the springs on the low side and relieving the springs on the opposite side to a similar extent; consequently the vertical resultant of the spring reaction was displaced and would intersect the normal line at a point at some distance from the centre of gravity, Fig. 13.

The difference between the points measured vertically was the metacentric height. If the distance was considerable, the righting moment was strong, the period of oscillation would be short, and

FIG. 13.

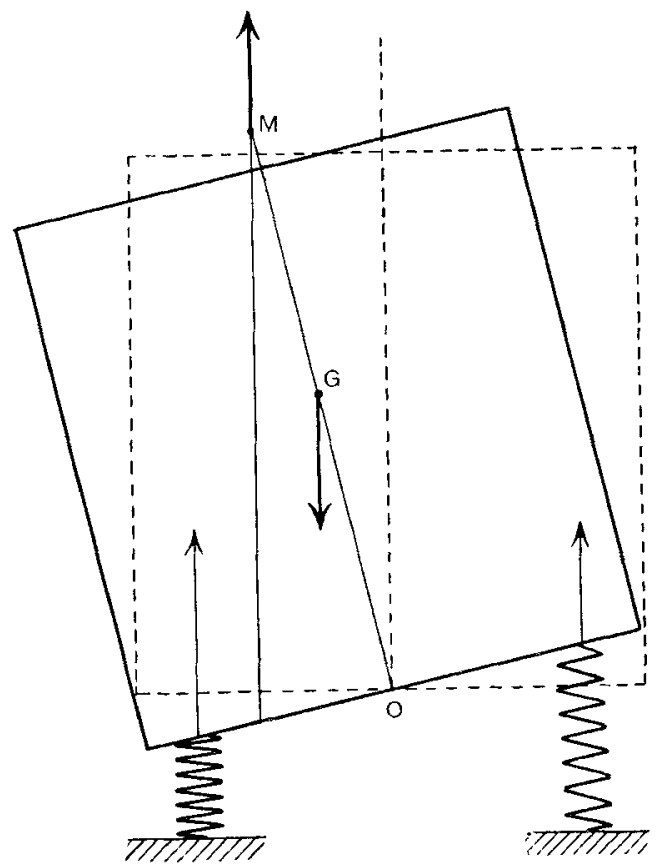

the movement uncomfortable, so that in a floating body the passengers would suffer some personal inconvenience, and in the case of a locomotive at high speed, the fireman would have some difficulty in finding the fire-hole.

From the physical characteristics could be calculated the period with which the locomotive would oscillate on its springs. If for any reason the centre of gravity could not be put exactly where it was wanted, the desired result might be obtained by other means. The plane of elastic support might be lowered, the flexibility of the 
springs increased, or the spring centres could be brought closer together, and each of those features would tend to reduce the distance at which the vertical resultant of the spring reaction intersected the line at M. As the distance MG was shortened the period of oscillation was lengthened, and consequently the locomotive was made to ride more easily on the track. If, however, the thing was carried too far and the height was made negative, the vessel or locomotive would capsize. It was therefore necessary to compromise between stability and steadiness, and, speaking generally, stability had to be sacrificed in order to acquire steadiness. A very similar relation existed in connexion with the fore-and-aft movements. In the case of a floating body, alteration of trim was accompanied by an alteration in the shape of the immersed cross-sections and a righting moment was thereby produced. In a spring supported vehicle, the control was obtained by differential deflections of the springs. The employment of stiff springs, without equalizers, would not give the wheel-base which was easiest on the track or most comfortable in riding.

Supposing the springs were connected by equalizers throughout, there would be no stability, and any alteration of trim would make the locomotive pitch forward or sit down until the leading or trailing boxes were home in the horns. The only rational system of equalizing was to connect the whole of the springs in the running gear into two complete groups, neither more nor less, no matter what number of axles the locomotive might have. With those two groups, properly selected, there would be control over the alterations of trim. A locomotive was continually altering its trim because the reaction to the tractive effort or to the brake retardation caused a tilt on the frame, which required to be balanced by redistribution of the loading upon the axles, and in the case of a driving wheel base combined with carrying axles, the alteration in the adhesive weight might be quite important. When two wheel-bases of the Pacific or 4-6-2 type were mounted under a single superstructure, as in some of the larger electric locomotives in America, and when that superstructure was supported by centre pivots reinforced by fore-and-aft steady plates, which tended to keep the bogie-frame parallel to the main frame, then the equalization which was correct for the steamlocomotive no longer applied. In that case the whole of the axles throughout the bogie should be equalized in one continuous group, so that the conclusion he arrived at was that, under any single locomotive superstructure the springs should be equalized into two groups, and that applied to a locomotive mounted on separate motor bogies and to a wheel-base under a single body and frame.

The Author drew a comparison between the bar-frame and plate- 
frame (page 384), which he thought had been limited a little too much to the frames as separate pieces. The frame when complete for its duty consisted of two longitudinal members with a number of crossconnexions, and in the case of the bar-frame, as fitted to American locomotives, there were usually in addition to the front bumper, foot-plate and saddle, three or four vertical plates attached to crossstays low down on the main frame and secured to the underside of the boiler barrel. Those plates, being quite thin, did not hinder longitudinal expansion of the boiler, but added enormously to the torsional and lateral rigidity of the frame. He could not understand the logic of providing a flexible frame and then transmitting upwards of $1,000 \mathrm{~h} . \mathrm{l}$. through different members of that frame and expecting to kecp the joumals perfectly in bearing. The true principle seemed to be to make the whel-base flexible to meet the requirements of the minimum curve and to make the frame as stiff as possible within the permissible weight.

In the 6-wheeled engines characteristic of former British practice, the frames did not consist merely of two plain slabs united near the two ends of the locomotive, but these were stiffened from the front buffer-beam to the foot-plate by means of the outside running plate, which formed a horizontal girder about 2 feet deep with a stout angle-bar along the outer edge. The plating, $1^{3} \frac{3}{6}$ inch or $\frac{1}{4}$ inch thick, and stiffened by suitable brackets, certainly prevented any considerable lateral deflections of the frame. As the length and size of engines increased, the horizontal foot-plate had to be cut away in order to clear the wheels, and the attachments to the main frame were no longer so complete. In many cases the larger engines had been built with insufficient bracing to counteract the loss of the side stiffening which the older engines possessed. In the case of engines built with outside framing and large wheels, it was obvious that there was no possibility of fitting a cross-stay to the frames within the space occupied by the wheel diameter, and consequently such frame-plates were unsupported for a length of 7 to 8 feet, except for a very narrow top angle-bar and foot-plate. Many of those engines, within a very few months of entering into service, developed cracks from the top corners of the horn opening.

Referring to the Author's remarks on the nosing of outside cylinder engines, he failed to see how a rigid frame could be made to nose by means of steam-pressure on the piston at low speeds, because the moment imposed on the cylinder and saddle casting was exactly equal to the reverse moment upon the axle acting through the horns, and the whole thing was in perfect balance as long as the speed wass slow and inertịa forces did not come into play. 
If there was nosing, it was a sign of slackness or abnormal yielding somewhere. In engines with outside cylinders, when the connectingrod was short and the stroke long, the reaction of the pressure on the slide-bars lifted the engine appreciably, first on one side and then on the other, and if there was a 3-point method of support that engine when pulling hard would in all probability show a distinct tendency to shoulder. The 3-point method of support was very popular in America, but he did not think it was to be commended for really high speeds.

The Author drew a comparison between the Adams' type of bogie centre and the ordinary $\Lambda$ merican swing-link type (page 390). He thought the great difference between the two was the fact that with the swing-link type the friction opposing the traverse of the bogie was very much less. With ordinary proportions he thought it would be about 12 per cent of the sliding friction of the Adams' pattern. In both cases, when the Adams' pattern was controlled by laminated or helical springs and the suspended type by the horizontal component of the load through the links, the bogie control was harmonic and responsive to anything that might give rise to synchronous oscillation, which might become dangerous at high speeds, particularly if the rigid wheel-base was short. The greater friction of the Adams' bogie was then rather useful, because it damped out the tendency to synchronize. He thought a more reasonable way to deal with the matter was to make the control aperiodic, and that could be done if the springs instead of being of the helical or laminated type, were suitably designed in the volute form.

Mr. W. P. F. Fanghamel said the Paper was of special interest to him, because the Author and himself were co-apprentices at Kentish Town. Locomotives which were suitable for one country were quite unsuitable for another. One had to consider the fuel and water, the topography of the country, and even the labour which had to be used. With regard to the great difference in construction between the American locomotives and the British, he thought it was customary for the American locomotive to begin with the cylinders in erection, but in this country they always started with the main frames. That meant that the cylinders were a much more integral part of the American locomotive, and as cylinders fractured and wore out, it became more difficult to replace these than on English locomotives. His experience of the American locomotives was that their frames were also conducive to weakness, the same as the British. He found that the usual point of fracture 
was through $\mathrm{AB}$, Fig. 14. Another point which the Author mentioned was the difficulty in the erecting shop when lifting a locomotive - that there was a liability to break it at CD. The plate-frames usually went at the corners.

With regard to horn stays, he would like to know which was considered the best practice on the English locomotives. There was something to be said for all the types, and he did not know any one which was thoroughly perfect. The usual form of stay for plate-frames was mentioned on page 386 . If the distance piece was not a good fit, the bolt would be tightened up very much and the frame put under stress. What actually happened in such a case was that the frame broke off at $x y$, Fig. 15. In the running shed, if the fitter wanted to get things up easily, he left the stay a loose

FIG. 14.

FIG. 15.
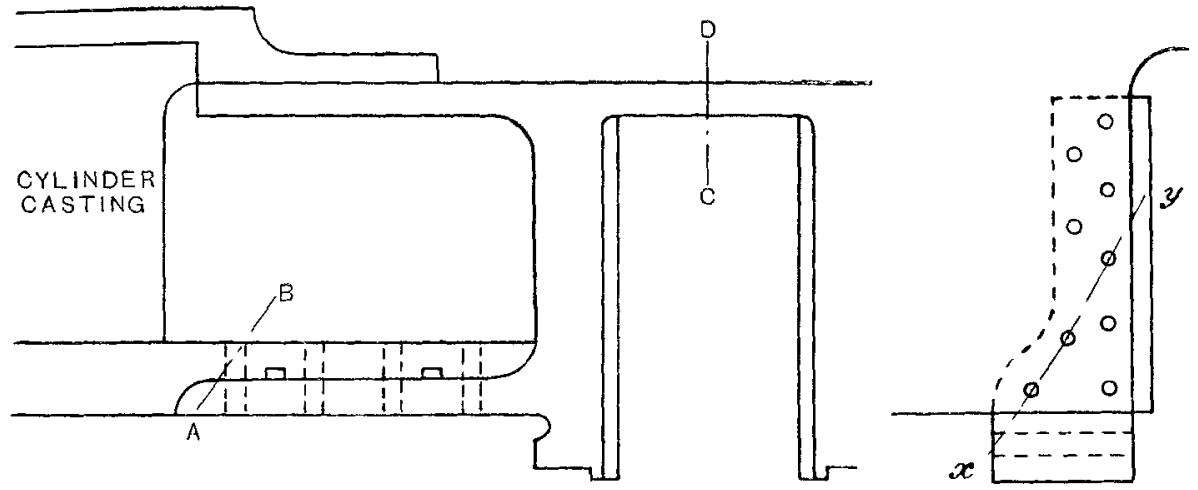

fit, tightening up with the bolt and incidentally fixing the axle-box, or he might put a stay in a little bigger and hammer it up, and then there would be a loose box and a stretched frame.

Sir Henry Fowler had mentioned that he found steel tubes no good on his line. No doubt many would disagree with him, but from his experience he thought Sir Henry was quite right; they were not much good for copper boxes. The locomotives spoken of by the Author had boxes of very mild steel, and the tube could be welded in. A copper ferrule was put between the tube and plate, and the beading then welded. There was no necessity to use the tube expander. The Americans simply fitted the tube in and welded it over at the end, and when they had to remove the tube they cut off the welded beading, and the undamaged tube was free to be pushed out. 
Another matter he thought the Author had omitted was the question of wash-out plugs, which was a matter of very great importance. Without these plugs in suitable positions, there was bound to be trouble with a boiler. Another point was that on the American locomotives they had the smoke-box door-plates twothirds the size of the British, and he would like to know how the lower tubes were got out.

The Presinent said, as Mr. Twinberrow had mentioned the subject of the welding of the tubes, it might be he thought that some of the weaknesses of drilling the holes would be overcome by the introduction of more welding in the locomotive-welding on the studs, for instance, instead of drilling a hole.

Mr. Twinkerrow thought that would be so. It might come into use with boilers, certainly.

Mr. George Watson thought that most speakers had agreed that the very large American engines and very long trains were not suitable to this country. There was not only the question of strengthening the bridges to carry heavy locomotives, but there was that of the couplings. He thought that the breaking of the couplings was due to increasing the length and heaviness of the train without altering the strength of the couplings. The sidings in this country were not long enough to accommodate very long trains, and if a train had to travel long distances to a siding it would get into the way of the high-speed passenger trains which were so frequent on British lines. British locomotive engineers would do far better by following and improving upon their own practice with their goods traffic, rather than attempting to imitate the American designs, because the conditions were enormously different. The sorting out of the trains was in itself a very difficult thing in this country, because a goods train did not go far without dropping a truck or two.

Nothing was said in the Paper about mechanical stoking because he believed that in America it had been introduced on locomotives, especially on very big engines. He did not think it had made very much progress, but he should like sone further information from locomotive men on the matter. With regard to the combustion in the fire-box, a good deal had been said about the particles of coal coming out; everybody had heard them rattle on the top of the carriages in tunnels, and noticed that they would set alight to dry grass on the side of the line, and to stacks of hay and corn. That showed that a great deal of coal was escaping unburned, and there 
was plenty of scope for improvement in the fire-box. It was very inconvenient; the grate was below the stoker, so that he could not rake it or deal with it as an ordinary stoker would do with an ordinary boiler furnace, and the difficulty of clinkering was very great. Firemen had to wait until the end of the day to do any clinkering at all.

He saw no reference to any attempt to alter the general pattern of the boiler and fire-box. He believed that in Belgium some time ago there were fire-boxes made with fire-brick linings, and the whole of the water-space around the fire-box and the stays was abolished. He did not know whether they were still in use, but great economies were claimed for this design at one time.

Mr. George Bulkeley (G.W.R.) said his exeuse for taking part in the discussion was that he had obtained his locomotive experience on English and Canadian railways. The statement of the Author which had impressed him most was that "the best locomotive could only be evolved after a thorough weighing of all the facts, and by a combination of the best points of each practice; and those most successful in thus combining would lead in locomotive construction and working." He submitted that that axiom was already justified by actual practice.

Taking one British railway-the Great Western-a cursory inspection of their modern locomotives showed that the following features were common to both Great Western and American practice : (a) the boiler was of larger diameter at the throat sheet than at the smoke-box end; $(b)$ the smoke-box was a circular extension of the boiler; (c) the arrangement of the blast-pipe and smoke-stack was similar; $(d)$ the cylinders were outside and their two castings formed the front anchorage for the boiler; $(e)$ the springs were compensated in certain cases; $(f)$ the outside motion bar brackets were bolted to a deep vertical transverse plate extending right across the engine, and itself bolted to both boiler and frames; $(g)$ inside valve-gear being employed in combination with outside cylinders having pistonvalves above them, the valve spindles were actuated through the medium of rocker-shafts; $(h)$ semi-plug piston-valves were used; (i) a two-wheeled pony-truck was used on medium-wheeled engines employed in fast passenger traffic: $(j)$ the cylinders were invariably set dead horizontally. This latter was an important point which was not always found in British practice, but by giving the piston a fore-and-aft movement parallel to the rails undoubtedly led to a smooth-running engine. He believed it was generally agreed that the Great Weitern locomotives were very scientifically designed 
machines, and he contended that, if independent engineers on either side of the Atlantic designed and produced locomotives which were doing notably efficient work, and it was found that in those locomotives there were points of coincidence, then those points must be hall marks of efficient locomotive design, fixed points, as it were, on the curve of locomotive development, and he submitted that the Author's axiom was justified and borne out in practice.

One of the most marked differences in British and American practice had been in the design of valve-gears. Generally speakingand the Great Western was again an exception in this countrydesiguers of valve-gears here had not given the length of travel to the valves which was aimed at on the other side of the Atlantic. With the ordinary Walschaert valve-gear the limit of travel of a valve was about 7 inches with an ordinary link, owing to the angularity of the link and the danger of getting it more or less on a dead centre with larger valve travels unless much larger links were used, which latter was being done in America and Canada. He had read recently that Mr. H. O. Young, the eminent American locomotive valve-gear authority, was now recommending valve travels of no less than 9 inches, perferably to using larger diameters of piston-valves, in order to get a freer exhaust. Locomotive valvegear development in America and Canada had dated, generally speaking, from Dr. Goss's instructive experiments with actual locomotives on the Purdue University locomotive testing plant at the beginning of this century, and it had been recognized that whilst it was very easy to get steam into a locomotive cylinder it was not anything like so easy to get it out freely, and what was aimed at generally in American valve-gear design was a full port opening to the exhaust when the port at the opposite end of the cylinder was about $\frac{1}{4}$ inch open to steam. Hence long valve travels, resulting in certainly very free running engines; also the long steam-laps which the long travel allowed to be used, did definitely produce an increased cylinder horse-power very economically.

$\mathrm{He}$ had been interested in what Mr. Twinberrow said about applying the calculation of metacentric height to locomotives, but there was one point he had not elucidated, namely, that in a ship, while the transverse metacentric height might vary from 1 foot 6 inches in a torpedo-boat to 6 feet or more in a larger ship, the longitudinal metacentric height might be 60 or 100 feet; so that any change of trim in the fore-and-aft direction meant the movement of greater weights through longer distances, conversely, very slight weight alterations in the fore-and-aft direstion would not affect 
the longitudinal metacentre anything like they would the transverse one, and he thought that would be the same in locomotives.

Mr. Twinberrow had also mentioned the difficulty of curving with very large American boilers. When he was in the employ of the Canadian Pacific Railway they designed an experimental Mallet articulated locomotive for use in the Rocky Mountains. The curves to be traversed were as sharp as 15 degrees, and the engine had to go round them. They laid down in the yards of the Angus shops at Montreal a 15-degree curve of standard rails, and, until the centring springs were adjusted by experiment, those rails were broken, which gave some idea of the force which large engines might set up when curving unless proper provision were made for this. Eventually, when the centring adjustment was got right and the engine put into service, only $\frac{3}{64}$ inch flange wear was found on the leading wheels after running 4,000 miles, so that it took the curves quite easily.

It had been mentioned that bar-framing often cracked just at the cylinder bolting. He had seen it stated that the chief mechanical engineer of the Canadian Pacific Railway had, in his latest series of engines, about doubled the thickness of the framing at that very point; this was particularly interesting in the Canadian case, because for several months of the year the engines were running over frozen ground.

Mr. H. P. Renwick (Great Indian Peninsula Railway) said that the Author, in referring to the difference between American and English blast-pipe practice, said: "It would be interesting to see this type of blast-pipe tried on express work in England." He was connected with the G.I.P.R., where a large number of experiments had been carried out with regard to the shortening of blast-pipes and the enlargement of the diameter of them. On a class of 4-6-0 locomotives used on express working, with cylinders 21 inches by 26 inches, the original design of blast-pipe allowed for a diameter of cap of $4 \frac{3}{1}$ inches, with the cap 3 inches below the boiler centre line, and a petticoat 12 inches high, 20 inches diameter at the bottom, tapering to 14 inches diameter at the top, 13 inches above the boiler centre line. A wire cone spark-arrester, from the blast-pipe top to the bottom of the petticoat, was also provided and another sparkarrester, a flat wire mesh plate, covered the area of the smoke-box at the bottom of the petticoat. Various experiments were made reducing the height of the blast-pipe and increasing the diameter until it was found that the best results were obtained by a blast-pipe 1 foot $0 \frac{11}{6}$ inch below the boiler centre line, with a diameter of the 
blast-pipe cap of $6 \frac{1}{4}$ inches, with four 1-inch triangular lugs. A straight petticoat pipe 1 foot 5 inches in diameter, with its bottom edge $4 \frac{5}{8}$ inches above the boiler centre line and connected to the base of the chimney, was provided and no spark-arresters were used.

In addition to that, certain alterations were made to the valvegear, which provided a maximum cut-off of 60 per cent instead of the normal 85, and a minimum normal working cut-off of as little as $12 \frac{1}{2}$ per cent, and yet in general working, whilst the blast was almost inaudible, it was found that as much steam could be obtained as was required. The coal was undoubtedly burned slowly. The coal consumption dropped, and he thought that by increasing the blastpipe diameter and by roughening the blast by the provision of triangular lugs, as was the normal American practice, considerable advantages were obtained. Similar results were obtained on all other classes of heavy engines, including 0-8-4 tanks used on banking service on inclines of one in thirty-seven.

With regard to the use of rocking grates, the Author did not appear to lay sufficient stress on the great advantage that could be secured in their use in conjunction with coals of low calorific value, otherwise more or less unsuitable for burning on fixed grates on account of the frequent fire-cleaning necessary. In India, rocking grates were in general use and were universally preferred by the engine staff. Apart from the physical exertion required to punch clinker and ash through fixed bars with a hook or pricker, frequently as often as ten times on a run of 100 miles with a goods train, a considerable waste of time was incurred in waiting to get up steam on account of the severe disturbance of the fire caused by this method.

With the rocking grate, the fire could be steadily lowered to any extent without disturbing the live coal on the top of the bed of fire, the up and down movement of the grate sections breaking up any clinker. No exertion on the part of the engine staff was required, as large grates could be operated by steam power through the medium of a small cylinder fixed to the drag-box casting. It was essential that ample ash-pan capacity should be given, otherwise the more frequent fire-cleaning filled up a shallow pan so quickly that grate sections or operating rods were liable to get burnt. No trouble should be experienced from warping or grates sticking up. Hopper bottom ash-pans were advisable.

Mr. James Clayton (S.E. and C.R.) said the Author expressed the opinion (page 377) that English railways ought to make greater use of the eight-coupled and even the ten-coupled locomotive, and 
he inferred that the Author thought it was because of the axleweight limits. He would suggest from experience that it was not so much individual axle-weight limits as the distribution of a large weight over a very limited wheel-base, which sorely tried bridges of short spans of from 10 to 50 feet. He was sure such engines would be used as soon as ever the bridge engineer was able to help the locomotive engineer in that respect.

The Author said that small use was made of the high-capacity low tare wagon, suggesting that it was the bridges that presumably accounted for it. He would again say that in this case it was not the bridges so much as the terminal facilities, and the wharf, dock, and warehouse accommodation which limited the use of these large vehicles in this country, in addition to the fact that the smaller vehicles had been found most suitable for the staple trade carried on most systems.

Under the heading of "Outside Cylinders" (page 383), the Author, in referring to the nosing or boxing, gave many reasons why nosing or boxing took place, but did not mention what was the obvious reason, namely, that, the cylinders being outside, their effect in causing an engine to nose was very much greater than with inside cylinders, owing to the greater distance between the centres.

He thought the Author was quite right in saying that the control by the bogie could influence it a great deal. On the South-Eastern and Chatham Railway in the latest engines, 2-6-0 tender and 2-6-4 tank, where a fairly long engine had been used with a two-wheeled truck in front, it had been found necessary to provide good lateral control, and that had been done very successfully by using the Cartazzi side control principle, the planes being inclined 1 in 6 . In those engines, built in 1917, nothing whatever had had to be done to the bogie in the four and a half years beyond attention to bearings.

In speaking of axle-boxes and journals, the Author pointed to a very good American practice of providing ample surfaces between the axle-box and the wheel-face. While that was a very good point indeed, it should be recognized as modern British practice, and he could point to the Midland Railway, the Great Western, the Great Northern, the Caledonian, and his own railway which were all providing it in their latest engines with very good results. On the same page the Author made out a good case for compensating, and it would seem that if compensating improved an engine riding over a rough road, it ought to reduce the wear and tear of an engine, which, like a British engine, ran over fairly good roads. He would like to ask what the effect at high speeds was of compensating an engine throughout which was previously not compensated. 
With regard to the Belpaire fire-box, the Author thought they were only used by railways in this country which had been accustomed to the crown-bar. The South-Eastern and Chatham was an exception to that. The old boilers designed by Mr. James Stirling were all of the round top, direct-stayed type, without provision for expansion, and the engines were still running with that method of staying. His railway had now adopted the Belpaire box, believing that this type gave the best method of staying, providing as it did for staying two opposite flat surfaces, with the pressure between them, to each other. To stay a flat surface to a round surface was to upset the equilibrium of the latter. When a flat surface was stayed to a round top it was necessary to provide transverse stays to prevent the round top from being pulled down.

In connexion with fire-grates, the Author referred to the dropgrate, and said be would like to see it tried in British practice. It had been already tried many times. The Midland Railway had five engines so fitted for many years, and ran them as long as they could, until the enginemen begged they should be taken off because they were always getting stuck up. The Great Western Railway had used them also for a long time, but had now given them up. The Author had referred to the doubtful use of the pilot-valve for the regulator, and suggested that its use was due to the want of proper leverage. It was this difficulty of providing the amount of leverage required to open a large regulator-valve with modern boiler pressures from 200 to $225 \mathrm{lb}$., which made the pilot-valve necessary.

With regard to the comparison of the cross-movement and pull-out handle, the Author favoured the latter, but it had one obvious disadvantage; it was a dangerous type unless used with a very good rack-control. In the old days, on the Glasgow and South Western Railway, a very serious accident occurred with a pull-out regulator. It was quite possible to arrange the crossmovement handle to give the advantage for which the Author asked, that it should be placed in a convenient position to give a good look-out for the driver. Modern engines on the Great Western and those of many other railways in this country were fitted with that type of regulator.

The Author referred to the spherical cone-joint for superheater elements as being a good thing, and many engineers would be glad to know this, as this joint was coming into favour here. He objected to the asbestos and copper joint for the superheater elements, and with good reason. A very good type of joint was mentioned by Sir Henry Fowler, and he himself also thought that a simple joint of 
the section shown, Fig. 16, a double-veed type, could be made to answer exceedingly well. In his experience so far, it was the best copper joint tried, as it was simple to make and answered very well in practice.

With regard to dampers in smoke-box, the Author suggested that they were a necessity. Experience in this country showed that dampers were not a necessity, and on his railway they had

FIG. 16.-Element Jointing Washer.
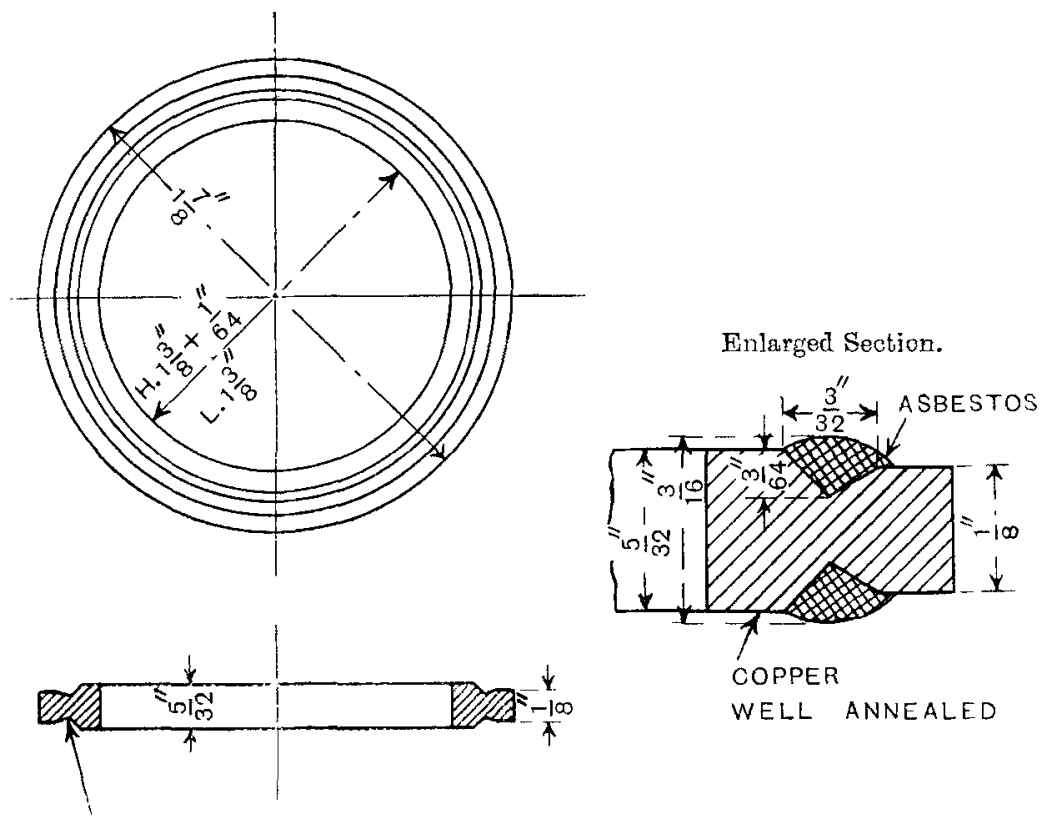

COPPER

WELL ANNEALED

The grooves are to be filled with asbestos so as to form a continuous joint witbout overlap.

not been used since 1914, and there had been no trouble whatever. It should, however, be stated that they used the automatic air-inlets which the Author said he had not tried, and no lubrication trouble was caused by their use.

In connexion with smoke-boxes, the Author spoke of the diaphragm plate being a good feature. They had just recently had the same experience on the S.E. and C.R., where with the extended type large capacity smoke-boxes, this diaphragm plate was found 
beneficial, Fig. 17. It was found that this application of the diaphragm plate not only prevented spark throwing, but caused a very much more uniform draught over the fire-grate, and made the engine steam more freely. It was also used by Mr. Churchward for the latest engines on the Great Western Railway. The Author rather ridiculed the British type of large smoke-box door, but he (Mr. Clayton) thought it had many advantages. He did not agree with

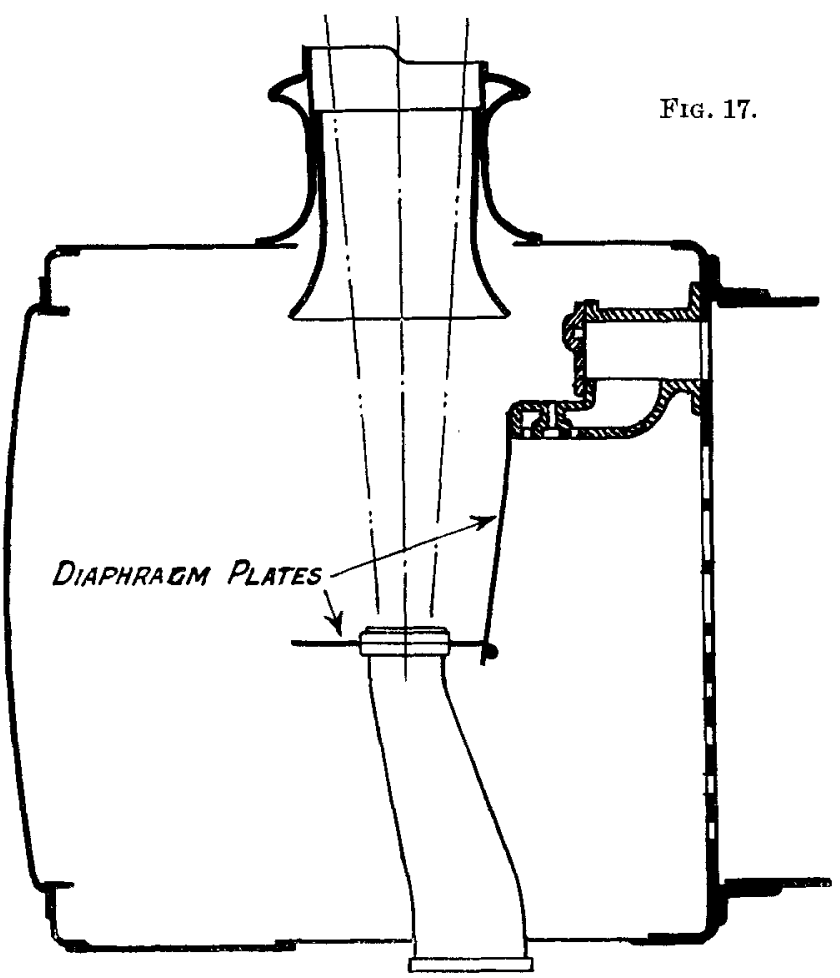

the Author that the tubes could be cleaned easily from the fire-box end. First of all it would be necessary to wait until the boiler was cold, also in cleaning the tubes from the fire-box end the cinders in the large superheater flues were driven further in and jammed amongst the elements. With a steam tube cleaner from the smokebox end, it was possible to clean the tubes readily. Blastpipe orifices, with projecting lugs, were tried in 1909 on the Midland Railway, where they were known as "Nibs." but their 
use was soon discontinued. He thought the plain low-position orifice, made to suit the diameter of chimney, was the best. The chimney must be large enough, so that it left an annulus of $1 \frac{1}{2}$ to 2 inches round the column of steam, and then generally the engine would give no difficulty in steaming.

With regard to injectors, the Author spoke of the British "Combination" pattern being quite unsuitable for Colonial use, and that also applied in this country with many feed-waters. It could not be used on the S.E. and C.R. where the water contained large quantities of carbonate of lime, which resulted in furring.

On page 408 the Author showed some good types of joints, and suggested No. $10(b)$ for the regulator stuffing-box, but there would be a great danger of jamming the regulator-rod in tightening the joint. Personally, he thought the British practice of the registered stuffing-box on a flat joint, metal to metal, was the best.

He wished the Author could have given a comparison of the merits of the British and American locomotives as regards maintenance and up-keep because that was where the real economy should be sought. He had gone carefully through the Paper and counted up the number of points on which the Author agreed with the British and American practice respectively, and under thirty-two headings he found that in eighteen the Author favoured British practice, or in about 60 per cent of the cases, which showed that the British locomotive stood the comparison very well. In addition the British locomotives on the same work, and both before and after rebuilding, showed a very handsome coal saving, something like $10 \mathrm{lb}$. and upwards a mile. He thought British locomotive builders might take heart of grace and still believe that the British designed and built locomotive required a great deal of beating, given an equal chance with its competitors.

Major P. J. Cowan, M.B.E., said, regarding the small use made in America of tank-engines, as far as his experience went, American designers always objected to tank-engines on the score of the variable adhesive weight. If a tank-engine were cylindered up to the limit of fully loaded conditions of bunker and water-tank, the engine would tend to slip when empty; if, on the other hand, the locomotive was only cylindered for light conditions - tanks and bunker emptyfull advantage could not be taken of the permissible adhesive weight. That in shunting engines, where very large units had to be dealt with as in America, was an important point.

He thought the Author charged bar-frames with something which was really not due to them, He spoke of the " narrow box difficulty 
produced by the use of bar-framing." In the old days fire-boxes were dropped in between the frames. Subsequently, however, fire-boxes were placed on the top of the frames, and then a box was obtained 42 inches wide inside at least, compared with the 40 or so inches in this country. The Americans were driven to the use of wide boxes, because as boiler capacity had to be increased, their grates ran to too great a length. If those grates had been used between plate-frames instead of above bar-frames, the length would have had to be further increased. The length of box necessary between plate-frames to give the grate area of the large Pennsylvania engines at the present day would have to be something like 19 feet, which was absolutely impossible. The Americans appreciated the advantages of the wider and shorter box, which they were absolutely driven to use, apart altogether from the question of plate- or barframes. That it was also not a question solely related to the use of idle trailing wheels was clear from the fact that the Pennsylvania box referred to- -9 feet 6 inches by 6 feet 8 inches-was used over coupled wheels.

The Author referred to the wearing surfaces of horns being less in American than in English practice, and Mr. Sanderson had pointed out that with the big engines that was not so. Even with the smaller frames and lighter engines this could be avoided by setting the centre of the frames in. The American system was to use a shoe with wings on the outside. It was perfectly easy when designing, if a wider face were required, to increase the thickness of these wings. It simply involved bringing the frames further in. That that could be done was proved by the fact that in a large engine with 7 -inch frames, the frame centres were 41 inches apart, whereas in the old and lighter engines, with frames 4 inches thick, the centres would be 47 inches.

The Author remarked that side-rod and crank-pins were of large diameter. As a matter of fact, they had become so large in American practice on the big engines that there was now trouble from high rubbing speeds. The Author gave drawings of methods of fixing side-rod bushes. It was rather interesting to note that, since 1912, instead of fixing bushes, the Americans had been using floating bushes both for main and side rods. By the kindness of the American Locomotive Company, who had collected some data for him, he could give a few particulars. These bushes could, of course, only be used for big ends with outside cylinders. The allowance usually given between the brass bush and the rod was about $\frac{1}{64}$ inch. They were grease lubricated, so that lubrication depended on the pin and bush getting slightly warm, Naturally the bush expanded slightly, 
and allowance had to be made for that in the fitting. The bush was a simple thing to make; it was a plain lathe job compared with the complicated work on square brasses. Renewal in the shed was a very simple matter. These bushes had been found to have a life as much as five times that of fixed bushes. Their use was now considered by some lines as past the experimental stage. At first they were used with a sort of make-shift, strap-ended rod for the main connectingrod, but solid ends were now used on several lines.

The Author stated in connexion with wheels that "up to long after the time when cast-steel came into favour in British practice, cast-iron continued to be used in American practice." In justice to American practice, it should be remembered that while this country had to go to Germany for sound steel castings for wheel centres when they came into favour here, the Americans at that time were both casting and using their own steel wheel centres of a very sound and excellent quality.

Major C. E. Willis ms (Crown Agents for the Colonies) said the Paper was especially interesting to those who were concerned in the design and supply of locomotives for the Colonies. He had had the good fortune to be able to study the American locomotive when running alongside the British locomotive in some of the Crown Colonies and his remarks would, therefore, be very practical. Under "Methods of Designing" (page 377), the Author stated that the American system was more satisfactory when fully detailed drawings were supplied by the purchasers before the engines were constructed, and that it was advantageous that the whole of the design should be actually in the hands of those who would have to operate and maintain them, namely, the purchasers. In his opinion, the chief inducement to purchase locomotives in America in preference to this country was either on account of the advantage in price or some advantage in delivery, and not generally on account of any superiority in design alone. He was of opinion that if the Author's suggestions were carried out, much of the advantage in first cost would be lost and deliveries would be decidedly longer than if a freer hand were given to the American builders. Further, if fully detailed drawings were supplied by the railways concerned, then the engines supplied could not be correctly described as of American design. They then became British designed engines built by American firms.

His experience had led him to believe that it was more satisfactory if one was forced to obtain locomotives from America for service in the Colonies, to allow the builders as much latitude as possible, stipulating only such essentials as the wheel arrangement, the load 
per axle, and that such parts as draw-gear, lamp irons and other necessary details, should be to the standard of the railway. Otherwise, the result obtained was a production which was neither truly British nor American, or more correctly it would result in a British engine with American workmanship, which he thought was generally admitted to be inferior to British workmanship. Some time ago his Department purchased ten locomotives for duty in one of the Crown Colonies, when quick delivery was absolutely essential. They merely specified the leading requirements such as draw and buffing gear, lamp-irons, the load to be handled, the axle-loads, copper fireboxes, and the curves that the engines would have to negotiate. The builders were otherwise given a free hand in design and material; it was even arranged for a representative of the builders to supervise the erection of the engines in the Colony. However, even that arrangement was not entirely satisfactory, chiefly on account of the class of workmanship. In support of that conclusion he would read a few extracts from the report that was obtained from the chief mechanical engineer regarding the engines as compared with British designed and built engines of a similar class and doing similar work: "From a purely mechanical standpoint, it must be said that our British built engines, both from the point of view of construction and economy in fuel consumption, are undoubtedly preferable to the American engines. . . . As regards construetion, the American engines have failed in a point where the British locomotives are eminently preferable, namely, boiler work. ... As regards fuel consumption, the British engines show a distinct advantage of $78 \mathrm{lb}$. of coal per train-mile against $84 \mathrm{lb}$. consumed by the American locomotive.... Oil consumption is in favour of the American locomotives. . . . To sum up shortly, British engines are to be preferred from the point of view of design, workmanship, and material, economy in fuel and probably longer total effective life of the locomotives-that is, in practically every respect from the mechanical point of view. . . The one great advantage of the American locomotive is the rapidity with which it is delivered."

Many of the comparisons drawn in the Paper, strictly speaking, compared American railroad practice with railroad practice in this country, but there was another aspect, namely the designs that emanated from the locomotive shops, what were known as contract shops in this country, who supplied a great number of engines for India, the Colonies, South America, and elsewhere. He thought it would be found that the best practice in many of those contract shops was somewhat less conservative than it was in the railway shops in this country, and for many reasons the practice in those 
contract shops was more nearly a combination of the best British and American practices. That was noticeable when considering such fine examples of first-class locomotives as were manufactured for South Africa and for India.

With regard to cabs, in British Colonial practice it had long been considered necessary to provide as large and as roomy a cab as possible, with every possible protection from the sun in hot climates, and every endeavour was made to enclose as little as possible of the back end of the boiler in the cab, with a view to keeping down the temperature in the cab. Seats were also supplied and doors at the front end leading on to the platform, the doors being frequently left open when running to admit a current of air. It was surprising to learn that the British combination pattern injector was found unsuitable for Colonial use. It would be interesting to hear the views of the injector makers on that point, as that type was used with satisfaction on many of the railways in the Crown Colonies.

The Author referred to the methods of making joints, and said that he preferred the American method of metal-to-metal joint as being superior to the British method of using asbestos and other means. With the metal-to-metal joint he was in entire agreement, and it would be found in specifications for locomotives for the Crown Colonies, and he believed for India; consequently that joint could not be claimed as purely an American practice.

Mr. EDMund WHITE said that some of the previous speakers had said that it was not possible to have larger engines in this country than in America on account of the track and the bridges. The railway engines and rolling stock which were employed years ago, when he lived on the Great Western Railway as a boy, were of wide gauge and very much larger, and the bridges were strong enough then; therefore he would like to know why engines of the present narrow gauge could not be used to-day, even of greater power, considering that the bridges had been widened and strengthened since that day. The rails were now fixed in chairs and were up to date in every way.

Professor P. M. BAKER said that, in his opinion, the question of the use of heavier and more efficient trucks with, as a corollary, increase in weight of engines and trains, seemed to hinge not so much on the bridges and track as on the couplings and brakes, the track in this country being of the same order of weight as that of Ainerican roads, 
A long goods train in this country, where much of the stock was privately owned and frequently without continuous brakes, would almost inevitably involve the mixture of heavy and light trucks, and it would not, he thought, be possible to run heavy trucks of, say, 100 tons capacity amongst 20-ton vehicles without danger.

The Presinent said that, many years ago, when he was Honorary Consulting Engineer to the Royal Lancashire Agricultural Society, a great deal of destruction of crops occurred in a dry summer by sparks from locomotives, and he was asked to report on this matter. Anyone who had the curiosity to look at that report would find that, in spite of the Act of Parliament that required efficient spark-arresters, he was able to show a great collection of large cinders from the different parts of Lancashire where evidently spark-arresters had not been efficient. He had been particularly interested, therefore, to hear the remarks of Mr. Renwick on the extraordinary way in which efficient spark-arresters had been produced without diminishing the draught, because, in connexion with his investigations, in every case it was found that a driver had either altogether removed the spark-arrester or with a hammer or chisel or other instrument had made large apertures all over the spark-arresters in order to improve the draught under his boiler.

Lieut.-Colonel E. Kitson Clark (Member of Council) thought it was obvious that the President was not a locomotive man or he would not have thought it necessary to mention the fact to which he had just referred. Most locomotive engineers had designed excellent spark-arresters and had tried to see them working, but had always seen them when they had not been working.

With regard to replying on the discussion, he thought possibly, in a way, the Paper answered itself. It was a comparison of the two countries, and those who had spoken had made their comments on that comparison. Two or three things arose out of the remarks made upon which he would venture to touch, but it must not be considered he was expressing the Author's opinion.

With regard to the action of unbalanced forces, that was one of the questions being considered with regard to the strength of bridges in India, so that the actual static weight of axle-load was ceasing to be considered as the final arbitrament, and they were considering whether the static load was relieved at all by the dynamic effects of the unbalanced parts. The unbalanced parts had been weighed and made much lighter by the introduction of the high-power steel to which allusion had been made. 
With regard to the fire-boxes on the top of the frames, that was referred to in a general kind of way. Anyone going through Austria and Hungary would see the ordinary fire-box perched right on the top of the frames, with the boiler centre 10 feet above the level of the rails, and would take a great deal of interest in the question of the metacentre and the rolling. Those engines ran extremely comfortably and well, and as long as it was not dangerous it was wise to go higher with the boiler centre. In Austria the whole fire-box was on the top of the frames, the object being-a point that had not been mentioned-to get at all the stays without any being hidden behind the frames.

With regard to the points that had not been mentioned, in English railways, on certain lines, ball-bearings were used for certain rods in the valve-motion, and he thought it would be found that it would not be very long before rustless steel was used for the frames, cabs and boilers so as to get rid of that very expensive commoditypaint.

With regard to the three and four-cylinder engines, he had expected a discussion upon the equal turning-moment which was so obvious and which was likely to come very much to the front with the internal-combustion engine, to which no doubt everyone was looking at the present time. On behalf of the Author he thanked the Members for the interest which they had taken in his Paper.

\section{Discussion at the North Western Branch Meeting in Munchester, on $23 r d$ March 1922.}

[The Paper was presented, on behalf of the Author, by Sir Henry Fowler, K.B.E., Vice-President.]

Mr. John G. RobINson (Chief Locomotive Engineer, G.C.R.) said the Author stated (page 401) that he favoured the American spherical joint for superheater units, as shown on page 409. Some years ago the Great Central Railway Co., like others, fitted up a number of locomotives with superheaters, the units being bolted to the header. Jointing rings of various types were tried, but in consequence of the high temperature of the smoke-box gases and superheated steam, the joints in question gave considerable trouble, necessitating the engines being from time to time stopped for remaking of joints and renewal of units damaged by corrosion at the front end, which corrosion was proved to be a direct consequence of leakage from the 
joints. A header was devised which eliminated all bolted joints, and the units were expanded directly into the header by means of simple appliances. This overcame all their difficulties, and judging from the number of such superheaters now in use all over the world, amounting to nearly 5,000, he could only conclude that other people had been equally fortunate in their experience. He could not speak from personal experience of the American spherical unit spoken of by the Author, as they had not fitted any on the Great Central Railway. During his visit to the United States in 1913 he discussed these joints with the leading engineers of the Baldwin Locomotive Co., and it was admitted that though the spherical joint was found to be a great improvement on the original system of using copper and asbestos or copper rings, nevertheless, it necessitated cost and attention on the part of the running maintenance staff at the round-houses in order to follow up the stretch of the bolts. Expanding the units into the header amounted to nothing more than expanding a boiler-tube into a tube-plate, which was common practice everywhere, the important difference being that a boilertube had to be expanded into two tube-plates and was therefore subject to expansion and contraction forces, whereas the superheater unit was free to expand and contract without restraint. On the Great Central Railway there were 405 engines so fitted, and so satisfactory was the expanded system that the cost of maintenance had been reduced to practically nothing, and only in cases where it was necessary to remove the units for boiler examination had they had to disturb them from shop to shop. Extraction of the units was quite as easy as expanding them in place, the process only reducing the thickness of the tube slightly. In point of fact, there were cases where units had been expanded and extracted as many as six times and were still in service. For example, the mileage per set of units in a 4-6-0 engine was found to have been 370,448 for a life of nine years and three months, from which it was evident that they must have been removed and replaced several times for retubing and examination. Almost identical figures were given by the 4-4-0 express passenger and the 4-6-2 passenger tank engines, and in the case of the 2-8-0 mineral engines a mileage of nearly 200,000 for nine years six months was realized.

With regard to dampers, when the G.C.R. Co. began to fit superheaters on the locomotives, they also supplied dampers worked automatically by the pressure in the steam-chest, and they were of the opinion that this was necessary to prevent damage to the unit ends when running without steam. In practice, it was found that the dampers interfered with the draught, and, therefore, 
with the steaming powers of the engine, and obstructed the proper cleaning of the tubes. Steam-jet retarders were tried to replace the dampers, and though they effected their purpose when new, they were costly to maintain and were therefore abandoned. They were now working without dampers or retarders, which, he believed, was in accordance with general European and some American practice, and had provided a valve which formed a blower and circulating device whereby a small flow of steam was maintained through the units when the blower had been opened beyond a predetermined amount. This was done, not so much with the idea of protecting the fire-box ends of the units as to meet the point referred to by the Author (page 417), to assist in the lubrication of cylinders and valves when drifting.

Any system of admitting steam to the steam-chests and cylinders, when the regulator was closed, entailed the provision of a device to prevent accumulation of pressure which would move the engine when it should be stationary. Automatic valves for this purpose were not reliable, and they employed a discharge valve of large capacity worked positively from the regulator-handle, the dischargevalve being fully open when the regulator was closed, and vice versa.

With reference to the lubrication of steam-chests and cylinders, in American practice, this was usually effected by means of a hydrostatic displacement lubricator, whereas since the advent of superheated steam-locomotives in this country, the common practice was to use a mechanical pump-lubricator. To ensure that the right amount of oil was being supplied to each point, it was necessary to have a sight-feed for each pipe-line. The sight-feed arrangement must be located in the engine cab, and, to ensure that the rate of feed observed at the sight-glass should also be that maintained at the point of lubrication, could only be done by working the distribution pipes full of oil under a pressure superior to that in the steamchests and cylinders against a constant resistance. This was effected successfully on the Great Central Railway by the "Intensifore" sight-feed lubricator and retention-valves.

Mr. Percy R. Gresham remarked on the Author's statement that his experience was altogether in favour of the American form of injector, and that the British combination injector was quite unsuitable for Colonial use. Without comparing the practice or theory of the American and British types of injectors, the speaker then explained some of the advantages of the British combination injector. The Author's statement that the internal delivery pipe got more quickly choked up than the external or side delivery pipe, 
showed that the temperature of the water delivered by the internal delivery pipe into the boiler must have been greater than the temperature of water delivered by the outside delivery pipe, for the higher the temperature of the water, the greater would be the deposit in the pipes.

$\mathrm{He}$ (Mr. Gresham) gave as an example an injector working with feed-water at $80^{\circ} \mathrm{F}$., delivering the water at $180^{\circ} \mathrm{F}$., through an internal feed-pipe, in a boiler temperature of $380^{\circ} \mathrm{F}$. (the temperature of steam at $180 \mathrm{lb}$.). If the transference of heat, due to the difference of temperature of $200^{\circ} \mathrm{F}$. was so rapid as to raise the temperature of the feed-water up to $212^{\circ} \mathrm{F}$. (which would be necesssary to make any marked difference in the rate of the deposit), then it was quite reasonable to expect that the transference of heat from the feedwater in the outside delivery pipe, due to the difference of $100^{\circ} \mathrm{F}$. between the temperature of the feed-water at $180^{\circ} \mathrm{F}$. and the temperature of the atmosphere at $80^{\circ} \mathrm{F}$. would be at least 25 per cent of the former and would show a loss of $8^{\circ} \mathrm{F}$. for the use of an external feed-pipe. The speaker pointed out that the loss of $10^{\circ} \mathrm{F}$. in the temperature of the feed-water meant the loss of 1 per cent in the coal consumption.

The sediment that choked up the delivery pipes and the cones of the injector also deposited on the boiler-tubes and on the fire-box, where the greatest transference of heat took place, thus reducing the evaporative capacity of the boiler. He thought it would be agreed that this sediment, which was the cause of all the trouble, would not favour either a British or American type of injector, but would affect both types equally. So that if the engine running time lost due to the extra time in cleaning out the boilers and feedpipes, etc., and the heat lost through bad feed-water were capitalized, it would provide a sum for a feed-water purifier, which would do away with the greatest cause of injectors not working satisfactorily in the Colonies.

With regard to the control over the rate of feed to the boiler, the amount of water fed into the boiler could be varied from 45 per cent to 50 per cent by reducing the steam, and regulating the water-cock in the British type of injectors. The screwed cock for injector steam-valve was much more easily kept steam tight than the pull-out valve which was discarded in this country forty to fifty years ago.

Mr. S. Jackson (Beyer, Peacock and Co.) wished it to be understood that his remarks referred mainly to British and American locomotives as made by private builders for service in foreign countries, and not to engines made for home railways. As the 
Author remarked, the basic principles underlying the design of both British and American locomotives were the same. One great difference in the two classes was that of workmanship and finish, the undoubted superiority of the British-made engine lying in the fact that the British builder prided himself upon supplying a firstclass machine in every respect, whereas the American considered that he supplied one wherein the workmanship was good enough for the job, whilst the finish was superfluous.

The fundamental difference between the British and American design of locomotive was in the plate- and bar-frames advocated by the respective designers, and much of the divergence in structural and detail design was a natural sequence to the type of framing adopted. The bar-frame certainly possessed advantages in the matter of solid horncheeks. just as the wrought-iron frames of the old British engines did, but as pointed out by the Author, various methods had been successfully used for overcoming the difficulty of loose hornblock bolts in plate-frames.

The speaker was rather surprised to note the $\Lambda$ uthor's claim for popularity of the American locomotive on the score of compensating gear in the spring rigging. Complete compensation of the spring gear to give an easy riding engine, and the use of flangeless wheels for ease on curves, had been standard British practice on foreign engines for upwards of fifty years.

The position of the dome on American engines was probably the result of the use of extended wagon-top boilers, where it was necessary to place this detail upon the largest ring, and in this connexion it might be noted that practically all the U.S.A. Government Standard designs had this type of boiler. In British designs the dome was placed most probably with an eye to symmetrical appearance, the position being also varied to suit the number of plates in the boiler barrel.

The Author mentioned Walschaert's valve gear as being the standard for American engines, and it was interesting to note that this admirable gear was standard for British-designed foreign locomotives having outside cylinders with valves on top, for at least twenty years before the Amerieans discovered it, along with the Mallet compound, in 1906.

Locomotive designers and builders in this country were only too pleased to embody in their designs any structural or detail improvements which colonial or other requirements had found advisable, and he thought it could be truly said that most of the outstanding improvements in locomotive design had originated either in this country or on the Continent, whilst the well-known 
articulated engines-the Fairlie, Meyer, Mallet, Kitson-Meyer, and Garratt-were invented and perfected in Europe. The comparative popularity of the American locomotive in many parts of the world could not be ascribed to any intrinsic superiority of the machine; it was most probably due to the low initial cost, the extremely short deliveries, and the admirable sales organizations which the Americans were able to maintain as the result of their enormous resources, developed by the favourable conditions of the home locomotive trade. A most important fact was that the majority of foreign locomotive engineers owed their training to the United States.

Mr. A. E. Kyfrin (Beyer, Peacock and Co.) thought the Paper was interesting as presenting in a compact form particulars of American practice as applied to locomotives built for lines of more recently developed lands, which were usually without the repair facilities of a great road and had a somewhat rough permanent way. In the speaker's experience of the design of British locomotives for overseas railways, compensating spring gear was almost invariably fitted by first-class firms, and flangeless wheels were a common feature when required by the curves. American boilers, perhaps, had the advantage, as they were normally designed for burning coal which was inferior to British. On the other hand, it would be found that if fuel quality, etc., was known, the capacity of British designed boilers was ample. As examples of boilers designed for burning inferior fuel the following particulars might be of interest as actual figures:-

\begin{tabular}{|c|c|c|c|}
\hline Grate & irea. & Cyli & r Diam \\
\hline $19 \cdot 3 \mathrm{sq}$ & feet. & $15_{4}^{\frac{3}{4}}$ & iches. \\
\hline $25 \cdot 0$ & , & 17 & $"$ \\
\hline $34 \cdot 8$, & , & 18 & ", \\
\hline $26 \cdot 0$, & ", & $18 ?$ & ", \\
\hline $28 \cdot 0$ & , & 19 & $"$ \\
\hline 27.5 & ," & 20 & , \\
\hline $29 \cdot 8$, & ", & 21 & ", \\
\hline $48 \cdot 0$, & $"$ & $21 \frac{1}{2}$ & ," \\
\hline
\end{tabular}

The Author's remarks would imply that the semi-circular brasses in axle-boxes were used in American practice only, but this was hardly the case, as axle-boxes of this type were extensively fitted to British-built locomotives. The same remarks held good of large wearing faces on the sides of axle-boxes next to the wheel-boxes.

Fireholes,--The Author's remarks regarding the Webb type 
were of interest, but the experience of at least two very large railways the speaker was acquainted with was not so favourable. Both at one time had many boilers with this feature, but it had been dropped in later designs in favour of the forged ring between the inner and outer plates, the ring being about $2 \frac{3}{4}$ inches thick and the copper plate dished to suit.

Regarding fire-grates, assuming that the condition of working and quality of fuel were known, the practice of British firms was very similar to that of the American, and the same remarks were good for ash-pans and smoke-boxes, for colonial and overseas service, rocking finger bars, drop-grates, and dumping ash-pans being frequently employed.

Mr. E. O'BRIEN (L. and N.W.R.) said the Author appeared to be quite correct in laying stress on the extent to which locomotive design was based on opinion; there was, considering the amount of experimental data available, an extraordinary lack of definiteness about locomotive design as compared with electric motors, for example. It was to be hoped that the discussion would elicit to what extent the problem of the use of the heavier locomotive of high tractive effort had been investigated in relation to the capital expenditure involved in bridge renewal. The L. and N.W. Railway Co. had a large number of powerful 0-8-0 engines, and undoubtedly could make use of 2-10-0 engines in considerable numbers.

The Author seemed rather uncertain about the four-cylinder engine which was rather astonishing in view of the success attained by this type both in Great Britain and on the Continent, particularly as a four-cylinder design was essential in order to obtain the maximum tractive effort permissible within the British loading gauge. Three 21-inch cylinders were the maximum permissible with the threecylinder design, whereas the four-cylinder permitted of four 20-inch cylinders and a boiler of sufficient capacity for these was just obtainable within the British loading gauge.

The Author did not mention the all-bronze axle-box; this type, though expensive in first cost, was actually the cheapest to maintain. The cast-steel axle-box was no more immune from fracture than the bronze box. In regard to tail-rods, measurements of wear made by the speaker on a number of similar engines with and without tail-rods with cylinders $20 \frac{1}{2}$ inches diameter and under, proved conclusively their uselessness; if a tail-rod was to be useful, a gland and slide-bars must be provided at the forward end of the cylinders. 
The Author had unfortunately not touched on those points of design, which, apart from the provision of ample grate area and wide bridges between tubes, had probably more influence on performance and economy than any others, namely : (1) the provision of large and straight steam and exhaust ports ; (2) the provision of ample bearing areas in the valve-motion pins; (3) the correct proportioning and placing of the blast-pipe in relation to the smokebox and chimney. If a locomotive were correctly designed in these respects, its performance would be more than satisfactory.

Mr. JoHN W. SMITH (G.C.R.), said that, with regard to the disparity of the comparative sizes of the American and British locomotive, latterly the size of the British locomotive had increased practically to the limits of the gauge. The demand in this country was for a quick and frequent service. This fact was often overlooked when making comparisons between British and American locomotive requirements. He had often wondered whether the American railway practice of accepting contractors' general designs did not tend to their policy of frequent renewals rather than periodical heavy general repairs; certainly it tended to an ever-changing design.

Ample boiler pressure was desirable from the point of view of work performance, but one must guard against the provision of boiler pressure too much in excess of the cylinder requirements, which was not satisfactory from the economical point of view.

With regard to the position of the cylinders, he (Mr. Smith) preferred inside cylinders for a two-cylinder express passenger engine, notwithstanding the objection to the crank-axle. There was no doubt that plate-frames gave greater room for the fire-boxes that went between the frames and were more elastic laterally than the bar-frame. The main advantage of the bar-frame was the one permitting an arrangement of spring compensating gears as illustrated on page 389 , which gave easier riding on bad roads. A second feature was the effective system of horn arrangement.

$\mathrm{He}$ was inclined to believe that if the railway companies in America built their own engines and repaired their boilers to the same extent as was done in this country, they would have changed from steel to copper for the inside boxes, and with regard to tubes, in recent years many of the British companies had replaced copper tubes by steel. The G.C.R. had nearly every one of their engines fitted with steel tubes. Circulating tubes had only been tried in a few instances in this country, but so far as he knew there were none still in service. Touching on brick arches, at one time the Americans used no brick-arch in their fire-boxes, and it was rather amusing to 
find the American technical press advertising the advantages of a brick arch which had been standard practice ever since locomotives began to be used in this country. There was no doubt these arches were of great utility.

In America as well as on the Continent, in working a locomotive, the door was only kept open sufficiently long to enable coal to be put in, whereas a British driver would not consider his engine was steaming properly unless he could run with his fire-door partially open. The reason for this was no doubt the fact that British locomotives were fitted with brick arches, and, further, the upper half of the fire-hole was fitted with a deflector plate for throwing the air which entered the fire-hole, under the arch. The British arrangement of brick arch and deflector plate was, no doubt, the real cause for the difference in working practice. The usual British practice was to fit internal steam-pipes of copper. A number of locomotives of which the speaker had knowledge were fitted with steel main steam-pipes, but these gave so much trouble, by corrosion and pitting, that they were replaced by copper.

Although a few engines were fitted with piston-valves as far back as the old days of the Blythe and Tyne Railway, they did not find favour until they were reintroduced on the North Eastern Railway in the early "Eighties," and later their use was extended to the Midland Railway. After the working of these pioneer engines, their use gradually became adopted in America, and with locomotives fitted with superheaters, a piston distributing-valve had practically become the standard valve.

Mr. E. M. Gsss (L. and Y.R.) noted that the Author suggested (page 377 ) that a much greater use could be made in this country of powerful eight-coupled engines, or even ten-coupled. There were a number of the former running in this country, but none of the latter, with the exception of probably the Midland tender-engine employed on banking. The non-use appeared to lie in the fact that it was difficult to obtain sufficient adhesion, and at the same time keep the weight below the Engineer's standard curve for under-bridges, on the assumption of two of these engines being coupled together, each having a tender capable of carrying 4,500 gallons of water and six tons of coal. Taking an axle-load of sixteen tons, and a coupled wheel-base of 22 feet, which was about as short as it could be in order to get in the necessary brake-blocks, it was found that the equivalent uniformly distributed live load per foot-run was above the bridge curve, on spans of 30 to 80 feet. The largest diameter of outside cylinder that could be employed on a load gauge of 8 feet 
8 inches wide was 19 inches. Assuming the engine to be equipped with four cylinders of this diameter, a piston stroke of 26 inches, a wheel diameter of 4 feet 6 inches, and a boiler pressure of $180 \mathrm{lb}$., the tractive effort at 85 per cent of boiler pressure was 53,187 lb. To absorb this tractive effort the weight upon the rails, on the assumption that adhesion was 25 per cent, then the total weight required was approximately 95 tons, or 19 tons per axle, yet 16 tons per axle was not allowable on short span bridges.

Respecting boiler power, the limit to make steam depended mainly on grate surface, and of course the quality of the fuel. The best proportion of grate to heating surface appeared to be about 1 to 60 , and 1 square foot of grate surface supplying 300 cubic inches of cylinder volume (one cylinder in the case of a twocylinder engine, and two cylinders for a four-cylinder type), the grate surface then became, for four 19 -inch by 26 -inch cylinders, approximately 50 square feet, and the heating surface 3,000 . A grate of this capacity arranged between the frames was not practical, as it meant a fire-box length of about 15 feet, so the wide box arranged above the wheels had to be resorted to, and this in turn resulted in a shallow fire-box with restricted volume, and little depth between the grate and brick arch, for the coal bed. For burning bituminous and semi-bituminous coals containing a high percentage of volatile matter, ample fire-box volume was essential for complete combustion. The difficulties that presented themselves in designing high-capacity 10-coupled engines to conform with the British load gauge and standard curve for under-bridges were (1) axle-load limits, (2) ample fire-box volume, and (3) restricted wheel-base to negotiate curves.

With reference to the Author's remarks respecting the advantages of outside cylinders and the employment of the Walschaert valvegear, the speaker added another point regarding its merits that it lent itself to the employment of long valve-travel. Regarding the better protection from radiation losses, the use of high superheat, which carried the steam dry to the point of exhaust, nullified any condensation that might arise with cylinders placed on the outside.

The design of fusible plug that was used by the L. and Y.R. projected into the water $\frac{5}{8}$ inch and was $1 \frac{7}{8}$ inch long over-all. It had a straight tapped hole through its centre slightly countersunk at the top end. The surface of the hole was tinned previous to pouring in the commercially pure lead, the hole being filled with the exception of $\frac{1}{2}$ inch from the fire-box end of the plug. This type gave satisfaction.

The Author appeared to prefer the double-beat regulator-valve 
to the sliding through-port type with pilot-valve. The speaker's experience was that the latter was more reliable in keeping tight; in addition, the pilot-valve was an advantage in governing the small supply of steam to the cylinders necessary when coasting.

The use of axle-box wedges was not universal. Several railway companies had either not employed them or had abandoned them. They might be of service providing that adjustment was properly carried out from time to time, but it was questionable whether this was always done at the running depots.

Mr. J. R. Billington (L. and Y.R.) did not think that the Author had made the matter clear of plate-frames versus barframes, because it was not so much one of rival design, but was simply an adaptation to circumstances in the first place, and afterwards one of growth and development. With the large fireboxes that were required in America for the poor fuel and rapid growth of locomotives, the bar-frame was well adapted. In the British Isles the richer fuel practically necessitated copper-boxes which were, of course, smaller, and these the plate-frame was well adapted to receive.

Mr. D. WILson noted that the Author referred briefly to the adoption of mechanical stokers on locomotives, and asked what type these generally were, how they were driven, and whether they had been applied on English railways.

Mr. Dantel Adamson (Member of Council) said, with regard to acid steel and basic steel plates, that in the latter there was always a doubt as to whether the steel was of the high quality necessary, variations occurring even in one ingot when manufactured under this process. Acid steel was much more reliable, as the material was bound to be of good quality before the process was begun.

When he first visited America he had been surprised at the method obtaining there of punching tube-holes in plates for locomotives, and, although these were hammered out afterwards, this method conapared badly with ordinary British practice.

Mr. Walter Leigh raised the question of lubrication and protection of exposed bearings of a locomotive. A great deal of money had been spent by the I. and N.W.R. Co. in re-ballasting tracks with granite instead of cinders to reduce the amount of dust. Locomotive engineers apparently were very backward in adopting an underscreen for keeping out the dust, and using forced lubrication. 
Motor engineers and mill engineers encased all bearings wherever possible, and the point to be considered was whether the life of the bearings would be increased sufficiently to compensate for increased protection.

Mr. R. MoRris (L. and Y.R.) thought more sympathetic consideration should be given to the question of boiler power. From the point of view of an operator, a more generous allowance of boiler power would mean greater efficiency, as this would obviate the necessity to clean out the fire, which entailed waste of coal and loss of time.

Mr. Rowland Jolliffe (L. and N.W.R.) asked whether it was advisable to have a dual crank-axle for a four-cylinder engine. The late Mr. Webb had made the compound type for passenger and goods service; these engines were driven off one axle, two lowpressure cylinders being inside and two high-pressures outside. The new "Claughton" type of four-cylinder engine had the driving force off one axle; to attach an outside big-end to a wheel, one must have an extended crank-pin on the leading engine-wheel. He would like to know as a driver if the life of an engine was not longer when one pair of wheels was the driving medium. He was of opinion that this was so, because on the L. and N.W.R. there were no wedges to the horn-blocks as in some other types made and designed by other companies and private builders.

Sir Henry Fowler, K.B.E. (Vice-President), said, with regard to basic and acid steel, that he was not in agreement with the Author. If basic steel were properly made, it could be as reliable as acid steel. It was the trouble that so frequently occurred in making that had discredited basic steel. British engineers' slowness in perfecting basic steel was to be regretted, as there were many ores available in England for basic steel.

With regard to mechanical stokers, the Locomotive Stoker Co. were the chief makers. By means of a screw-feed the stoker brought the coal forward from the tender up the back of the ordinary fire-box, and it was then sprayed on the fire. When one considered the large amount of coal that had to be put in and the distance it had to be thrown, it was necessary to have a mechanical stoker. They were extensively used in the United States, but not at all in this country.

With regard to dual driving-axles, he said this was advisable and sometimes necessary, otherwise the connecting-rod was too short to work efficiently. 
It was well known that the coal now turned out by the collieries was inferior to that produced before the War. In one case, analysis showed that there was 18 per cent of ash in the coal. This would form a bad clinker and the fire would have to be cleaned ont frequently. In America there were various methods of cleaning the fire out while on the road, one of which had been tried, but unsuccessfully, by the Midland Railway.

His Company had used steel fire-boxes during the War, but had replaced them with copper ones as soon as possible, as these lasted about twice as long as the steel ones. His experience on the Midland Railway was in favour of copper tubes also. Out of 3.000 locomotives only about a quarter had steel tubes. He did not think brass tubes were used to any extent in England.

Mr. Robinson had mentioned difficulty in making joints on superheaters. On the Midland Railway a simple arrangement consisting of a copper ring of diamond section was used.

With regard to radial stays in fire-boxes, these were used on a line recently taken over by the Midland Reilway, but it was proposed to replace them by Belpaire fire-boxes, as it was found they gave a better service.

\section{Discussion at the For7shire Branch Meeting in Leeds, on 27 th March 1922.}

[The Paper was presented, on behalf of the Author by Mr. T. H. Brocklebank, O.B.E., Member.]

The Chairmax, Major F. L. Watson, M.C. (Member of Council), said it would appear that in the Author's view the British engine, in regard to workmanship and material, was superior to American locomotive practice. As in regard to many other kinds of machinery there seemed to be a curious willingness to accept from America designs and methods which would be roundly condemned if adopted by English makers, and this tendency enabled America to put in lower prices. In fact, American practice seemed to be to make the engine as cheap as possible, consistently with the customers' demands, whereas the British practice was to make it of the highest possible quality for the money available. In view of this it was rather distressing that orders should go to America in consequence of points in design such as the compensation of spring mountings, which could be as well carried out by the English as by the American 
firms, if the railway engineers would specify what they wanted in such respects.

Mr. C. O. Becker said that, speaking generally, the American locomotive during the last century was evolved almost entirely by practical men, who had spent years in the shops and on the footplate, and whose lives had become part of the locomotive itself. About twenty years since the demand for more power meant larger locomotives and new types, and, as the proportions could not be guessed at, an immense amount of experimental work was undertaken in order to determine what were the best proportions. In this way the American locomotive had been evolved by the process of theory following practice. At the other extreme it might be said that Continental Engineers had developed the locomotive by the reverse process of practice following theory, with the result that their engines had always been more complicated, and therefore not so well adapted for countries where skilled attention was not obtainable.

He would like to ask whether the Author was not rather too sweeping in his remarks regarding the position of the steam-dome on American locomotives. He himself had examined a large number of engines and found that in nearly every case the dome was situated on the centre line of the water surface, before the reduction in the diameter of the boiler shell. Thus, in cross-section the dome was placed where there was the greatest steam-space and where the velocity of the steam entering the steam-pipe would be lowest. On the older engines, with fire-boxes supported by roof stays of the bar pattern, it was usual to place the dome over the fire-box, but it was of large diameter and where there was a maximum of steam space. On the modern engines the safety-valves were placed on a separate seating owing to the limitations of the loading gauge, but whether they were on the steam-dome or not mattered very little, for they blew off far oftener with the throttle closed, and therefore could not affect the quality of the steam admitted to the cylinders.

The American practice of supporting the springs by means of keys passed through slotted links was far preferable to the British practice of using round pins for these parts. When worn into curious shapes it was a most difficult matter to get these pins either in or out of the holes. Copper fire-box tube-plates were distorted by faulty tube expanding. The holes got quite oval. He had measured some $2 \frac{1}{2}$ inches by $1 \frac{7}{8}$ inch, and the whole tube plate was swelled out and up. It seemed incredible that the tubes could be 
made tight in such holes, but they were packed up with copper strips to make the holes fairly round, then the tubes were rolled in with great force, sufficient to distort the whole tube-plate. Steel fire-box tube-plates could not be distorted so badly in this way as the copper ones, and were therefore to be preferred where the workmanship on repairs was so defective. American builders always allowed plenty of play for the axle-boxes, which was a very desirable advantage over the British engines which seldom had enough play in the horns.

He was surprised at the Author's remarks regarding the comforts provided for engine-men in the cabs, and did not agree with his views at all. Some time ago he discussed this question with a French locomotive superintendent, who said that he did not provide either cabs or seats for the engine-men because he was afraid they might go to sleep when on duty. On that line, instead of staying on their engines, the men took every opportunity to leave the engine and go to sit in an empty compartment on the train. In America good cabs were always provided with comfortable seats for the men, and that policy had not led to any slackness on the part of the driver. He could not agree with the Author's remarks regarding the use of the reversing lever on theAmerican locomotives. The practice on the roads that he was connected with was to run with the throttle full open and to notch up to about 30 per cent cut-off before beginning to throttle down. It was quite easy to shift the lever notch by notch while running.

American firms employed their own experts who were constantly visiting the railway officials, and their catalogues were to be found in every office. German firms had also been in the habit of sending out technical men, but to a much less extent than the American, and they had supplied more engines of purely American design than the British had. American and German manufacturers had in this way better opportunities than British to compete for contracts, especially when it was taken into consideration that the American type was often preferred, and they made fewer mistakes because they were better informed as to the actual conditions on the roads.

Mr. Fred Clements said the Author stated that in British practice acid steel plates were practically always used for boilers, whilst in America basic steel was permitted and extensively used. The Author considered the acid process steel the more suitable, and the speaker would like to know if any definite data supporting this conclusion could be supplied. Basic steel plates for locomotive boilers had been used in England for many years, the Park Gate Co. 
(Rotherham), having supplied both the Great Western Railway Co., and the Great Central Railway Co., as well as many of the leading private firms building locomotives with basic plates instead of the acid process material which was previously used. Particulars selected at random from the test records of the Park Gate Company revealed the following results :-

\begin{tabular}{|c|c|c|c|c|c|c|c|c|c|c|}
\hline \multirow{2}{*}{ Purchaser. } & \multirow{2}{*}{$\begin{array}{c}\text { Class } \\
\text { of } \\
\text { Streel. }\end{array}$} & \multirow{2}{*}{$\begin{array}{l}\text { Test- } \\
\text { Piece. }\end{array}$} & \multirow{2}{*}{$\begin{array}{c}\text { Max. } \\
\text { Stress. }\end{array}$} & \multirow{2}{*}{ 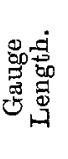 } & \multirow{2}{*}{ 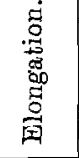 } & \multicolumn{5}{|c|}{ Analysis. } \\
\hline & & & & & & C. & Si. & S. & P. & Mn. \\
\hline \multirow{5}{*}{$\begin{array}{c}\text { Great } \\
\text { Gentral } \\
\text { Railway Co. }\end{array}$} & \multirow{3}{*}{ Acid } & \multirow[b]{2}{*}{ Length } & $\begin{array}{c}\text { Per } \\
\text { sq. in. }\end{array}$ & \multirow{2}{*}{$\begin{array}{l}\text { in. } \\
10\end{array}$} & $\begin{array}{l}\text { Per } \\
\text { cent. }\end{array}$ & $\begin{array}{l}\text { Per } \\
\text { cent. }\end{array}$ & \multirow{2}{*}{$\begin{array}{l}\text { Per } \\
\text { cent. } \\
0.02\end{array}$} & \multirow{2}{*}{$\begin{array}{l}\text { Per } \\
\text { cent. } \\
0.052\end{array}$} & \multirow{2}{*}{$\begin{array}{c}\text { Per } \\
\text { cent. } \\
0.046\end{array}$} & \multirow{2}{*}{$\begin{array}{l}\text { Per } \\
\text { cent } \\
0.58\end{array}$} \\
\hline & & & $28 \cdot 7$ & & $25 \cdot 0$ & \multirow[t]{2}{*}{$0 \cdot 17$} & & & & \\
\hline & & Across & $28 \cdot 5$ & 10 & $23 \cdot 5$ ) & & & & & \\
\hline & Basic & Length & $28 \cdot 4$ & 10 & $24 \cdot 5$ & 0.17 & 0.04 & 0.035 & 0.038 & \multirow[t]{2}{*}{$0 \cdot 63$} \\
\hline & & Across & $28 \cdot 2$ & 10 & $24 \cdot 0$ & & & & & \\
\hline \multirow{4}{*}{$\begin{array}{c}\text { Great } \\
\text { Western } \\
\text { Railway Co. }\end{array}$} & \multirow[t]{2}{*}{ Acid } & Length & $29 \cdot 7$ & & $29 \cdot 0$ & \multirow[t]{2}{*}{$0 \cdot 18$} & \multirow[t]{2}{*}{0.023} & \multirow[t]{2}{*}{0.045} & \multirow[t]{2}{*}{0.036} & \multirow[t]{2}{*}{0.68} \\
\hline & & Across & $29 \cdot 0$ & 8 & $28 \cdot 01$ & & & & & \\
\hline & Basic & & & 8 & $25 \cdot 5$ & $0 \cdot 17$ & 0.02 & 0.035 & 0.033 & 0.55 \\
\hline & & Across & $29 \cdot 4$ & 8 & $25 \cdot 0)$ & & & & & \\
\hline
\end{tabular}

The Table showed that the mechanical results were practically identical, whilst in chemical composition the basic steel was freer from the deleterious elements, sulphur and phosphorus, than the acid steel. He also asked if the Author could give any information regarding the life obtained from steel fire-boxes supplied by British builders as compared with those fitted by American firms. Observations also as to the behaviour and appearance of the material when a steel fire-box failed would be valuable to steel manufacturers.

Major F. H. PHILIIPS, R.A.O.C., said that respecting the welding of fire-boxes, he considered this a dangerous practice and one he would hesitate to adopt. In American boilers where they had a drum-head tube-plate, the longitudinal seams were welded up for about 8 inches to 12 inches. In putting the tube-plate in position, 
there was a great tendency for the seam to open up, which was overcome by their system of welding.

With regard to axle-boxes, in his railway experience he repeatedly had trouble with the heating of the inner radius, but in the type of axles with straight-through journals, no abnormal heating whatever was set up, and this American practice was now to a large extent being adopted in this country. He agreed with the Author's remarks respecting the position of the dome on the boiler, but would rather hesitate about fitting such a small smoke-box door as indicated in the Paper.

With regard to the vexed question of the respective merits of bar-frames and plate-frames, this was a point which was certainly not settled yet. His firm had recently supplied locomotives for work in South America with plate-frames, which had proved a great success, as would be gathered from the fact that some eighteen months after the engines had been working, they received a further application from another South American company many miles away for the supply of engines, which were specified to be of exactly the same type as those referred to. This was practical evidence of the success of the plate type of frame on light tracks over very rough country.

Mr. EDgAR AlCock, M.B.F., said that he disagreed entirely with those who upheld American locomotive practice to the detriment of engines made in this country. From information received from one of his colleagues who had visited some of the larger locomotive works in the States, he gathered that the workmanship was very much below the standard to be found in this country.

Mr. Gur L. Murray said he was glad the Author had called attention to the care required in handling the bar-frames in the erecting and repair shops. He could speak from experience that in handling these frames, especially before t'se horn-stays were in position and locked, one was very liable to damage seriously the top member unless special precautions were taken. He believed that in the carly days the bar-frame was entirely made up of welded bars, and one must agree that a bar of about 4 inches square section was well suited to this purpose. The next stage in its development was to produce the complote frame in the form of a steel casting, which practice, he believed, was still carried ont in America and in Germany. This latter method undoubtedly made a very cheap proposition from a production point of view, but he had doubts as to its ultimate efficiency. On the otler hand, the waste and 
expense involved in making the bar-frame by the methods adopted when engines of this type had to be built in this country was very striking. He had a case in mind in which the steel slab for producing a single bar-frame weighed 8 tons, while the finished machined frame was under 2 tons ; this meant over 6 tons of scrap material. When one compared this with the fact that the ingot to produce a pair of plate-frames was approximately only 5 tons in weight, the extravagance and waste resulting in the case of the bar-frame was very noticeable, and he considered that the Author should add this point to the list of disadvantages given respecting bar-frames, together with the fact that it was an exceedingly difficult structure to cross-stay satisfactorily. In passing, he would also add that the inconvenience of attaching side tanks to a bar-frame engine had, perhaps, something to do with the almost complete absence of the tank-engine in America.

Respecting the question of bojler power, it was quite common to find American two-cylinder engines fitted with boilers of considerably over 4,000 square feet heating surface, and when one bore in mind that the boiler on Mr. Churchward's "Great Bear," which had to supply four simple cylinders, had a heating surface of only 3,400 square feet, the huge differences of boiler capacities were very apparent.

Referring to the steam-chest cover and copper ring joint in Fig. 10 (a) (page 408), he would like to ask the Author if he had had any experience under running conditions in the use of the "Hulburd" type serrated copper joint-ring, as he, the speaker, had found this very simple and effective-at any rate during erecting shop tests. With reference to the question of using ground joint-rings with copper steam-pipes which the Author referred to as the solution to the steam-pipe problem, he had on many occasions supplied this type of joint under conditions practically identical with those shown in Fig. $10(\mathrm{c})$.

Finally, perhaps the most satisfactory statement, from the British manufacturer's point of view, was as follows (page 420) :"The channel-frame American tenders usually last about fifteen years .... whereas the British tender lasts forty years or so, and is often used on a second locomotive." There, in his opinion, was the gist of the whole question-the life of the British compared with the American locomotive--and he considered that the Author, with his extensive running experience, could probably supply a comparative list of the lives of such vital parts as, say, boilers, fire-boxes, frames, wheels and axles, motion, etc., which would probably be very illuminating, and would add greatly to the value of the Paper. 
Mr. T. H. SANDERS said the engine bar-frames and tender channel-frames referred to were now very largely made as steel castings in chrome-vanadium steel. The tender-frames were not quite so usually castings, but when such were employed the whole underframe was generally in one piece, including both solebars, longitudinals, cross-stays, etc. With regard to the side thrust of axle-boxes, the Author did not refer to the usual practice of American builders of placing a brass liner or "hub plate " on the inside of the coupled-wheel bosses to take this action. The question of compensating rigging was a vexed one. The staggered rail-joint always used in American practice was responsible to no small degree for the need for compensating gear. The American designers maintained strict adherence to the three-point system of suspension. It was certain that no American engine would keep to the staggered joint road bed, with 25 -ton axle weights, without the compensating gear, at the running speeds employed.

It was now a very usual practice to make piston-heads about 2 inches wider along, say, $90^{\circ}$ of the bottom circumference, than their top width. Also, in view of the very large cylinders in use, without piston tail-rods, it was not unusual to camber the rod about $\frac{3}{8}$ inch when light, so that it was straight with the head on.

The shrinkage allowance for tyres was given as $1 / 750$, which was substantially more than British practice permitted. The chief reason why this practice was admitted with impunity was due to the relative softness of the American tyre, which was generally betweeu 50 and 55 tons tensile, whereas here they were 55 to 70 tons. Furthermore, it was general here to use some form of securing device, whereas in America shrinkage only was generally depended upon, and a large shrinkage allowance on high tensile tyres might cause such inherent stress (their being on a stiff wheel centre) as to bring about early failure. Doubtless one reason for the softer tyre being so largely used in America was due to their high speed methods of repair work.

Tenders gave more trouble in American practice than any other, probably due to the great difference between tare and loaded weights, and inefficient washplate arrangements. When elliptic springs were used, breakages were so common that the spring units were not bolted up, but placed loose in castings to facilitate replacements. According to one high authority, the retention of the staggered-rail joint permanent way was due solely to the tender.

The simple design of laminated springs was characteristic of American practice and much to be commended. Most springs had plain top plates, with some form of loose washer, as against the 
welded top plate (involving different steel qualities) usual here. The wear of the pins in the latter type frequently caused difficulties in removal and repair, apart from the fact that the top plate as such was an expensive and none too sound feature. All springs were of one thickness, rarely exceeding $\frac{1}{2}$ inch, and generally 4,5 , or 6 inches wide. Springs were also invariably overhung, which obviated the use of complicated central hoops. Certain features of American spring design seemed doubtful, as complaints had been heard of axle-boxes striking the frame-tops, owing to superdeflection or set of the springs. The distance they had to travel before this could occur was about 4 inches. American springs were generally tempered softer than they were here, resulting in setting occurring before breakage.

Mr. T. H. Brocklebank (Kitson and Co.) said that the subject of British and American locomotive design so ably considered by the Author was very wide and affected by many different conditions. The more important of these were :-

(a) The differences between the sizes of the loading gauges, the British being much smaller than the American.

(b) The differences in the distances between the important cities and trade centres, between the weights of the trains to be hauled and their frequency.

(c) The differences between the character of most portions of the permanent way and road beds.

(d) The small dimensions of the British loading gauge restricting the size of the locomotives.

Due to the comparatively short distances in this country for trains to be hauled, their light weight and frequency, it had been found advisable to retain the use of six wheels coupled goods and four wheels coupled passenger locomotives.

Referring to the Author's remarks with regard to the more extended use of eight and ten wheels coupled locomotives in this country, he said that both these types had been introduced here for some years where found allowable and advisable. Further, due to the solid character of the design, the workmanship, and the good quality of the materials used, locomotives of British construction remained in service forty or fifty years or more and still gave good results. According to all accounts nothing like this length of service was expected or obtained in America; therefore the types of the locomotives could be changed more quickly than here. Due to the solid character of the permanent way of the British main lines, it had been found unnecessary to retain the use of compensated 
spring gear, although this was used in this country in early times. Compensated spring gear, however, in his opinion, was in most cases fitted to the locomotives manufactured in this country for colonial and foreign railways.

With regard to the relative flexibility both vertically and laterally of the bar and plate frames, he considered that both types should be made as rigid as possible in both directions, for if not, all kinds of trouble might be the result, such as hot axle-boxes, connecting and coupling-rod bushes, and valve-motion. He looked upon the frames of a locomotive as the bed-plate of a stationary engine, and considered that allowances should be made for traversing the curves on the railway by the correct amount of side play necessary in the axle-boxes and horn-blocks, connecting and coupling rod bushes, and by reduction in the thickness of some of the flanges of the tyres, and that the allowance for vertical adjustment should be made by suitable springs and gear. He would not recommend the use of flangeless tyres wherever it was possible to avoid them.

Regarding boiler power, there were so many conditions to be taken into consideration, that it would appear unwise to dogmatize too much regarding the relative capacities of the boiler and cylinders. In this country, where the coal was generally of a high heating value, and the trains to be hauled were comparatively light, it had been found economical to have smaller boiler capacitics in relation to the cylinder capacities than in some- other cases. Comparatively large cylinders were required for starting the train from rest, but when in motion the valve-motion might be notched up and the steam used more economically in a large cylinder than one of smaller diameter. In the case of locomotives required for abroad, it was usual to ask for the largest possible load to be hauled over steep gradients, combined with sharp curves on a very light track necessitating a small axle-load.

Mr. JohN STansfecd wrote that he would have been glad if some comparative figures on the life and on the maintenance cost on some of the various details of the British and American locomotives had been given. The life of steel locomotive tubes in England averaged about 100,000 miles, and copper about 320,000 miles; in some instances 480,000 miles had been attained. Over a period of twelve years three sets of steel tubes would be required to one of copper. When the number of locomotives was taken into account, the total loss of revenue of a large railway company would amount to a considerable sum when using steel tubes, due to the frequency of the re-tubing operations. The Author referred to the 
high coefficient of expansion of copper tubes; this, the writer claimed, was a decided merit. The alternate expansion and contraction tended to keep the copper locomotive tube practically free from scale; a steel tube from its inherent physical properties could have no such virtue. This "self cleaning from scale" property of the copper tube had considerable good influence in coal consumption on a locomotive.

The Author drew attention to locomotives for foreign service, and he, the writer, pointed out that in such cases the cost of transit and delivery at their ultimate destination (in this case Jamaica) was an important factor in the total expense incurred, and in view of the fact that at least three sets of steel tubes must be supplied to do the work of one set of copper tubes, the extra freight and delivery charges involved by the use of steel tubes must be taken into account. It should be emphasized that scrap steel locomotive tubes in the Colonies could have practically no monetary value owing to the limited ferrous remelting facilities which these countries possessed, whereas copper would command its market price anywhere in the world by reason of its intrinsic virtues.

A remark was made by the Author that steel tubes did not suffer from erosion at the fire-box end, but surely this was a matter which, in the case of copper tubes, was easily overcome in one or two ways in a thoroughly practical fashion, and the writer questioned a judgment in which steel locomotive tubes were given the preference over those of copper for this reason.

With regard to conductivity, the National Physical Laboratory gave the heat conductivity of copper as 91.8 per cent, and of steel as 11.6 per cent, and, neglecting for the moment the presence of scale, one would expect less wasteful consumption of fuel and increased evaporation by the use of copper tubes, but authoritative figures with special regard to locomotives were not available. He wished to endorse the Author's remark of the desirability of some full scale experiments to determine once and for all this vexed question, and he would further suggest that the subject was one that the Institution of Mechanical Engineers could take in hand in conjunction with one of the leading railway companies, as the economy of coal was more important to-day than ever. 


\section{Communications.}

Mr. E. L. Anrons wrote that the Author referred to wheels with flangeless tyres, of which there were many instances in British locomotive designs. The removal or thinning of certain flanges did not always improve the curving property of an engine or reduce the flange pressures in the least. The removal of the flanges of the second coupled axle of an 8-coupled freight engine did not alter the position of the engine on a sharp curve, and the flange pressures of the outer leading coupled wheels, which it was desirable to reduce, were not affected. If the flanges of the third pair of coupled wheels were removed, the position which the engine would take upon a curve was altered. The flange pressure of the outer leading wheel would be reduced, but this advantage was partially discounted, since the angle of approach of the flange of the leading wheel to the rail was increased, and the tendency to cut into the rail was greater.

Recent American practice was to retain the flanges, but to modify the distances between the tyres. In a 2-8-0 engine the tyres on the leading and trailing coupled axles were set closer together than those of the second and third coupled axles, the difference in spacing between the tyres being about $\frac{1}{8}$ to $\frac{1}{4}$ inch. The object was to compel the second pair of coupled wheels to assist in guiding the engine round a curve. One objection to this, from a British point of view, was the danger of the flanges of the end pairs of wheels striking the guard rails on crossings. But the American practice appeared to be based upon an assumption that all the flanges of a locomotive ran against the outer rail on a curve. This was not the case, for the flange of the trailing wheel would do so only if the speed of the engine was excessive and greater than that allowed by the superelevation of the outer rail. The best means of reducing flange pressures and tyre wear in an 8-wheels coupled engine, and of enabling it to " curve" with least resistance, was to leave the flanges alone, make the first and third coupled axles rigid, and allow the second and fourth coupled axles sufficient side play in the axle-boxes. The system had been successfully used abroad, especially by the late v. Gölsdorf on the Austrian railways.

The Author suggested the addition of pony trucks or bogies for shunting engines to allow tank-engines to be used instead of the American tender-engines. In the writer's opinion shunting tankengines should be of the simple $0-6-0$ or $0-8-0$ type, provided that 
the weights on the wheels were not excessive. The addition of a truck or bogie might be absolutely detrimental. At the leading end, when the engine was moving chimney first, the truck assisted in curving the engine, since the controlling force provided pulled the head of the engine round in the right direction. But a truck at the trailing end, or what amounted to the same thing, a leading truck when the engine was moving bunker first, acted detrimentally, since the controlling force of the truck pulled the front end of the main frame round towards the outside of the curve and considerably increased the flange pressures of the leading coupled wheels. This action is more marked in a 0-8-2 than in a 0-6-2 engine, and in yards or sidings with sharp curves might cause derailment, apart from the excessive wear of the leading flanges.

The pendulum or swing link bogie had been used on a large number of engines on British railways. Mr. George Hughes, * Member, stated that the first 4-4-2 engines of the Lancashire and Yorkshire

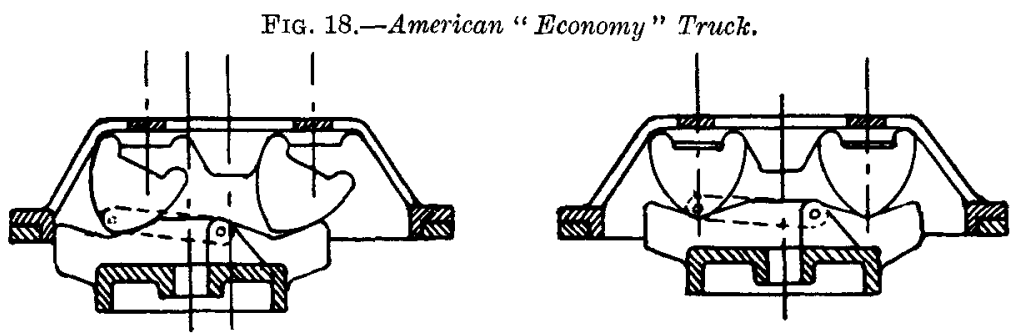

Railway were fitted with this bogie, but that considerable rolling was experienced, and a sliding type of bogie was afterwards adopted which resulted in steadier riding engines. The Great Western Railway, which used the pendulum link type with 3-point suspension, also reverted to the Adams' sliding type. The Adams' bogie had more frictional resistance, but this was an advantage in that the swinging movement of the leading end was damped and the engines "curve" more steadily. The pendulum link bogie with the usual single pin suspension and flat bearing plates had the defect that when displaced to one side on a curve, the front end of the body of the engine was tilted laterally.

The Americans appeared to be discarding the pendulum link type, both for four-wheeled bogies and two-wheeled trucks, for a new design known as the "Economy" truck, in which the bolster

* “Locomotives designed and built at Horwich," Proc. I.Mech.E., 1909, page 561 . 
moved laterally on two heart-shaped cams as shown in the diagrams, Fig. 18. In this truck the front of the engine was lifted, but not tilted laterally. A higher initial resistance to lateral displacement than in the three-point pendulum bogie was obtained, with the additional advantage that the cams could be so shaped that this resistance remained constant throughout the displacement and did not increase rapidly as with the pendulum bogie.

With regard to the use of a 2-6-2 engine on fast passenger trains instead of one of the 4-6-2 or 4-6-0 type, it was an undoubted fact that a leading four-wheeled bogie was safer and had greater lateral steadiness than a two-wheeled truck. The pony truck tended to hunt too much from side to side, an action which at high speeds was detrimental to the permanent way. In Germany experience of pony trucks on 2-6-0 engines was such that their use was limited to trains not exceeding a maximum speed of 45 miles per hour. Above this speed some form of four-wheeled bogie was recommended. This agreed with the American practice mentioned by the Author.

The Author's figures for tyre shrinkage allowance hardly seemed correct. The British allowance varied from $\frac{1}{50}$ of the diameter of the wheel centre on one railway to about $\frac{1}{120} \overline{0}$ on another, the average allowance being $\frac{1}{1} \overline{0}$. The American Master Mechanics' allowance varied with the diameter of the wheel centres from $r^{\frac{1}{4}} \mathrm{I}$ for a centre 6 feet 6 inches in diameter to $\frac{1}{5} \frac{1}{5}$ for a 3 feet 2 inches centre.

The writer wished to ask the Author whether he had any further information with regard to the deterioration in service of the circulating tubes which supported the brick arch in an American fire-box. Fire-box water tubes appeared to develop "pin-holes," the catse of which was obscure.

Professor W. E. Dalby, F.R.S. (Member of Council), wrote that he desired to put in a plea that we should adopt one branch of the work on locomotives which originated in America and had found its home there, namely, the laboratory test of the engine. There was a science of the locomotive as well as a practice, and American engineers had well understood the importance of investigating the locomotive from both points of view. The testing plant put down at Purdue University furnished interesting scientific data relating to the locomotive of the American type represented by Schnectady No. 1 and Schnectady No. 2. Later there were the unique set of trials carried out at the St. Louis Exhibition and recorded in "Tests and Exhibits" of the 
Pennsylvania Railroad Company. It was data of this kind that was lacking for British locomotives. It was perfectly true that the final test of a locomotive was on the road, but it was equally true that the information to be obtained from a locomotive test plant was of paramount importance, because it guided unerringly to the essentials of the type which should be designed to carry out a particular service. No one who contemplated the multiplicity of types of engines in this country, many of them designed to do practically the same work, could help feeling that some standardization was necessary in the interest of economy. The sure way of leading to standard designs was to determine the influence of each variable separately. As there were so many variables, and as these of necessity varied together in a road test, the latter alone could not give the necessary fundamental data. The road test should be supplemented by test in a laboratory.

The writer had made an exhaustive analysis, with the aid of some of the students in the Post-Graduate Course in Railway Engineering of the City and Guilds (Engineering) College, of laboratory tests carried out in America, and the information derived therefrom was of first-rate importance to locomotive designers. It would be a greater advantage to British designers if it were possible to get corresponding data for British locomotives. In order to illustrate his point, he appended a Table (pages 488-9) of calculations and data relating to the boiler of a locomotive tested in America on a locomotive testing plant.

A glance at Col. 5 showed that combustion was far from satisfactory. The last trial showed 4 per cent of $\mathrm{CO}$ in the chimney gas. Something was wrong with the design of a furnace when so much $\mathrm{CO}$ appeared in the chimney gas. In the bottom line, eleventh column, it was found that the corresponding air supply was only $12.7 \mathrm{lb}$. per $\mathrm{lb}$. of carbon found in the dry furnace gas. This was not enough for good combustion, so that the design should be modified in order to get more air through the furnace. Good combustion was obtained only when the air-supply was 16 to $18 \mathrm{lb}$. per $1 \mathrm{~b}$. of carbon. If this engine were tried on the road, it would certainly not give a good performance in relation to work done and coal used, but it would be a difficult matter to tell that its poor performance was due to a defective air-supply alone.

Another important point brought out by the Table was that the efficiency of heat transference was not affected by the poor furnace performance, because, of the heat developed by combustion, about 75 per cent got transferred to the water in the boiler in all conditions of working. This showed the necessity of treating 
TABLE.

\begin{tabular}{|c|c|c|c|c|c|c|c|c|c|c|c|c|c|c|}
\hline \multirow{2}{*}{$\begin{array}{c}\text { Trial No. } \\
101\end{array}$} & \multirow{2}{*}{$\begin{array}{c}\text { Drycoal } \\
\text { fred per } \\
\text { sq. ft. } \\
\text { of grate } \\
\text { per } \\
\text { hour. } \\
\\
\mathrm{Lb} . \\
86 \cdot 4\end{array}$} & \multicolumn{4}{|c|}{ Gas Analysis by Volume. } & \multirow{2}{*}{$\begin{array}{c}\text { Temp. } \\
\text { in } \\
\text { Smoke- } \\
\text { Box T. } \\
\\
\text { Fahr. } \\
714\end{array}$} & \multirow{2}{*}{$\begin{array}{c}\text { Temp. } \\
\text { in } \\
\text { Lab. } t .\end{array}$} & \multirow{2}{*}{\begin{tabular}{|c}
$\begin{array}{c}\text { Boiler } \\
\text { Effi- } \\
\text { ciency. }\end{array}$ \\
$\begin{array}{c}\text { Per cent. } \\
45.37\end{array}$
\end{tabular}} & \multirow{2}{*}{$\begin{array}{c}\text { Loss } \\
\text { per lb. of } \\
\mathrm{C} \text { in dry } \\
\text { gases due } \\
\text { to for- } \\
\text { mation of } \\
\mathrm{CO}=\mathrm{U} .\end{array}$} & \multirow{2}{*}{ 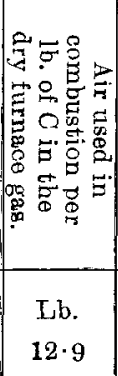 } & \multirow{2}{*}{$\begin{array}{c}\mathrm{T}-t . \\
\text { Fabr. } \\
640\end{array}$} & \multirow{2}{*}{ 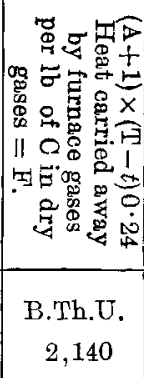 } & \multirow{2}{*}{ 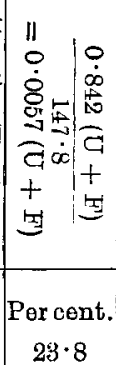 } & \multirow{2}{*}{ 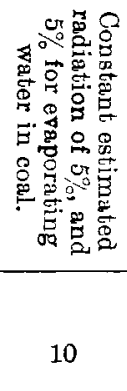 } \\
\hline & & $\begin{array}{c}\mathrm{O}_{2} \\
3 \cdot 17\end{array}$ & $\begin{array}{c}\mathrm{CO}_{2} . \\
11.67\end{array}$ & $\begin{array}{c}\mathrm{CO} \\
2 \cdot 93\end{array}$ & $\begin{array}{c}\mathrm{N}_{2} \\
82 \cdot 23\end{array}$ & & & & & & & & & \\
\hline 102 & $66 \cdot 5$ & $4 \cdot 44$ & $13 \cdot 03$ & $1 \cdot 13$ & $81 \cdot 40$ & 654 & $71 \cdot 1$ & $48 \cdot 40$ & 812 & $14 \cdot 7$ & 583 & 2,197 & $17 \cdot 1$ & 10 \\
\hline 103 & $42 \cdot 4$ & 5.38 & $12 \cdot 15$ & $1 \cdot 40$ & $81 \cdot 07$ & 562 & $78 \cdot 3$ & $67 \cdot 25$ & 1,050 & $15 \cdot 5$ & 484 & $\mathbf{1}, 916$ & $16 \cdot 9$ & 10 \\
\hline 105 & $77 \cdot 8$ & $5 \cdot 07$ & $11 \cdot 73$ & $1 \cdot 63$ & $81 \cdot 57$ & 691 & $70 \cdot 3$ & $47 \cdot 04$ & 1,240 & $15 \cdot 2$ & 621 & 2,413 & $20 \cdot 8$ & 10 \\
\hline 109 & $42 \cdot 6$ & $6 \cdot 00$ & $11 \cdot 97$ & $1 \cdot 08$ & $80 \cdot 95$ & 565 & $70 \cdot 7$ & $59 \cdot 92$ & 842 & $16 \cdot 2$ & 494 & 2,040 & $16 \cdot 4$ & 10 \\
\hline 110 & $22 \cdot 7$ & $7 \cdot 40$ & $11 \cdot 70$ & 0.07 & $80 \cdot 83$ & 561 & $75 \cdot 9$ & $78 \cdot 93$ & 61 & $18 \cdot 8$ & 485 & 2,306 & $13 \cdot 5$ & 10 \\
\hline 111 & $27 \cdot 8$ & $5 \cdot 96$ & $12 \cdot 90$ & 0.07 & $81 \cdot 07$ & 581 & $72 \cdot 5$ & $77 \cdot 45$ & 0.55 & $16 \cdot 8$ & 508 & 2,173 & $12 \cdot 7$ & 10 \\
\hline 112 & $56 \cdot 2$ & $3 \cdot 33$ & $12 \cdot 40$ & $2 \cdot 57$ & $81 \cdot 70$ & 656 & $74 \cdot 1$ & $55 \cdot 94$ & 1,750 & $13 \cdot 1$ & 582 & 1,969 & $21 \cdot 2$ & 10 \\
\hline 115 & $82 \cdot 1$ & $2 \cdot 20$ & $12 \cdot 43$ & $4 \cdot 53$ & $80 \cdot 84$ & 794 & $78 \cdot 1$ & $50 \cdot 59$ & 2,720 & $11 \cdot 5$ & 646 & 1,938 & $26 \cdot 5$ & 10 \\
\hline 116 & $71 \cdot 5$ & $3 \cdot 67$ & $12 \cdot 23$ & $3 \cdot 30$ & $80 \cdot 80$ & 722 & $73 \cdot 6$ & $55 \cdot 57$ & 2,160 & $13 \cdot 0$ & 648 & 2,179 & $24 \cdot 7$ & 10 \\
\hline 117 & $84 \cdot 6$ & $6 \cdot 90$ & $9 \cdot 75$ & $2 \cdot 25$ & $81 \cdot 10$ & 726 & $78 \cdot 6$ & $48 \cdot 69$ & 1,910 & $17 \cdot 10$ & 647 & 2,813 & $26 \cdot 9$ & 10 \\
\hline 118 & $70 \cdot 1$ & $3 \cdot 60$ & $11 \cdot 70$ & $4 \cdot 13$ & $80 \cdot 57$ & 685 & $82 \cdot 2$ & $53 \cdot 15$ & 2,660 & $12 \cdot 70$ & 603 & 1,980 & $26 \cdot 4$ & 10 \\
\hline
\end{tabular}


TABLE-(continued).

\begin{tabular}{|c|c|c|c|c|c|c|c|c|c|c|c|c|c|}
\hline \multirow[b]{2}{*}{$\begin{array}{l}\text { Trial No. } \\
\text { in the } \\
\text { St. Louis } \\
\text { Reports. }\end{array}$} & \multirow{2}{*}{ 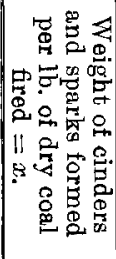 } & \multirow{2}{*}{ 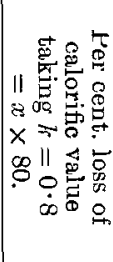 } & \multirow{2}{*}{ 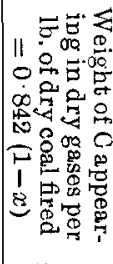 } & \multirow[b]{2}{*}{$\begin{array}{c}\text { Coal } \\
\text { fred } \\
\text { per } \\
\text { min. }\end{array}$} & \multirow{2}{*}{$\begin{array}{c}\text { Calorific } \\
\text { value } \\
\text { of } \\
\text { coal } \\
\text { per } \mathrm{lb} .\end{array}$} & \multirow{2}{*}{$\begin{array}{c}\text { Heat } \\
\text { corre- } \\
\text { sponding } \\
\text { to } \\
\text { coal fired. }\end{array}$} & \multirow{2}{*}{$\begin{array}{l}\text { Heat } \\
\text { actually } \\
\text { produced } \\
\text { in boiler } \\
\text { per min. }\end{array}$} & \multirow{2}{*}{$\begin{array}{l}\text { Heat } \\
\text { produced } \\
\text { in boiler } \\
\text { per lb. } \\
\text { of coal } \\
\text { fired. }\end{array}$} & \multicolumn{4}{|c|}{ Per cent. per lb. of dry coal fired. } & \multirow{2}{*}{ 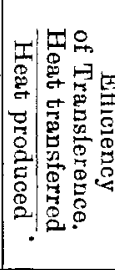 } \\
\hline & & & & & & & & & 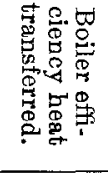 & 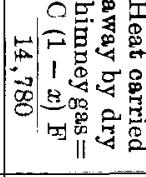 & 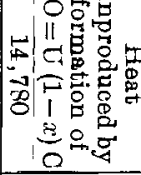 & $\begin{array}{l}\text { Loss by } \\
\text { cinders } \\
\text { and } \\
\text { sparks. }\end{array}$ & \\
\hline 101 & $\begin{array}{c}\mathrm{Lb} . \\
0.37\end{array}$ & $\begin{array}{c}\text { Per cent. } \\
29 \cdot 6\end{array}$ & $\begin{array}{c}\mathrm{Lb} . \\
0.53\end{array}$ & $\begin{array}{l}\text { Lb. } \\
71 \cdot 0\end{array}$ & $\begin{array}{r}\text { B.Th.U. } \\
14,780\end{array}$ & $\begin{array}{l}\text { B.Th.U. } \\
1,000,600\end{array}$ & $\begin{array}{l}\text { B.Th.U. } \\
630,000\end{array}$ & Percent. & $\begin{array}{c}\text { Percent. } \\
45 \cdot 4\end{array}$ & $\begin{array}{c}\text { Per cent. } \\
7 \cdot 7\end{array}$ & $\begin{array}{c}\text { Per cent. } \\
8.0\end{array}$ & $\begin{array}{c}\text { Percent } \\
29 \cdot 6\end{array}$ & $0 \cdot 72$ \\
\hline 102 & 0.39 & $31 \cdot 2$ & 0.51 & $54 \cdot 5$ & - & 811,900 & 528,000 & $66 \cdot 0$ & $48 \cdot 4$ & $7 \cdot 6$ & $2 \cdot 8$ & $31 \cdot 2$ & 0.73 \\
\hline 103 & 0.09 & $7 \cdot 2$ & 0.77 & $34 \cdot 8$ & - & 492,200 & 430,000 & $87 \cdot 4$ & $67 \cdot 2$ & $10 \cdot 0$ & $5 \cdot 4$ & $7 \cdot 2$ & $0 \cdot 77$ \\
\hline 105 & 0.37 & $29 \cdot 6$ & 0.53 & $63 \cdot 7$ & - & 941,800 & 624,000 & $65 \cdot 9$ & $47 \cdot 0$ & $8 \cdot 6$ & $4 \cdot 4$ & $29 \cdot 6$ & $0 \cdot 71$ \\
\hline 109 & $0 \cdot 21$ & $16 \cdot 8$ & $0 \cdot 66$ & $34 \cdot 9$ & - & 494,000 & 389,000 & $79 \cdot 4$ & $60 \cdot 0$ & $9 \cdot 1$ & $4 \cdot 3$ & $16 \cdot 8$ & $0 \cdot 76$ \\
\hline 110 & -0.03 & 0 & $0 \cdot 84$ & $18 \cdot 6$ & 一 & 262,500 & 262,000 & $99 \cdot 7$ & $79 \cdot 0$ & $13 \cdot 1$ & 0.34 & 0 & 0.79 \\
\hline 111 & -0.02 & 0 & 0.84 & $22 \cdot 8$ & - & 319,500 & 319,000 & $99 \cdot 7$ & $77 \cdot 4$ & $12 \cdot 4$ & $0 \cdot 3$ & 0 & $0 \cdot 78$ \\
\hline 112 & $0 \cdot 22$ & $17 \cdot 6$ & 0.66 & $46 \cdot 1$ & - & 656,900 & 490,000 & $74 \cdot 6$ & $55 \cdot 9$ & $8 \cdot 8$ & $7 \cdot 8$ & $17 \cdot 6$ & $0 \cdot 75$ \\
\hline 115 & $0 \cdot 24$ & $19 \cdot 2$ & 0.64 & $67 \cdot 4$ & - & 951,400 & 650,000 & $68 \cdot 0$ & $50 \cdot 6$ & $8 \cdot 4$ & $11 \cdot 8$ & $19 \cdot 2$ & 0.74 \\
\hline 116 & $0 \cdot 18$ & $14 \cdot 4$ & 0.69 & $58 \cdot 5$ & - & 807,000 & 601,000 & $75 \cdot 5$ & $55 \cdot 6$ & $10 \cdot 2$ & $10 \cdot 1$ & $14 \cdot 4$ & 0.74 \\
\hline 117 & $0 \cdot 27$ & $21 \cdot 6$ & 0.61 & $54 \cdot 4$ & - & $1,016,700$ & 717,000 & $70 \cdot 5$ & $48 \cdot 7$ & $11 \cdot 6$ & $7 \cdot 9$ & $21 \cdot 6$ & 0.69 \\
\hline 118 & $0 \cdot 20$ & $16 \cdot 0$ & 0.59 & $57 \cdot 4$ & - & 851,300 & 629,000 & $73 \cdot 4$ & $53 \cdot 1$ & $7 \cdot 71$ & $11 \cdot 1$ & $16 \cdot 0$ & 0.76 \\
\hline
\end{tabular}


furnace efficiency separately from boiler efficiency. As given in the ordinary way, the boiler efficiency usually combined two efficiencies - the furnace efficiency and the efficiency of transmission.

The writer had similar data for a large number of trials, and had found that, generally speaking, however widely the conditions of working varied, the locomotive boiler would transmit about 75 per cent of the heat actually produced by combustion to the water. He hoped that now that big railway amalgamations were taking place, the new Companies growing from the ashes of the old ones would see that it was to their advantage to have a proper research laboratory put down for the common use of them all, suitably equipped and staffed so that an engine could be sent there, tested, and reported upon.

Lieut.-Colonel L. F. R. Feld, D.S.O., O.B.E., R.A.F. (Directorate of Research, Air Ministry), wrote that, having left locomotive engineering for aerial locomotion, it was extremely interesting to note to what extent the wide developments in engineering due to the manufacture of aviation engines had been applied in the design and construction of locomotives. He ventured to suggest, however, that there were even more lines of development brought about by aircraft engineering which might be applied.

With regard to the selection of materials, on page 386 , for instance, the difficulties in maintaining frame bolts tight was mentioned. This, as the writer knew, was practically the determining factor in the life of an engine, for, if the frame bolts came loose, the holes became enlarged beyond the size that was possible to reamer them. out any further to fit new bolts, and, therefore, the frames were scrap. Aviation had made commercially possible 60-75 ton steels, and there seemed no reason why such materials should not be employed in locomotive building.

On page 387 the white-metalling of axle-boxes was referred to. It was considered that aviation experience could be of great assistance here. An aero-engine big-end metalled on the lines which he was accustomed to see before leaving the railway would not last half an hour. It was considered that the majority of failures of axle-box white-metalling was due to the composition of the metal having been destroyed before pouring, by overheating. In white-metalling the big-ends of aeroplane engines-which, though not very much more heavily loaded than locomotive bearings, ran at a higher temperature and without the benefit of the air-cooling which all locomotive bearings got-it had been found that the temperature at which both the tinning was done before running in 
the white-metal, and the temperature at which the white-metal was maintained before pouring, must be within a few degrees of the correct one, generally $320^{\circ} \mathrm{C}$., in order to get any life from the bearing. It had also been found that there was no necessity to have a great thickness of white-metal, as was so frequently the case with locomotive axle-boxes. It would be interesting to know whether bearing failures had ever been investigated from this standpoint.

On page 411 the weight of valve-gear motions was referred to, and in order to maintain the valve-setting correct, it was necessary that all pins should be a very good fit ; it was almost always necessary to lap out all holes and renew all pins at each overhaul. It was suggested that this trouble could be entirely overcome by fitting ball-bearings throughout.

The necessity for reducing the weight of piston-heads was referred to (page 412), and it was suggested that aircraft experience could be applied in this direction. Recently a single-cylinder unit engine had been constructed for the Air Ministry of 12-inch bore, pistonspeed 2,000 feet per minute, and, as the engine, which was of the ordinary four-stroke cycle, had a horse-power of 220 , the piston received a 20 -tons blow at each power stroke. When detonation was taking place, this blow was considerably heavier. As would be expected, considerable trouble was experienced with the piston, and no form of cast aluminium, which had previously been a standard material for such work, was found able to stand up to the work.

A new aluminium alloy had, however, been produced with nickel, magnesium, copper contents. When forged, this alloy had a tensile strength of 22 tons with a fine close structure. The forging process was perfectly simple, and could be carried out by any engineer equipped with hammers of the necessary capacity. The material had to be worked to a very fine temperature range, but, provided attention was paid to this, no other difficulties presented themselves. The specific gravity of this material was $2 \cdot 75$, that is, 10 per cent lighter than ordinary aluminium, against a specific gravity of steel, $7 \cdot 85$. It was not thought that the tensile strength of the steel castings, now largely adopted for English locomotives, was much above 22 , so that the design could be practically identical. He thought that this material could with very great advantage be adapted for locomotive pistons.

Another interesting point regarding the 12-inch cylinder mentioned above was that the piston-rings were also made from the same material as the piston, as no cast-iron rings which were tried would ever stand up for more than about half an hour's running. So far it had been found impossible to break one of these forged 
aluminiun rings; in fact, forged rings were fitted to one of the east aluminium pistons tried before the forged one was made up. In this case the piston was completely disintegrated inside the cylinder, but the piston-rings remained absolutely intact, except for the fact that they were slightly bent inside the cylinder.

With regard to lubrication (page 416 ), it had always appealed to the writer that the ordinary worsted trimming fitted to the locomotive was, to say the least of it, a most unsatisfactory fitting. A bad feature of the trimming was that if, when an oil cup was full, it was so designed that it gave twenty drops per minute, when the oil had dropped an inch in level, that same trimming would only deliver about one drop every two minutes. The trimming, therefore, was responsible for a wastage of oil, which, on the face of it, would appear to be at least 50 per cent of the total quantity used; for if the bearings would run satisfactorily, as apparently they did, with one drop every two minutes, at no time did they require twenty drops per minute; also, the worst lubrication was obtained at the end of the run, when the best lubrication was, of course, most desirable. It would be very interesting to know whether any satisfactory scheme beyond the fitting of a inechanical lubricator of the Wakefield or other type had been tried with successful results.

Mr. J. W. Hobson (R. and W. Hawthorn Leslie and Co., Ltd.), wrote that it was rather surprising to find that the Author stated (page 378 ) that bar-frames were as rigid vertically as the plate-frames. However, when dealing with the subject in more detail (page 384), he modified this statement considerably. With regard to boiler power, actual experience had shown that ample boiler capacity and economical fuel consumption went hand in hand, but at the same time there was undoubtedly something to be said for the employment of large cylinders and early cut-offs to obtain economy. In this connexion it was interesting to note that in a recent design of 2-10-0 locomotive of large proportions for the Pennsylvania Railroad, the cylinders were purposely made of large capacity and the cut-off arranged so that the maximum was about 50 per cent of the stroke.*

Locomotives with three or four cylinders did not as yet appear to have met with much favour in the United States, though it was gratifying to find that the advantages of the three-cylinder locomotive were being realized in British practice and on certain railways in South America. There was no question that the even turning-moment

* Engineering, 22nd and 29th October, 1920. 
of the three-cylinder engine was a decided advantage, especially where the adhesive factor was low. The nosing of outside cylinder locomotives was more pronounced than that of inside cylinder engines, on account of the greater distance from the centre line of engine to the centre line of cylinder in the case of the former. Stronger bogie-control-springs and longer wheelbases reduced this effect considerably, but the fact remained that the locomotive with inside cylinders would always be steadier in motion. The two main features in favour of outside cylinders were (1) accessibility, (2) abolition of the crank-axle; and for all but the fastest services these advantages outweighed the disadvantage of greater oscillation.

Compensating gear was not usually used in English practice, not because its advantages were not recognized, but because the excellent track in this country rendered it unnecessary. It might be worthy of note that compensating gear was invented by Messrs. R. and W. Hawthorn, of Newcastle, in 1851, and its merits were quickly appreciated, particularly in America.

With regard to material for fire-boxes, it was interesting to note that the Author preferred copper, especially seeing that experience on the Central Argentine Railway seemed to favour the use of steel.* In any case, however, it was largely a question of quality of water used. American opinion as to the advantages of arch tubes appeared to be divided. They seemed analogous to Mr. Drummond's watertubes formerly used on the London and South Western Railway. These had been discarded by his successor. It was surprising to find that superheater dampers were advocated, as the whole trend of modern British practice was to discontinue their use.

The balanced form of slide-valve was commonly used in British practice prior to the extensive use of piston-valves. Many engineers, however, did not favour it on account of the considerable opportunities presented by some types for allowing live steam to escape direct to the blast-pipe, and types of valves which relied mainly on springs and asbestos packing to prevent live steam passing had a decided tendency to become unbalanced after a few weeks' wear.

Mr. F. J. Hoокнам wrote that he would like to discuss the paragraph "Lubrication" (page 416) briefly, on the question of consumption, more especially as it furnished one of the few examples of quantitative comparison for which one speaker expressed a

* Deakin's Paper, Soutb American Section of the Institution of Locomotive Engineers, at Perez. 
desire. The total consumption figure for a large American engine of twelve wheels with eight-wheeled tender (twenty axle-boxes) was equivalent to 4.8 pints per 100 miles expressed in the unit generally used for comparison. Unfortunately, conditions were not stated, but if this referred to actual issues to the driver it appeared good practice. Sir Henry Fowler stated that his locomotives could do with 66 per cent of this figure (about $3 \frac{1}{4}$ pints per 100 miles) but possibly on fewer axle-boxes. If, on the other hand, the figure referred to the average obtained by dividing consumption over a period by engine-miles worked, for a number of engines, it was a very favourable figure, and showed at least one point in which the American practice was ahead of British. The monthly figures furnished for sixteen British railways in the Ministry of Transport railway statistics went to confirm this. The Midland Railway, which had the lowest consumption, used 5 pints per 100 miles, but the average was about $7 \frac{3}{4}$ pints, running as high as $10-11$ in one case. These figures were influenced by waste and losses arising out of the methods of working in this country at present, and were probably considerably in excess of the net actual requirements of the locomotive.

Mr. H. G. KING wrote that about twenty years ago the Great Central, Great Northern, and Midland Railways each ordered a batch of six-coupled goods-engines, from America, with a more or less free hand as regards design. These engines were of the 2-6-0 type, having outside cylinders, bar-frames, and compensating arrangements in the spring rigging. They presented an excellent opportunity for comparison with British-designed standard sixcoupled goods-engines of equivalent power. Under identical traffic conditions the American engines burned 25 per cent more coal. All fire-boxes were of copper, having a grate area of only $16 \cdot 7$ square feet in the American engines and 17.8 square feet in the standard British engine. The life of the fire-boxes averaged only eighty-eight months as against 126 months respectively. The comparatively short life of the American box was no doubt due to this restricted grate area consequent upon the bar-frames. The area of fire-grate was limited by narrow fire-box and bar-frames to about 25 square feet, and with plate-frames an area of 28 square feet could not be exceeded without the adoption of the wide fire-box resting on top of the frames.

American engines were bujlt primarily for rapid production and short life. In the case of the engines here quoted the entire batch had been broken up some five or six years ago, whereas the British 
engines were still doing excellent service, but were of too small a power to meet modern conditions, and had recently been rebuilt with new boilers, cylinders, etc., thus virtually constituting entirely new engines. In the light of modern practice the system of building engines for a useful life of ten years instead of forty years appeared to be warranted when the lower capital cost was considered, especially in the case of freight and suburban engines. It was of interest to learn that fusible plugs were omitted from most Canadian and American engines, and that at least one of the locomotive superintendents in this country agreed with this practice. In the writer's opinion the fusible plug was responsible for far more failures than were avoided by their adoption.

The AurHor wrote that he wished to express his keen appreciation of the very kind manner in which his Paper had been received at the various Meetings, his regret at being unable to present the Paper in person, and his thanks to Lieut.-Colonel Kitson Clark, Sir Henry Fowler, and Mr. T. H. Brocklebank for stepping into the breach and presenting the Paper so ably. The discussions proved that the steam-locomotive still held possibilities of further improvement and usefulness, notwithstanding the strides made in electric traction. One noteworthy feature observable in the discussions was that almost without exception where a speaker had disagreed with a statement or opinion given in the Paper, another speaker or speakers had referred to the same point as one with which he or they particularly agreed. In this sense certainly, as mentioned by Colonel Kitson Clark, the Paper might almost be said to have answered itself.

As in many cases similar points were referred to by more than one speaker, the Author had endeavoured to group some of his replies, and therefore, although a number of speakers were not mentioned, their points were incorporated in replies to others on the same subject.

Preliminarily, the Author would point out in connexion with remarks by Sir Henry Fowler and others as to whether his (the Author's) object was to bring forward the difficulties he had experienced with British and American locomotives respectively or to discuss the different practice of the two countries, that the object was to compare the average practices of the two countries, based principally on personal experience of the difficulties encountered with earh-which was the negative, and undoubtedly the best, method of comparison-at the same time leaving out as far as possible special or abnormal features. This also applied to the remarks of 
Mr. Sanderson and Major Cowan as to the Author not having made comparison with the most up-to-date-that is, large-American locomotives.

The same object had been kept in view in comparing details and in regard to certain items mentioned by Captain Beames and Mr. Hookham, as being instances where details referred to in the Paper as American were in use on certain British railways, such as axle-box, hub-liners, round-topped axle-boxes, etc., together with a number of important features mentioned by Mr. Bulkeley as now standard on the Great Western Railway; these were exceptions to the general British practice. As to most of the itemsparticularly many on the Great Western Railway-they formed cases specially referred to in the Paper as items of practice transplanted from one country to another.

Before proceeding to reply to the various speakers, the Author wished to amplify the opening remarks of Lieut.-Colonel KitsonClark in regard to the rigidity, or otherwise, of the plate-frame. He (the Author) had explained in detail elsewhere that he had no intention of suggesting that plate-frames should accommodate themselves to the curvature of the railway; that practice, he considered, would he fundamentally wrong. Whilst, however, it was true that a pair of plate-frames properly assembled and connected across by the various castings and cross-stays were theoretically a rigid box-form structure, yet anyone who had dealt with axleboxes and horns, or closely watched engines running at speed would be aware that plate-frames did "give" near the horns, particularly at the lower part; this was most pronounced in inside-cylindered engines, and was due to the impossibility of locating cross-stays nearer together than the motion-plate, and in the front and rear of the fire-box.

In reference to the remarks of Sir Henry Fowler respecting the difficulties confronting the prospective users of larger locomotives and wagons (page 426), the Author realized these difficulties, but hoped that it would be found possible under the new grouping of railways to accelerate the work of strengthening the bridges where necessary.

The Author appreciated the position taken up in respect to basic steel, that if it were correctly made and therefore proper material, it could be used for any purpose, and the instances of successful flanging were valuable guides; he noted that cross-stays and other parts up to three-quarters of an inch thick were flanged with ease. His view was that while basic steel was satisfactory in a general way, yet for boiler work he preferred what might be described as the extra security of acid steel. 
The experience with steel fire-boxes on the railway with which Sir Henry was connected appeared to have been a bad one, and the Author could only imagine there was some specially adverse condition causing such results. On the point of whether British coal was more severe than American on steel fire-boxes, he could say that, whilst for about eight years before the War, Welsh coal was extensively used on the Author's railway-and had recently been reverted to-during the years 1914-20 American (bituminous) coal was employed, and no difference in the effects on fire-boxes had been observed. The Author was surprised to learn that the casualties with steel tubes (in copper fire-boxes) had been found so excessive on the Midland Railway. He had always felt that owing to the ductility of the metal, copper tubes in copper fire-boxes should give less trouble from leaking-although probably at the cost of considerable "breathing " and distortion of the tube-platethan any other combination, but a freedom from leakage factor of 30 to 1 in favour of copper tubes appeared altogether greater than would be expected.

The method in vogue on the Midland Railway of reheating fusible plugs in a muffle was clearly a further improvement in dealing with this small but important detail. In regard to a fixed flange being disadvantageous in the superheater joint attachments, he (the Author) would point out that the spherical-cone joint mentioned in the Paper allowed considerable liberty in alignment, due to the design of the joint itself and to that of the clip. Belpaire fire-boxes were heavier than the round-topped pattern, reducing by that extent the boiler power which could otherwise be obtained. Flat crowned inside fire-boxes were unsuitable for lines with much curvature-and therefore super-elevation in the track-and, in any event, he considered no fire-box crown should be flat transversely nor horizontal longitudinally.

Before dealing with the points raised by Mr. Sanderson (page 429), it was necessary to state that his suggestion of lack of size and modernity of the American pattern locomotives used on the Jamaica Railways was hardly correct, inasmuch as the majority of such locomotives under the Author's control weighed from 105 to 109 tons (British) engine and tender, had a greater hauling capacity than the average locomotives in use in Great Britain, and had been constructed since 1919; they could hardly be described as small, and in respect to modernity it seemed reasonable to consider engines built within the last two years or so as representing recent American practice.

The Author also observed that many of the details of American 
practice adversely criticized in the Paper were stated to be now obsolete; these cases of course supported his (the Author's) views, although it appeared that details which had become obsolete in the United States continued to be supplied from there to other countries. In regard to Mr. Sanderson's statement that the latest American practice was for the railway mechanical staff to design their engines in detail, this was considered a great step in advance and fully bore out the advocacy of that method in the Paper. He was fully aware that the American builders would build strictly to drawings - of American, British or any other pattern-when specially required to do so, but the cost and time of delivery of such railway-designed. engines were usually greater and longer than where the usual (old) practice was followed.

The Author employed the method of setting-in the front and back tyres on engines with leading pony-trucks, but the mileage obtained before wheel flanges needed attention was only 40 per cent of that obtained when a leading bogie was followed by a flangeless wheel. The reasons given by Mr. Sanderson for the small use made of tank-engines in the United States were realized, but he (the Author) did not see why, for the lesser shunting duties, efforts were not made to develop a one-unit shunting engine; it would, he thought, in many such cases be found that a margin existed for more weight on the engine-axles, and this could be taken advantage of by transferring part of the water-carrying capacity of the tender to sidetanks, and the remainder, together with the fuel, to a rear tank producing a 2-8-4 tank-engine.

The reference to plate-frames as having an advantage due to a certain amount of lateral elasticity or "give" appeared to have conveyed the impression that he (the Author) meant that such frames would accommodate themselves to the curvature of the railway. What he referred to was perhaps better described as resiliency and was apparent when entering a curve at speed, the lateral checking of the plate-framed engine being quite different to, and in his (the Author's) opinion, much less injurious to both engine and track than the dead slam of the bar-frame.

The reason for the prevalence of the trailer-truck or idle rearaxle type of engine was clearly demonstrated by Mr. Sanderson in relation to very large engines (which engines however were excluded from the remarks on the subject in the Paper), but in respect to the cases of medium size engines and the engines of a few years ago the Author considered his remarks still held good. Even in presentday practice it was significant that the Pennyslvania Railroad had adopted the 2-10-0 type in preference to the 2-10-2, and obtained 
very many improved efficiency factors thereby, thus indicating that the idle trailing wheel would be generally eliminated if it could be.

Regarding the correctness or otherwise of the Author's reference to the American practice being to place side-liners on axle-boxes, a glance at a late edition of the American "Locomotive Dictionary" showed that almost without exception side-liners were shown on the axle-box ; certainly it was also common practice to use liners on the hubs, but the principle of taking up the side-thrust was the same as given in the Paper. He was surprised to see it stated that there would not be many bogie-frames of the type mentioned in the Paper on engines of recent design in main line service; he thought it would be found that 90 per cent to 95 per cent were of that type; on referring to this subject in the same authoritative work on American locomotives mentioned above, it would be found that the whole of the twenty-seven bogie-frames shown therein were of the top-rail type. The latest development of the "Hodges" trailing truck referred to by Mr. Sanderson as having been omitted was referred to in the section of the Paper on that subject. Mr. Sanderson had also apparently misread the remarks in the Paper in which it was stated that the Great Western Railway "coned." type boiler came into vogue about the time that its prototype, that is the old extendedwagon-top boiler, went out of favour.

The Author did not agree that welding the seams in fire-box crowns was not (as long as the stays held) a source of danger by becoming disconnected in case of shortage of water and overheating. Whilst the plates were connected entire, the tendency to draw off from the stays was direct-and cases occurred where the crownplate drew away from forty or fifty stays and formed an exaggerated bulge, the vacant stay-holes relieving the pressure in the form of a somewhat modified explosion; whilst if the seams gave out, the plate would tear away from each row of stays successively and fold back in the same manner that all sheet metal would when its continuity of surface was cut. It was interesting to have further explanation of the reasons for abandoning the circulating tubes in America.

Finally, in regard to the bushes in coupling-rods, he (the Author) would point out that they were inserted under pressure everywhere, but nevertheless worked slack occasionally in heavy service, and then the method of security fastening became of first importance.

In reply to Captain Beames (page 434), the Author would say that the advantage of recentring wheels under an engine allowed by detachable shoes and wedges, was a real advantage where lifting and drop-pit facilities were scarce. It was interesting to learn that 
experiments had shown that engine-frames extended between the horns, and that allowance was made on the London and North Western Railway for this, by making the coupling-rod centres correspondingly longer. Another reason for making the centres of coupling-rods slightly longer than the distance between the centres of the horns was that owing to the height of the axle-boxes in the horns continually varying when running, due to the irregularities of the line, the actual distance between centres of coupling-pins would frequently become greater than the nominal distance although (neglecting the effects of slipping) it could not become less. Hence an allowance, approximately $\frac{1}{32}$ inch extra length was given on the rod.

The Author regretted he could not give personal experience with the Nicholson thermic siphon system, nor had he any definite reports as to its success in everyday service; from a study of its methods of application, however, he observed that a considerable amount of electric welding took place in its installation, in fact it appeared that only electric welding brought it within the bounds of practical maintenance, and for reasons stated in the Paper he did not consider such welding was desirable in fire-box crowns.

In reply to Mr. Hookham (page 437), the Author would refer to what he had already written on the same point in reply to Mr. Sanderson, that is, his purpose was to compare the general practice of each country and naturally there were cases similar to those mentioned where details coincided. He appreciated the argument that the flat-topped shell should give some amount of freedom to the rise of the fire-box, but would point out that if this rise were of any appreciable extent it must mean the crippling of the roofstays by bending, and the early destruction of the upper rows of side stays by side flexure. He did not consider any fire-box should have an absolutely flat top for service reasons, and by slightly curving the crown, having well rounded shoulders and radial staying, the Author considered the best solution was reached.

The Author realized the original reason for the pilot-valve in the sliding type regulator having been that of relieving pressure off the main valve and so allowing it to be opened gradually, but as stated in the Paper all regulators were susceptible of gradual opening with proper leverage, and this applied particularly to the double-beat type which could be designed with just sufficient bias to close it if any failure of gear took place. The American practice in regard to superheater dampers was invariably to use them; at the same time their recent practice had been to omit cylinder by-pass valves entirely.

Mr. Hookham had read into the Paper the curious idea that it supported an attempt to remedy weak frames by supplying 
weak coupling-rods; what the Author considered he had made clear was that it was possible to overdo the lateral rigidity of the rod, so easily obtained by the I section, compared with the flat plate-frame. In respect to levers being predominant on goods engines, he believed it would be found that the majority of goods engines in Great Britain were so fitted. Regarding the manufacture of bar-frames, these were now always steel castings; any other method was out of date and did not affect the question.

The Author agreed that it was a question whether any method of securing tyres was necessary; as stated by Mr. Hookham, the lip on the outside of the tyre prevented it coming off on the inside and the flange prevented it coming off on the outside. Mr. Hookham appeared to have a rather limited view of the duties of the set-screws ; the Author considered the primary reason for these was to prevent any part of a broken tyre from flying off a wheel at speed by centrifugal action. In regard to the prevention of lateral movement of tyres on wheel-centres, since writing the Paper the Author had adopted the simple expedient of electrically welding a small "hump" at four places on the protruding inside (wheel centre seat) part of the tyre after shrinking on to the wheel, so that it was impossible for a tyre to come off outwards even without regard to the flange keeping it on the rail; this method together with the lip on the outside surmounted all difficulties arising from tyres becoming loose.

In reply to Mr. Chorlton (page 440), the Author was in agreement with him that it was possible to overdo the large boiler principle under certain circumstances, but considered it hardly possible to do so in regard to locomotives for modern main line loads and services under the restrictions of the British loading gauge. Ample grate area, by allowing steam to be maintained with a soft blast, was economical by reason of better combustion generally; on the other hand, whenever the demands were appreciably less than the area of grate was designed to cope with, there was difficulty in preventing "blowing-off," and in the case of standing-in-steam the losses were correspondingly greater.

Regarding the use of special steels-generally heat-treatedfor the purpose of reducing the unbalanced forces by lightening the reciprocating and other parts, in England Mr. Gresley had given particular attention to connecting-rods and coupling rods, etc., whilst in America the Pennyslvania Railroad had dealt with the lightening of the motion parts, the employment of hollow pistonrods, etc., and the Philadelphia and Reading Railroad had a number of express locomotives in service with hollow axles. 
The remarks of Mr. Twinberrow (page 441), in connexion with lateral oscillation and the effect of equalizing on the longitudinal trim of a locomotive were a valuable addition to the Paper. With regard to the application of equalizers connected throughout each wheel-base when two (unsymmetrical) wheel-bases were under a single superstructure, however, the Author must differ ; the principle which applied to a group of wheels under a single superstructure also applied to the other case, and he considered dependence should not be placed on fore-and-aft steady plates to correct the pitch allowed by continuous equalizing. The Author had not previously viewed the outside running-plate as a girder stiffener preventing lateral deflections of the plate-frame, and still doubted its effectiveness as such-principally for the reason that its position was generally at the top of the frame, some distance above the axle centres in the case of goods engines, and owing to 50 to 60 per cent of it being cut away in the case of passenger engines.

In respect to "nosing," the Author's experience was that all outside cylinder engines " nosed" at comparatively low speeds, and that the possibility of such taking place was due to the cumulative effect of various small clearances, such as that between the wheelflanges and the rail gauge, axle-box side play on journals and in horns, etc.; he had found it much less on engines with the lateral movement of the bogie centre controlled by three-point suspension hangers, and was inclined to agree that for high speeds the Adams bogie control was the best, but in the case of engines working excessively curved lines he considered the swing link with doublesuspension (or three-point) hangers was far more effective and safe. Such hangers did not allow engines to "hunt" at high speeds on comparatively straight track, the weight keeping the hangers down in contact with both of each pair of top pins, until a curve of sufficient severity caused the equilibrium to be upset.

The Author agreed with Mr. Fanghaenel (page 445) in his remarks regarding methods of erection of American locomotives, also in regard to the weaknesses and points of fracture in plate and bar frames mentioned by him. He considered the distance-piece and bolts provided the most effective horn-stay, although an adaptation of the usual American pattern was promising when it could be got in.

Wash-out plugs were not mentioned in the Paper, and Mr. Fanghaenel was correct in emphasizing their importance; the Author had additional wash-out holes placed in the barrels of his boilers, near to each tube-plate and at a suitable height to enable a light to be inserted in the corresponding hole on the opposite side of the boiler, so that the exact state of cleanliness or otherwise of the 
tubes near their entrance into the tube-plates might be observed, and that this most important place might be readily got at by the washing-out jet. In respect to the question as to how the lower tubes were got out with the small door smoke-box, it was pointed out in the Paper that American smoke-box fronts were bolted on and easily detachable, being taken off when work of any extent was to be done in the smoke-box.

In reply to Mr. Watson (page 447), mechanical stoking was briefly referred to in the Paper, but no comparisons were made for the reasons as stated, that the British loading gauge and necessities did not call for the use of such a device. In respect to dealing with clinkers, etc., rocking grates broke up the clinker and drop plates enabled it to be cleared from the fire-box in a few minutes and without waiting until the end of the run. In regard to special types of boilers, the only special pattern referred to in the Paper was the Wootten, the reason being that there was no special type characteristic of British practice. The abolition of the water-space feature for fireboxes mentioned by Mr. Watson did not appeal to the Author at all, the sacrifice of the comparatively direct transmission of radiant heat in the ordinary fire-box, which was much more effective than tube heating surface, seemed a most serious loss.

From the items enumerated by Mr. Bulkeley (page 448), the Great Western Railway had evidently adopted a considerable number of American features, the majority of them good ones. The Author agreed that a long valve-travel gave opportunity to produce a very free running engine; there was however a stage where excessive friction would develop.

The experiments with blast-pipes, etc., mentioned by Mr. Renwick (page 450), went to support the views of the Author that a low blastpipe-providing it and the chimney were set dead true-gave the best results. The Author's engines were all equipped with rocking grates and drop plates-and he had adopted a system of waterflush for such cases where ash-pans had side surfaces not far removed from horizontal in places ; this was effected by leading the overflow from each injector to each side of the ash-pan, discharging in the direction desired; the system cooled off and flushed out the ash-pan whilst running if necessary.

In reply to Mr. Clayton (page 451), it was not supposed that individual axle-weights were the difficulty in respect to using heavier locomotives, but that the concentration of the load on a few axles produced an excessive weight-per-foot-run, hence the suggestion of using more axles as a method of resolving some of the bridge difficulties in the case of bridges 10 to 25 feet long, which 
it was understood were the principal obstruction. There was also no intention of suggesting that the bridge question affected the adoption of higher capacity wagons.

The effect of compensating on engines with few axles was mentioned in the Paper, but in regard to the other cases he found the system excellent; the 4-8-0 type engines referred to as equalized by the Author had given trouble for years by derailments, which the equalizing completely stopped; no compensation should be installed "throughout." Referring to the staying of round-topped fire-boxes, modern boilers with such fire-boxes were stayed radially, other methods being incorrect.

The Author could not agree that the cross-movement regulator handle could be made so convenient as the pull-out type, and in respect to the suggested lack of safety of the latter, that was a question of proper design and maintenance.

Most of Major Cowan's remarks (page 456) were anticipated by Mr. Sanderson and were referred to in the reply thereto. In regard to the point that on the large American pattern engines, the shoes and wedges could be, and sometimes were, made with much larger wearing surfaces than the dimensions given by the Author; that was correct, but the Author's comparisons were made between engines of approximately the same capacity.

The particulars of application and service results of floating bushes for connecting and coupling-rods were particularly interesting to the Author, on account of the extremely difficult curvature conditions his locomotives had to meet. He had found the simple method of allowing considerable side-play of bushes on crank-pins to be very successful, as much as $\frac{5}{8}$ inch in some cases.

Major Williams (page 458) appeared to have slightly misread the Author's meaning in reference to the American system of design; the intention was to make clear the advantages of the British system of builders working to detail drawings provided by the purchasing railway. It did not follow that because detailed drawings were sent to American builders that they must be of British design; they might be of entirely American or - as the Author considered preferable-a combination of the best features of each. He was convinced that the best method was for the railway detailed design to be worked to; the question of workmanship did not affect the question in that regard. Rapidity of delivery was very desirable, but might be at the expense of future maintenance costs. With regard to the American builders' custom of sending a representative to supervise the erection of engines abroad, the Author knew of cases abroad where distinct harm had been done to the prestige 
of British locomotives from the want of such a representative on the spot at the time the engines were erected and put into service. All engineers knew that, despite every care, small difficulties arose occasionally, both in erection and in preliminary service of locomotives.

In reply to Professor Baker (page 460) the Author would point out that the question of couplings and brakes could not be allowed to stand in the way of the adoption of heavier trains and locomotives. The question of running vehicles of considerably different capacities was, however, a more difficult one; the Author from experience was aware that considerable risk was incurred in so doing with vehicles having much less variation than the 20 tons and 100 tons mentioned.

With reference to the remarks of the President (page 461), the American pattern spark-arresters were very efficient; of course, it was true that no spark-arrester would prevent every spark, however small, from escaping, and it was equally true that a sparkarrester which was effective impeded the draught to some extent. The wire-mesh netting employed by the Author had $\frac{1}{4}$-inch holes, and the engines passed through cane fields, etc., which were very inflammable at most times.

With regard to the Discussion at the Manchester MeEting, the Author noted the success that had been attained by Mr. Robinson (page 462) with the expanded type of superheater unit joint, but conld assure him that it was quite unnecessary to follow up the stretch of bolts, or in fact to interfere in any way with the sphericalcone bolted joints, when once they were properly applied. Out of sixteen of the Author's engines with superheaters equipped with this joint, and having run an aggregate mileage of 1,340,000, only two cases of joint leakage had occurred; one happened shortly after the erection of a new locomotive, due to poor work, and the other apparently was a case of bolt stretch after some months' service, the service conditions being probably more trying to superheater parts than any in England. In respect to superheater dampers, the Author did not favour a damper being used when it could be avoided, particularly for engines on services with frequent stops, owing to loss of superheat occasioned thereby, but specially severe conditions such as existed on his railway, in his opinion, necessitated dampers.

Mr. Gresham's point (page 465) in connexion with the heat losses due to the use of outside delivery pipes was of value, and the Author was in general agreement therewith; but, unfortunately, 
although something less than 1 per cent improvement in coal consumption was a desirable thing, yet the mechanical department of a railway, having to handle all the traffic its locomotive stock was capable of, could not afford to have engines out of service for cleaning of injector internal delivery pipes The further point made by Mr. Gresham in reference to deposit in boilers, which the Author did not suggest favoured the British or American type of injector, was met to a great extent by the adoption of top feed arrangements. Certainly water purification was the ideal method of curing injector, and many other, troubles, but it must be remembered that in the Colonies running sheds were often at great distances apart, and held a few engines only, whilst water stations were of necessity comparatively frequent; so that to have an effective system of purifiers would be prohibitive. In the case of the railway with which the Author was connected, it would mean a water purifier for every $2 \cdot 25$ locomotives.

The Author was in general agreement with the majority of Mr. Jackson's remarks (page 465), but was rather surprised to see his (Mr. Jackson's) statement that complete compensation of the spring gear had been standard British practice for foreign engines for upwards of fifty years. The Author's foreign and colonial experience and observation were not in accord with it; he agreed, however, that in later years many British engines had been built for abroad in which compensating gear and flangeless wheels had been made use of, but not to the extent generally adopted by American builders.

In reply to Mr. Kyffin (page 467), it was not the Author's intention to imply that the semi-circular brasses and large wearing faces on the sides of axle-boxes were exclusively American practices-they were dealt with in the Paper as representative of American practices. On this point, however, it should be noted that the old British semicircular brass was not pressed in from the side as in American practice, but fitted in, in a similar manner to the British flat-crowned box. Regarding fire-hole rings, the Author had found conclusively that they could not be successfully used with steel fire-boxes owing to the excessive rigidity imparted by them to the inside plate, and to their large mass causing the overheating and deterioration of the inside plate; this being the case with steel fire-boxes, it followed the same action was taking place-but of lesser effect-with copper fire-boxes.

Mr. O'Brien (page 468), in referring to the all-bronze axle-box, mentioned that the cast-steel box was no more immune from fracture than the bronze box; the Author's experience differed 
from this, he having observed that cracking down the flanges in line with the horn-cheek face and cracking across the flanges was much more prevalent with bronze axle-boxes than with cast steel. The information in respect to tail-rods supported the American view that they were of little use. In regard to the three important points of design, namely: (1) large and straight ports ; (2) ample beating areas on motion-pins; and (3) the correct draught arrangements, of which Mr. O'Brien rightly stressed the importance, reference to the advantage derived by the American designs in respect to (1) was referred to in the Paper under "Distribution Valves" (page 412), the British superiority in regard to (2) under "Motions" (page 411), and the respective general practices of each country regarding (3) under "Blast Pipes" (page 404).

It was interesting to note that Mr. Smith stated (page 469) that the G.C.R. had nearly the whole of their engines fitted with steel tubes; this appeared to confirm the Author's view that steel tubes in conjunction with copper fire-boxes could be successful.

The statement of Mr. Gass (page 470) that the maximum axleload allowable on short span bridges was under 16 tons was startling, and if this applied to any important British main line, the Author considered it a serious obstacle to economical operation. He appreciated the difficulties mentioned as presenting themselves in designing high-capacity locomotives, and considered there was much seope for the employment of types such as 2-8-0, 4-8-0, 0-8-2, and 2-8-2, to meet such special conditions.

In regard to Mr. Billington's remarks (page 472) concerning the comparisons made between the bar and plate frames, the Author considered he had made clear at the end of the Paper that the principal differences in practice were due to different conditions; this, however, did not invalidate balancing the pros and cons of the many features of each frame and its development.

Dealing with the Discussion at the Yorkshire Menting, the Author did not consider he was incorrect in the approximate position he ascribed to the dome in American practice; it was undoubtedly customary to place it on the ring next the fire-box with both straighttopped and conical boilers, and even with straight-topped boilers containing combustion chambers. Certain of the more conservative American railroads, such as the Pennsylvania and Chicago, Burlington and Quincey, placed the dome fairly well forward, but the general practice was as stated in the Paper. Mr. Becker (page 475) appeared to be mistaken in regard to his (the Author's) intention in advocating that the safety-valves be apart from the 
dome; it was of little moment if they blew off when the regulator was fairly well open, but when partly shutting the regulator on entering a comparatively easy gradient after stiff pulling with a heavy fire, their intermittent action appeared to lift the water. The Author's view in regard to cabs was that comfortable cabs with seats were essential, but that it was possible to overdo the comfort. In regard to notching-up with the lever notch while running, this could, of course, be done, and was done every time after starting, but having notched up about 30 per cent, the tendency was to let the lever remain there.

Mr. Clement's Table of comparative test records (page 477) showed nothing to choose between acid and basic steel, and the Author could usefully augment his reply to Sir Henry Fowler that the former was more generally trustworthy. He had not observed sufficient difference between steel fire-boxes made by British and American firms to warrant placing an advantage either way, ten years being about the average life of each. The fundamental cause of failure was wasting of the plates adjacent to the corners; this took place at fire level and its action was like an intensified form of corrosion, and when the plate became thin (often with a crack running horizontally) a local patch must be applied.

It did not appear fair, as suggested by Mr. Murray (page 478) to add a disadvantage to the bar-frame based on a comparison with such frames machined out of a solid slab-a most extravagant method; and although the Author agreed that cross-stays were easier of attachment to plate-frames, yet there was no real difficulty in these days of cast-steel cross-stays to arrange suitable connexions with bar-frames. The Hulburd copper joint-ring had been used by the Author and found effective, but not more simple or reliable than a plain copper-wire ring. He regretted that he had not the opportunity at present to get out a list of the comparative life of various parts, a matter which would take some considerable time.

In respect to Mr. Sanders' reference to hub-liners (page 480), the Author would point out that whether the side-thrust was taken up by a plate on the wheel-hub, a plate on the axle-box, or both combined as was often done, the effect was the same.

With regard to Mr. Brocklebank's remarks (page 481) as to the necessity of complete rigidity of all frames, the Author agreed that all the allowances requisite for lateral and vertical movement should be provided irrespective of the frames, also that flangeless wheels should not be employed except when necessary, but, on the other hand, it was incorrect to design a locomotive which would just manage to traverse the curves met with, 
Mr. Stansfeld (page 482), in referring to the life of steel-tubes, quoted 100,000 miles and three sets in twelve years, whereas the Author found the average life six years and mileage about 150,000 , and considered that the water used had very great effect on the relative life of steel and copper tubes. He had not observed any very effective scale-cleaning properties of copper tubes, if the difference between the coefficient of expansion of steel and copper tubes was sufficient to accomplish this, then he considered a decided point in favour of the latter had been adduced. Mr. Stansfeld referred to the various expense items affecting the use of steel or copper tubes for foreign service; this question was similar to-and was co-ordinate with-the use of steel or copper fire-boxes, and depended on many factors affecting any particular railway in question.

In reply to Mr. Ahrons (page 484) the Author would like to state that, in mentioning flangeless wheels as being an item contributing to the popularity of American engines in recently developed countries, he referred to designs where flangeless wheels improved the curving properties ; in the case of an 0-8-0 engine referred to by Mr. Ahrons, its curving would be improved by setting-in the flanges of the leading and trailing coupled wheels a quarter of an inch, and providing a pony-truck to steady the engine on the straight in a similar manner to that described by him. The method referred to as successfully used on the Austrian railways appeared the best solution otherwise, providing the second axle was not given sufficient play to leave the whole of the curving to be done by the leading axle. The Author agreed that a comparatively symmetrical wheel-base was desirable for all shunting engines; at least two additional axles would be needed in place of a tender to take a fair proportion of fuel and water.

Swing link bogies of the single-pin suspension type certainly had the disadvantage of allowing rolling or swaying of the engines, also tilting of the front end of the engine on curves; the double suspension hangers, however, did not allow either the swaying or the tilting, lifting the front end of the engine level; and by varying the relative spacing of the two top pins in relation to the distance from the lower pin, varying degrees of resistance could be obtained. The "Economy" truck mentioned, with its heart-shaped cams, was an improved form of the same principle as the double suspension hangers. The increase of resistance in the pendulum type bogie was a distinct advantage on sharp curves as it increased the weight on the bogie-wheels automatically in relation to the sharpness of the curve. In regard to tyre shrinkage allowance, the Author's 
data gave approximately the figures mentioned in the Paper ; perhaps $40-45$ per cent greater would have been a closer figure. He had not so far found any excessive deterioration in the fire-box circulating tubes, which he had had now in service for over two years.

The Author was at one with Professor Dalby (page 486) in his plea for the establishment of a thoroughly comprehensive test plant in England, and the hope that one of the advantages of railway amalgamation would be the provision of such equipment. He did not propose to comment on Professor Dalby's Tables, but pointed out that information derived from such tabulated records of tests could not be satisfactorily obtained in any other way. The development of such a scheme as the foregoing, together with the recent growth of an Institution directing its energies particularly to locomotive work, should eventually place British locomotive engineers in a similar position in regard to research as their American confrères.

Lieut.-Colonel Fell's remarks (page 490) concerning the bad effect of overheating of white-metal no doubt explained the cause of many bearing failures; thin white-metal lining was very liable to become "beaten out," and eventually part of it became detached from its base. The new aluminium alloy mentioned, with a specific gravity of only $2 \cdot 75$ and a tensile strength of 22 tons, would apparently be of great use for pistons, etc., as although its tensile strength was rather lower than that of steel castings generally used in locomotive work, yet its advantages in respect to lightness were very great. He (the Author) agreed that the ordinary trimming was the reverse of correct in its functioning, but short of a complete pressure-fed system, he did not see an alternative method for axleboxes, etc. (except the application of the entire lubrication from below the axle), unless drip-feed lubricators were applied for each axle-box.

The Author observed that Mr. Hobson (page 492) was surprised to find that he (the Author) had stated (page 378) that bar-frames were as rigid vertically as plate frames, but modified (page 384) that statement considerably. Reference to the Paper would show that the former statement was in reference to the relation of barframing to the track, "when the horn-stays are in position as when running "; whilst the latter had reference to the frame in the shops without the support of its horn-stays.

In regard to the Author's preference for copper fire-boxes, this was stated in respect to general dependability, and whether the extra cost of the copper fire-box was justified; the majority of the locomotives in his charge had steel fire-boxes operating successfully. 
In reply to Mr. F. J. Hookham (page 493) the Author stated that the figure of oil consumption given was the average of a number of locomotives of similar type-4-8-0 tender-but not identical, obtained by dividing total issues of oil over a period by enginemiles worked, and over excessively curved lines and in a tropical climate; he believed it to be a very good figure indeed.

Finally, in regard to the question of relative expenditure for service obtained, the Author could state that, from a general average based on many years' figures of locomotives on the railway with which he was connected, the actual maintenance and repair expenses were practically the same for both British and American locomotives. He found, however, that the time out of service for petty and medium repairs was somewhat greater with American locomotives; whilst of course, if depreciation were allowed for, the British engine lasting, say, thirty years, was superior to the American lasting generally fifteen to twenty years, notwithstanding the lesser first cost of the latter. 